\title{
Chronic graft-versus-host disease, autoimmunity and microvascular pathology : an experimental approach to scleroderma
}

Citation for published version (APA):

Bos, G. M. J. (1989). Chronic graft-versus-host disease, autoimmunity and microvascular pathology : an experimental approach to scleroderma. [Doctoral Thesis, Maastricht University]. Thesis. https://doi.org/10.26481/dis.19890310gb

Document status and date:

Published: 01/01/1989

DOI:

10.26481/dis.19890310gb

Document Version:

Publisher's PDF, also known as Version of record

Please check the document version of this publication:

- A submitted manuscript is the version of the article upon submission and before peer-review. There can be important differences between the submitted version and the official published version of record.

People interested in the research are advised to contact the author for the final version of the publication, or visit the DOI to the publisher's website.

- The final author version and the galley proof are versions of the publication after peer review.

- The final published version features the final layout of the paper including the volume, issue and page numbers.

Link to publication

\footnotetext{
General rights rights.

- You may freely distribute the URL identifying the publication in the public portal. please follow below link for the End User Agreement:

www.umlib.nl/taverne-license

Take down policy

If you believe that this document breaches copyright please contact us at:

repository@maastrichtuniversity.nl

providing details and we will investigate your claim.
}

Copyright and moral rights for the publications made accessible in the public portal are retained by the authors and/or other copyright owners and it is a condition of accessing publications that users recognise and abide by the legal requirements associated with these

- Users may download and print one copy of any publication from the public portal for the purpose of private study or research.

- You may not further distribute the material or use it for any profit-making activity or commercial gain

If the publication is distributed under the terms of Article $25 \mathrm{fa}$ of the Dutch Copyright Act, indicated by the "Taverne" license above, 
CHRONIC GRAFT-VERSUS-HOST DISEASE, AUTOIMMUNITY AND MICROVASCULAR PATHOLOGY :

AN EXPERIMENTAL APPROACH TO SCLERODERMA 



\title{
CHRONIC GRAFT-VERSUS-HOST DISEASE, AUTOIMMUNITY AND MICROVASCULAR PATHOLOGY : AN EXPERIMENTAL APPROACH TO SCLERODERMA
}

\author{
Proefschrift
}

ter verkrijging van de graad van doctor

aan de Rijksuniversiteit Limburg te Maastricht, op gezag van de Rector Magnificus, Prof. dr. F.I.M. Bonke, volgens het besluit van het College van Dekanen, in het openbaar te verdedigen op vrijdag 10 maart 1989 om 16.00 uur door GERARDUS MARINUS JOSEF BOS geboren te Wageningen op 5 mei 1960 
Promotores:

Co-Promotores:

Beoordelingscommissie: Prof Dr GH Blijham, voorzitter

Prof J-W Arends

Prof Dr JMJP vd Linden

Prof Dr H Schmid-Schönbein

Prof Dr TH The

Paranimfen:
Prof Dr PJC van Breda Vriesman

Prof Dr RS Reneman

Dr GD Majoor

Dr DW Slaaf

\section{CIP-GEGEVENS KONINKLIJKE BIBLIOTHEEK, DEN HAAG}

Bos, Gerardus Marinus Josef

Chronic graft-versus-host dise ase, autoimmunity and microvascular pathology : an experimental approach to scleroderma / Gerardus Marinus Josef Bos; [ill. from the author]. - Haarlem : Thesis. - III.

Proefschrift Maastricht. - Met lit. opg.

ISBN 90-5170-010-5

SISO 605.18 UDC 616.72-002.77(043.3)

Trefw.: reuma.

Het in dit proefschrift gepresenteerde onderzoek alsmede de uitgave van dit boekje werden in belangrijke mate mogelijk gemaakt door subsidie van de Nederlandse Vereniging voor Reumabestrijding.Verdere bijdragen werden ontvangen van de stichting Het Scholten Cordes Fonds, de Jan Dekkerstichting \& Dr. Ludgardine Bouwmanstichting en de firma's Sandoz en Merck Sharp \& Dohme.

Uitgave : uitgeverij Thesis, Amsterdam / Haarlem

Lay-out: Datawyse, Sciencepark II, Maastricht 
Het enige principe dat de vooruitgang niet tegenhoudt luidt: alles is mogelijk

Paul Feyerabend: In strijd met de methode. Aanzet tot een anarchistische kennistheorie, 1977.

Voor mijn ouders

Aan Pauline 



\section{CONTENTS}

Introduction

Chapter I

Scleroderma and graft-versus-host disease.

An overview of the literature $\ldots \ldots \ldots \ldots \ldots \ldots \ldots \ldots$

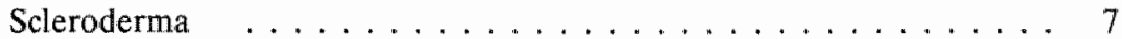

- Definition and history

- Epidemiology

- Signs and symptoms of disease

- Histopathology

- Pathogenesis of scleroderma

Allogeneic and syngeneic acute and chronic graft-versus-host reactions

- Introduction

- History and definition of the classical graft-versus-host reaction

- Genetics of the graft-versus-host reaction

- Etiology of acute graft-versus-host disease

- Pathology of acute graft-versus-host disease

- Etiology of chronic graft-versus-host disease

- Pathology of chronic graft-versus-host disease

- Syngeneic and autologous graft-versus-host reactions

- Cyclosporine-A- and cyclophoshamide/ busulphan-induced graft-versus-host / autoimmune reactions

Chronic graft-versus-host disease and scleroderma

- Association of chronic graft-versus-host disease and scleroderma in man

- Similarity of pathology associated with chronic graft-versus-host disease in rodents and scleroderma in man

Summary ........................... 26

- Is chronic graft-versus-host disease an adequate model for scleroderma?

\section{Chapter II}


Chapter III

In vivo demonstration of microvascular pathology in experimental

scleroderma

Chapter IV

Chronic cyclosporine-induced autoimmune disease in the rat:

a new experimental model for scleroderma

Chapter V

CD4-positive lymphocytes and cyclosporine-induced autoimmune disease

Summary and concluding remarks ...................... 97

Nederlandstalige samenvatting $\ldots \ldots \ldots \ldots$. . . . . . . . . . . . .

List of abbreviations $\ldots \ldots \ldots \ldots \ldots \ldots$

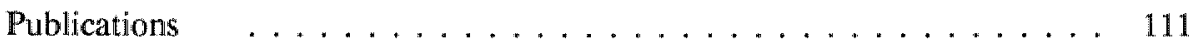

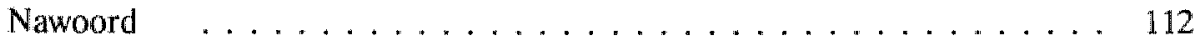

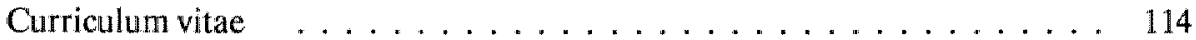

Klimmen en dalen $\ldots \ldots \ldots \ldots \ldots \ldots$ 


\section{INTRODUCTION}





\section{INTRODUCTION.}

Scleroderma or systemic sclerosis is a disease of connective tissue, mainly affecting the skin, gastrointestinal tract, lungs, heart, and kidneys. The pathology of the disease is characterized by sclerosis of the above-mentioned organs (Barnet, 1974; Krieg and Meurer, 1988). In addition to abnormal deposition of collagen in these organs, abnormalities of the (micro-)circulation have been observed in patients with scleroderma, which may lead to Raynaud's phenomenon, ischemic ulcerations of digits, and/or telangiectasia (Hughes, 1987).

The etiology of scleroderma is unknown. Autoimmune phenomena are supposed to play an important role, although the antigen(s) to which such autoimmune reactions could be directed are not known (reviewed by Postlethwaite and Kang, 1984). The presence of microvascular pathology, sometimes years before any clinical or histological evidence for scleroderma, has led to the hypothesis that the microvasculature might be the primary target of (autoimmune) reactions ultimately causing sclerosis of the target organs, possibly due to a disturbed perfusion of these organs (reviewed by Fleischmajer and Perlish, 1983). Since the pathogenesis of scleroderma is unknown, specific therapy for patients with this disease is not available. Consequently, progression of the disease may lead to marked morbidity, and life expectancy can be significantly reduced (Medsger and Masi, 1979; Hochberg et al., 1980).

In order to obtain insight into the pathogenesis of scleroderma, several investigators have sought for animal models. A first description of such a model derives from Stastny, who observed scleroderma-like lesions in rats as a late complication of a chronic graftversus-host (GVH) reaction (Stastny et al., 1963). Chronic GVH reactions can be a corollary of the transplantation of immunocompetent cells to immunodeficient, histoincompatible recipients (Billingham, 1967-1968). Since the pathology associated with this chronic GVH reaction showed striking similarities to the pathology of patients with scleroderma, animal models of chronic GVH disease have been advocated as models to study the etiology and pathophysiology of scleroderma (Stastny et al., 1963; Beschorner et al., 1982).

Chapter I consists of a review of the literature on scleroderma and GVH disease and discusses the similarity between chronic GVH disease and scleroderma. As pointed out in this chapter, microvascular abnormalities are considered to be clinical hallmarks for scleroderma in man, which may be of pathogenetic importance. Although in the experimental models of chronic GVH disease histological lesions analogous to those observed in scleroderma have been observed, no microvascular pathology has been documented in these models to date. The presence of both an immunological laboratory and a laboratory for microcirculation within our institute, enabled it to address the question whether or not microvascular pathology is present in animal models with clinical and histological signs or symptoms suggestive of scleroderma.

Therefore, the principle aim of this study was to document the possible occurrence of vascular pathology in an animal model of chronic GVH disease, which is associated 
with scleroderma-like histopathological lesions. Establishment of vascular pathology would validate the model of chronic GVH disease as a model for scleroderma. Moreover, it would open the possibility to study the role of microvascular pathology in the dewelopment of scleroderma in an animal model. Eventually, such a model would create the possibility to study therapeutical strategies.

Microvascular abnormalities in patients with scleroderma are usually diagnosed by intravital microscopy (Maricq and LeRoy, 1973). A model comparable to that used for studying the microcirculation in man had to be developed in order to permit the study of possible microvascular pathology in rats with chronic GVH disease. This technique is described in chapter II.

After this technique had become operational, the microcirculation of the skin of rats with chronic GVH disease, brought about by histoincompatible bone marrow transplantation, was studied. The results of this study are presented in chapter III. In this chapter the observation of morphological abnormalities of the microvasculature in rats with chronic GVH disease is described.

Chronic GVH disease is based on complex immunological mechanisms which are not fully understood, and which may or may not include autoimmune mechanisms. Hence, from an immunological point of view the rodent model of chronic GVH disease is not exemplary for the study of autoimmune disease in man (Deeg, 1985; Seemayer, 1979.). Therefore, the development of an autoimmune rodent model for scleroderma was the second aim of this study. The model investigated is based on manipulation of the immune system with the aid of the immunosuppressant Cyclosporine-A (Cy-A) (Glazier et al., 1983). Our studies using this model are described in chapter IV.

Finally, in chapter $\mathrm{V}$, a study is described on the cellular mechanisms which may be important in the pathogenesis of $\mathrm{Cy}$-A mediated autoimmune disease.

In summary, this thesis encompasses:

- A literature review on scleroderma, graft-versus-host disease and the association of chronic graft-versus-host disease and scleroderma (chapter I).

- The development of a model to study the microcirculation of the rat skin in vivo (chapter II).

- The presence of microvascular pathology in chronic graft-versus-host disease, an experimental model for scleroderma (chapter III).

- The application of a new autoimmune experimental model for induction of scleroderma in rats (chapter IV).

- Cellular mechanisms involved in Cyclosporine-A induced autoimmunity in the rat (chapter V).

This thesis ends with a summary, including some concluding remarks. 


\section{REFERENCES TO INTRODUCTION}

Barnett AJ (1974) Scleroderma (progressive systemic sclerosis). C Thomas, Springfield

Beschorner W, PJ Tutschka, and GW Santos (1982) Chronic graft versus host disease in the rat tradiation chimera.. Transplantation 33:393-399

Billingham RE (1967-1968) The biology of graft wersus host reactions. Harvey Lectures 62:21-78

Deeg HJ (1985) The biology of chronic graft-versus-host disease. Exp Haemat \$ 17 13:128-130

Fleischmajer $\mathbf{R}$, and JS Perlish (1983) The vascular, inflammatory, and fibrotic conponent in selcrodermit skin. In: Connective tissue disease BM Wagner et ol (eds) Williams : Wilkins, London pp.40-49

Glazier A, PJ Tutschka, ER Farmer, GW Santos (1983) Graft versus hosi disease in cyclosporin-A treaied rats after syngeneic and autologous bone mar row transplantation. J Exp Med 158:1-8

Hochberg MC, PA Holt, MG Kane, FC Arnett, and MB Stevens (1980) Surwival in systemic sclerosis (scleroderma). Arthr Rheum 23:689-690

Hughes GRV (1987) Connective tissue disease. Blackwell scientific publications, Oxford pp. 150-171

Krieg Th, and M Meurer (1988) Systemic sclerosis. Clinical and pathophysiologic aspects. I Am Acad Dermatol 18:457-481

Maricq HR, and EC LeRoy (1.973) Patterns of finger capillary abnormalities in connective tissue disease by wide field microscopy. Arthr Rheum 16:619-628

Medsger TA, and AF Masi (1979) Epidemiology of progressive systemic sclerosis. Clin Rheum Dis 5:15. 25

Postlethwaite AE, and AH Kang (1984) Pathogenesis of progressive systemic sclerosis. J Clin Lab Med 103:506-509

Seemayer TA (1979) The graft versus host reaction: A pathogenctic mechanism of experimental and human disease. Prospective in pathology. Vol 5 Fudenberget al (eds.) Mason, New York pp. 93-133

Stastny P, VA Stembridge, T Vischer, and M Zifr (1963) Homologous disease in the adult rat, a model for autoimmune disease. 1. General features and cutancous lesions. J Exp Med 118:635 

CHAPTER I

\section{SCLERODERMA AND \\ GRAFT-VERSUS-HOST DISEASE}

AN OVERVIEW OF THE LITERATURE 



\section{SCLERODERMA.}

\section{Definition and history}

Scleroderma or systemic sclerosis is a disorder of connective tissne and the (micro-)circulation (small arteries, arterioles and capillaries), characterized by fibrosis of the skin and occasionally the gastrointestinal tract, heart, lungs and/or kidneys. Systemic sclerosis is classified among the connective tissue or rheumatic diseases, and is nowadays considered to be of autoimmune origin.

The first description of a patient with clinical signs, now recognized to be possibly due to scleroderma, was presented by Hippocrates (460-370 B.C.), who described a case of "a certain Athenian whose skin was so indurated that it could not be pinched" (cited by Barnett, 1974). A more detailed case of a patient with scleroderma was described by Curzio in 1753 (Curzio 1753, translated by Watson, 1754). After the publication of 7 more cases the term scleroderma was introduced by Gintrac (Gintrac, 1847). The history of scleroderma as described in the medical literature has been extensively reviewed by Rodnan and Benedek (Rodnan and Benedek, 1962).

The observation that scleroderma is not limited to the skin, but may also involve other organs, led to replacement of the name scleroderma by progressive systemic sclerosis (Goetz, 1945). However, since systemic sclerosis is not always a progressive disease, the term systemic sclerosis is nowadays preferred over progressive systemic sclerosis and generally used as a synonym for scleroderma (Krieg and Meurer, 1988).

\section{Epidemiology.}

The incidence of scleroderma is low with 2.7 to 12 new cases per million as diagnosed in different studies in the United States (reviewed by Medsger and Masi, 1979). However, it is the third most frequent connective tissue disease (Kahaleh, 1979). Female incidence exceeds male incidence by a factor of approximately 3. More recently, the anmual mortality was reported to be between 2.1 and 2.8 per million (Medsger, 1985). Although some reports show a higher incidence of scleroderma in relatives (Medsger and Masi, 1979 ; Sheldon, 1981), evidence for genetic factors predisposing for scleroderma has not been established and at present data on the association of scleroderma with certain histocompatibility haplotypes are not conclusive (Luderschmidt, 1987 ; Lynch, 1982).

\section{Signs and symptoms of disease}

As can be derived from the term scieroderma, the skin is frequently affected in this disease. In fact, a tight skin is its clinical hallmark (Barnett, 1974 ; Krieg and Meurer, 1988). According to (preliminary) criteria of the American R heumatism Association, the pre- 
sence of proximal scleroderma - i.e. proximal to the digits - is the only major criterium for the diagnosis scleroderma. Sclerodactyly, pitting scars of fingertips or loss of substance of the distal finger pad, and bibasilar pulmonary fibrosis are minor criteria. The presence of the major criterium or two or more minor criteria were suggested to be diagnostic for scleroderma (Subcommittee American Association of Rheumatologists, 1980).

Clinically, tightness of the skin can be preceded by a short period of edematous skin changes, evolving to hardening of the skin within a period of several months. Most frequently, the alterations start in the fingers and the hands. Later the face may be involved and next spreading to more proximal parts of the extremities or trunk may occur (Barnett, 1974). The extension of the lesions in the skin can, however, markedly differ from patient to patient. Differences in extension and differences in localization of the lesions have become important in the classification of scleroderma in several subsets of disease suggested by different authors (see below).

In addition to the hidebound skin, the presence of Raynaud's phenomenon is a second hallmark of this disease. In its classical form, Raynaud's phenomenon is a tri-phasic discoloration of the hands (white, blue and red) and sometimes the feet which is usually induced by cold. The association of scleroderma and Raynaud's phenomenon was presented in the literature for the first time in 1865, by Maurice Raynaud himself. Raynaud's phenomenon prevails in approximately $90 \%$ of the patients with scleroderma and is the most obvious sign of an abnormal function of the blood circulation in this disease (Masi, 1980). However, Raynaud's phenomenon is not a pathognomic symptom for scleroderma, since it can be present without any other sign of underlying disease (so-called primary Raynaud's disease) or in association with a variety of other diseases. With respect to the discussion on pathogenic mechanisms in scleroderma, it should be noticed that Raynaud's phenomenon may preceed any other sign or symptom of scleroderma by several years (Masi, 1980).

Another sign of microvascular abnormalities in scleroderma are dilated skin capillaries, as first described by Brown and O'Leary in 1925. By using a stereomicroscope they observed giant capillary loops in nailfolds of patients with scleroderma. Furthermore, they observed a reduced number of capillary loops and diminished flow in the remaining capillaries (Brown and O'Leary, 1925). These observations of capillary abnormalities could be confirmed by the use of intravital microscopy and even by the use of a simple ophthalmoscope (Maricq and LeRoy, 1973 ; Ranft, 1987). Capillary abnormalities were observed as the first sign of scleroderma in some patients, and correlated with the number of organs involved in the disease (Maricq et al., 1976; 1982 ; Houtman, 1985). However, nailfold capillary abnormalities are also seen in other diseases (Maricq, 1980; Wysenbeek, 1985; Ganzarczyk, 1988). In a study comparing several groups of diseases, giant capillary loops in the nailfold were found to be most specific for scleroderma. Furthermore, avascular areas were observed at this site (Maricq, 1980). The level of avascularity as observed by intravital microscopy correlated well with the number of capillaries counted in histological sections (Thompson ef al., 1985). 
Table 1. Subsets of systemic sclerosis

1) Diffuse cutaneous systemic sclerosis $(\mathrm{dSSc})$ :

- Onset of Raynaud's phenomenom within 1 year of onset of skin changes (puffy or hidebound).

- Truncal and acral involvement.

- Presence of tendon friction rubs.

- Early and significant incidence of interstitial Ing discase, oliguric renal failure, diffuse gastrointestinal disease, and myocardial involvenent.

- Absence of anti-centromere antibodies.

- Nailfold capillary dilatation and capillary destruction.

- Anti-topoisomerase antibodies (30\% of patients).

2) Limited cutaneous scleroderma (ISSC).

- Raynaud's phenomenon for years (occasionally decades).

- Skin involvement limited to hands, face, feet, and forearms (acral) or absent.

- A significant late incidence of pulmonary hypertension, with or without interstitial lung disease, trigeminal neuralgia, skin calcifications, telangiectasia.

- A high incidence of anti-centromere antibodies (70. $80 \%)$

- Dilated nailfold capillary loops, usually without capillary dropouts.

(Reproduced from LeRoy et al., 1988)

In addition to these morphological abnormalities, it was observec that increased transcapillary transudation, as observed by the use of sodium-fluorescein during intravital microscopy, may be present in patients with scleroderma (Bollinger et al., 1979, 1983). The precise mechanism of this increased transudation is not known, but it indicates an enhanced capillary or pericapillary permeability. Rheological abnormalities. were also observed in patients with scleroderma, including higher blood viscosity and increased red blood cell aggregation (Tietjen, 1975 ; Jacobs, 1987).

In addition to capillary changes, abnormalities in the small and medium-sized arteries were found. These have been diagnosed by angiography, showing occlusion of the vessels (Janevski, 1982 ; Wagner, 1985). The abnormalities in these arteries probably contribute to the development of Raynaud's phenomenon, decreased perfusion of the skin and decreased reactive hyperemia (Kristensen, 1978; 1979; 1981).

In addition to the above-mentioned lesions, scleroderma may involve several other organ systems. Gastrointestinal tract, heart, lungs, muscles, joints and kidneys are most frequently affected (D'Angelo et al., 1969). Furthermore, scleroderma is often observed in association with Sjögren disease, an autoimmune disease mainly affecting the minor salivary glands (Osial et al., 1983). The involvement of these organs in scleroderma largely predicts the outcome of the patients (Medsger an Masi, 1979; Hochberg et al., 1980). 
The heterogeneous manifestations of scleroderma led to several attempts to classify scleroderma or systemic sclerosis into subcategories (Barnet, 1974; Jablonska 1975; Winkelman, 1976; Livingston, 1987). Scleroderma without organ involvement, or in association with visceral abnormalities has been considered an important discriminating factor in all of the attempts to classify scleroderma. Furthermore, the localization of the lesions in the skin is an important factor in categorizing patients (Holzmann et al., 1987). More recently a new classification scheme has been suggested, as shown in Table 1 (LeRoy et al., 1988) : diffuse cutaneous systemic sclerosis (dSSc) and limited cutaneous scleroderma (ISSc). New arguments for discriminating these subsets are the abnormalities of the microcirculation of the nailfold, and the presence or absence of specific anti-nuclear autoantibodies. These two aspects will be discussed more extensively in the following paragraphs.

\section{Histopathollogy.}

Since the skin is most commonly affected in scleroderma and skin biopsies are easily performed, descriptions of the skin pathology of most stages of scleroderma are present. However, no pathognomic histopathological features exist to diagnose scleroderma. The histopathological findings in scleroderma are largely dependent on the duration of the disease. In the early phase the reticular dermis shows thickening of collagen bundles and a mild inflammatory reaction. The inflammatory infiltrate consists mostly of lymphocytes, and some plasma cells around capillaries, arterioles, sebaceous glands, eccrine sweat glands, hair follicles, and superficial nerves. The most striking abnormalities in the early phase of scleroderma are in the deeper dermis and/or in the subcutaneous fat, showing a marked inflammatory reaction of mononuclear cells, and replacement of subcutaneous fat by collagen (Lever and Schaumburg-Lever, 1983; Barnett, 1974 ; Hughes, 1987). The lymphocytes in the infiltrate are mainly T lymphocytes, with a preponderance of CD4 positive, $T$ helper and/or delayed-type hypersensitivity effector lymphocytes (Roumm et al., 1984). Langerhans cells may be remarkably reduced in patients with scleroderma, whereas an increased number of mast cells could be demonstrated in the early phase of scleroderma (Andrews et al., 1986 ; Nishioka et al., 1987). In the late phase, the epidermis may become atrophic, the rete ridges may disappear, the collagen in the dermis becomes more homogeneous whereas the elastin fibers do disappear, and there is atrophy of the appendages. Inflammatory reactions have mostly disappeared by this time, except for some infiltrates in the subcutaneous fat. The subcutaneous tissue might be completely replaced by collagen, an observation suggested to be most specific for scleroderma (Fleischmajer et al., 1971). The collagen that replaces the subcutaneous fat consists of thick, homogeneous or hyalinized bundles (Lever and Schaumburg-Lever, 1983 ; Barnett, 1974, Hughes, 1987). 
Vascular alterations in scleroderma are merely present at the late stage of scleroderma and include a reduction of the number of skin capillaries in the dermis and dilatation of some of the remaining capillaries. Dilatation of capillaries is possibly due to an increase of endothelial cell proliferation (Fleischmajer and Perlish, 1983).

In the lungs and kidneys, histological changes of the small arteries are the main features of scleroderma. The arterial lesions consist of intima proliferation, fibrinoid necrosis, lumen narrowing and increased collagen deposition (Young and Mark, 1978; Rowell, 1980 ; Trostle, 1988). Furthermore, increased fibrosis has been described in the lungs, heart and esophagus (Botstein, 1981; Hendel, 1984 ; Steen, 1985 ; Rossi, 1985).

\section{Pathogenesis of scleroderma.}

As discussed above, the formation of an abnormal amount of collagen in skin and other organs is the primary hallmark of scleroderma. Secondly, microvascular lesions are frequently observed. The presence of these two sets of lesions has dominated the discussion on the etiology of scleroderma for nearly hundred years : Dinkler emphasized the vascular lesions in scleroderma and considered these of primary importance in the development of scleroderma, whereas Unna suggested that the vascular changes were secondary to the connective tissue sclerosis (Dinkler, 1891 ; Unna, 1896). Since that time evidence in favor of both theories has been presented and more recent reviews on scleroderma still tackle the question what factors are of primary importance (Campbell, 1975 ; LeRoy, 1982 ; Fleischmajer, 1983 ; Postlethwaite and Kang, 1984 ; Hughes, 1987).

The cell responsible for the increased collagen synthesis is the fibroblast. Increased production of collagen has been monitored in the serum and urine of patients with scleroderma by measuring procollagens and hydroxyproline-containing polypeptides. These peptides have been demonstrated to be markers for disease activity (Krieg et al., 1986; Horslev-Petersen et al., 1987). In vitro, fibroblasts obtained from patients with scleroderma produce more collagen than control fibroblasts (Botstein et al., 1982 ; Krieg et al., 1986; Maxwell et al., 1987). Control fibroblasts, in addition, may be acti. vated to produce more collagen by mediators (e.g. interleukins) secreted by stimulated lymphocytes obtained from patients with scleroderma (Johnson and Ziff, 1976; Whiteside et al., 1985 ; Peltonen et al., 1985).

The early presence of microvascular pathology suggests a role of the vascular system in eliciting scleroderma. In 1979, Kahaleh and co-workers demonstrated a factor in sera of patients with scleroderma with cytotoxic activity to cultured endothelial cells (Kahalehet al., 1979). This observation could be repeated by others (Cohen et al., 1983). This cytotoxic activity is probably due to a protease, since the reaction can be abolished by protease inhibitors (Kahaleh and LeRoy, 1983). The precise origin of this factor is, however, not known. An in vivo effect of this factor was observed in rabbits treated with purified factor obtained from scleroderma patients. Firstly, an increase in activity of 
Von Willebrand factor was observed. This increase may also be observed in patients with scleroderma and indicates an altered blood clotting activity, possibly responsible for the obstructive lesions in arteries of scleroderma patients. Furthermore, administration of this factor led to endothelial swelling and proliferation of vessel walls (Wagner and Marder, 1983 ; Seibold and Harris, 1985 ; Drenk and Deicher, 1987).

Abnormal cellular and humoral immunological parameters in patients with scleroderma suggest a role for immune mechanisms in this disease. Although abnormal ratio's of Thelper (Th) and T killer/suppressor (Tk/s) lymphocytes (due to a decreased number of Tk/s cells) have been documented by several authors, these observations could not be reproduced by others, who on the contrary observed an increased number of $\mathrm{Tk} / \mathrm{s}$ cells in patients with scleroderma (Inoshita et al., 1981; Keystone et al., 1982; Whiteside et al., 1983 ; Dustoor et al., 1987). A decreased number of Tk/s cells may account for a reduced suppressive activity, which in turn might be associated with autoimmune reactions. However, no association between altered numbers of suppressor cells and disease activity could be observed (Whiteside et al. 1983). An enhanced stimulatory effect of Th cells on B cells is a second abnormal cellular parameter observed in patients with scleroderma (Alarcon-Segovia et al., 1981 ; Dustoor et al., 1987). This enhanced stimulatory effect may account for the hypergammaglobulinemia and the presence of autoantibodies in patients with scleroderma.

In patients with scleroderma, anti-nuclear and/or anti-nucleolar antibodies can be observed in $90-100 \%$ of patients (Bernstein, 1982 ; Grench, 1985). Moreover, the presence of antibodies against several autoantigens has been documented. Most frequently, antibodies against topoisomerase I and a centromere antigen (kinetochore) have been demonstrated (Steen, 1984 ; Shero et al., 1986 ; Guldner et al., 1986). Pertinent is the observation that patients belonging to different clinical subsets of scleroderma have autoantibodies against different antigens. Antibodies directed against the centromere are restricted to patients with limited cutaneous scleroderma (Tan, 1980 ; Kallenberg, 1982). On the other hand, antibodies against topoisomerase I are merely present in patients with diffuse cutaneous systemic sclerosis (van Venrooij, 1985; Shero et al., 1986 ; Guldner et al., 1986 ; Weiner, 1988).

Although these antibodies are specific for patients with scleroderma, they are only present in some of these patients. In addition, the search for an association between the presence of autoantibodies and the severity of disease has demonstrated contradicting observations (Kallenberg et al., 1980 ; Houtman et al., 1985; Weiner et al., 1988). Therefore, the pathogenetic meaning of these autoantibodies is unclear.

In summary, there is circumstantial evidence for a role of auto-immune mechanisms in the development of scleroderma. It is not clear, however, how these autoimmune phenomenona are elicited.

The question whether microvascular or collagen abnormalities or both are of primary importance in the development of scleroderma still remains to be answered. 


\section{ALLOGENEIC AND SYNGENEIC ACUTE AND CHRONIC}

\section{GRAFT-VERSUS-HOST REACTIONS.}

\section{Introduction}

Graft-versus-host (GVH) disease is a disease that may develop as a consequence of a GVH reaction to transplantation antigens. Of this GVH disease an acute and a chronic form exist. Chronic graft-versus-host disease may develop as a late manifestation of acute graft-versus-host disease, or de novo. The pathology of chronic GVH disease shows similarities to scleroderma, and therefore chronic GVH disease has been used as a model for this disease.

In addition to $\mathrm{GVH}$ disease after transplantation across histocompatibility barriers, similar pathology has been described after syngeneic or autologous bone marrow transplantations both in man and rodents. From an immunological point of view, however, no GVH reaction could exist in these cases, but other mechanisms must account for the induction of the pathology that is indistinguishable from the classical GVH disease.

In the following paragraphs, classical GVH reactions, syngeneic GVH reactions, acute and chronic GVH disease, and the similarity of chronic GVH disease and scleroderma will be discussed.

\section{History and definition of the classical graft-versus-host reaction.}

A first description of what is now known as a GVH reaction was given by Murphy in 1916. He studied the behaviour of cancer cells in chicken embryos by implanting these cells on the chorioallantoic membrane. Using control spleen cells only, he observed a reaction of disseminated "nodules" in the chorioallantoic membrane and an enlargement of the chicken's spleen with comparable nodules (Murphy, 1916). However, at that time his observation was not interpreted as a reaction of the graft directed to the recipient. In 1953 the term GVH reaction was introduced in the literature simultaneously by Simonsen and Dempster, as a possible explanation for the "pyroninophilic" interstitial infiltrates observed in kidney allografts in dogs. They believed these cells to be of graft origin and directed towards host alloantigens. The phenomenon was, however, due to a host-versus-graft reaction and therefore the term GVH reaction was improperly used (Simonsen, 1953, 1985; Dempster, 1953).

In 1954 Medawar was the first to describe that parental grafts transplanted to Fi hybrid mice were genetically qualified to react against their hosts (Medawar, 1954). In 1957 Simonsen, and Billingham \& Brent described a clinical picture of diarrhea, skin lesions, retarded growth and eventually death in newborn animals injected with allogeneic blood, leukocytes or spleen cells; Billingham \& Brent called this syndrome "runt disease" (Simonsen, 1957 ; Billingham and Brent, 1957). At the same time, observa- 
tions were documented on a similar clinical and histological syndrome occurring after transfer of allogeneic bone marrow cells to lethally irradiated mice and rats. This syndrome was called secondary disease (the initial abnormalities due to the $\mathrm{X}$-irradiation were termed primary disease) or homologous disease (van Bekkum en Vos, 1957; Congdon and Urso, 1957). A similar observation was made after the transfer of semiallogeneic parental cells to F1 hybrid mice, one year later (Cole and Ellis, 1958).

Although no experimental evidence was present at that time, the tissue damage in the experiments described above was thought to be secondary to an interaction between effector (donor) lymphocytes and target cells (Rosenau and Moon, 1961). Indeed, small lymphocytes in thoracic duct lymph were identified as being responsible for the indwction of disease in newborn rats (Billingham et al, 1962), F1 hybrid rats (Fl) (Gowans, 1962 ) and lethally X-irradiated mice (Gowans et al., 1962). At that time, the above described syndromes of runt disease, secondary disease or homologous disease and the pathology in $F 1$ animals were definitively interpreted as GVH disease (Simonsen, 1962)

On the basis of the experiments described above, Billingham formulated the essential requirements to elicit a GVH reaction (Billingham, 1967 - 1968):

- The graft must contain immunologically competent cells.

- The host must possess important transplantation isoantigens that are lacking in the graft donor, so that the host appears foreign to it and is therefore capable of stimulating it antigenically.

- The host itself must be incapable of mounting an effective immunological reaction against the graft, at least for sufficient time for the latter to manifest its immunological capabilities, i.e. the graft must have some security of tenure.

Hence, on the basis of this theoretical description, a GVH reaction can be induced by transferring histoincompatible, immunologically competent cells to a recipient in six different situations, partly illustrated by the experimental studies described above and by the experiments further described in this thesis. These conditions are :

1. Maternal transfer through the placenta into the immunoincompetent fetus.

2. In parabiosis, a spontaneous or artificially introduced situation in individuals whose blood circulations are linked, so cell transfer from one individual to the other is possible.

3. Injection into newborn animals that are immunologically unresponsive for a certain period after birth (i.e mice or rats).

4. Transfer of cells to amimals neonatally made tolerant for antigens of those transferred cells.

5. In certain genetically defined situations, where the recipient is unable to recognize the graft. This experimental situation exists when a $F 1$ hybrid animal is grafted with parental (P) cells. In that case the recipient cannot recognize the graft, but the donor can be stimulated by antigenic differences on the F1 recipient tissues $(P \Rightarrow F 1$ modiels).

6. Transfer to congenital or acquired immunosuppressed recipients. The latter either by severe disease status, immunosuppressive pharmaca and/or (total body) irradiation. 
Examples one and two can occur spontaneously or can be simulated in experimental designs (Klein, 1982); examples three and four are only used in experimental studies, whereas examples five and six may be used in experimental studies, but also refer to the clinical situations of bone marrow transplantation or transfer of lymphocytes to immunosuppressed recipients.

\section{Genetics of the graft-versus-host reaction.}

According to the basic law of transplantation, organ grafts will be accepted if donor and graft are genetically identical (Klein, 1982). This can easily be proven by the acceptance of organ grafts such as skin, kidney, and heart using donors and recipients of the same inbred strain. If, however, organs or cells are exchanged between animals of two strains that are not genetically identical, these organs are likely to be rejected by the immune system of the recipient. The antigens eliciting graft rejection are called histocompatibility antigens (HA). Within the HA one group of antigens plays a dominant role, and therefore are called the major histocompatibility antigens (MHA) (Counce, 1956; de Vries, and van Rood, 1982). All other HA are called minor antigens (MiHA). Within the MHA [or major histocompatibility complex (MHC) encoded antigens, referring to the genes coding for these antigens] two groups have been identified, class I and class II antigens. In rats the MHC is called RT1, in mice $\mathrm{H}-2$, and in man HLA (= human leukocyte antigen).

The contribution of HA to GVH reactions after bone marrow transplantation (BMT) is a topic of debate. In general, a severe GVH reaction will occur when MHC mismatched donors and recipients of one species are used. If the mismatch between donors and recipients is only partial, the frequency and severity of a GVH reaction will depend on the number of loci differing and some alleles have been shown to be more important in GVH reactions than others (Storb, 1983). It has been demonstrated in rats and mice that when a difference among class II antigens exists, a GVH reaction is more easily and frequently elicited compared to when isolated class I antigen disparities exist (Rappaport, 1979 ; Oaks and Cramer, 1985). However, this could not be proven in man (Beatty 1985). Furthermore, the predominance of class II antigens in the induction of GVH reactions could not be confirmed using a $\mathrm{P} \Rightarrow \mathrm{F} 1$ model in mice. In this model an acute GVH reaction could only be elicited provided a difference of both class II and class I antigens existed. No GVH reaction occurred if only class I incompatibilities were present, and chronic GVH reactions (see below) were only observed if transplantation was performed over isolated class II differences (Rolink et al., 1982, 1983).

In addition to the role of MHC antigens in eliciting an acute GVH reaction, it should be pointed out that after BMT between fully MHC-matched donors and recipients, a GVH reaction may still occur (Thomas, 1975 ; Korngold and Sprent, 1978 ; Storb, 1983, 1985). GVH reactions reaction against MiHA might play a role in these situations (Goulmy et al., 1983). However, the role for MiHA in inducing an acute GVH reaction 
is complex. In rats it has been demonstrated that reciprocal exchange of BMT between animals only incompatible for MiHA, yielded GVH reactions in only one direction; one strain was proven to be fully resistant to GVH reactions (Oaks and Cramer, 1985). Also in mice it was demonstrated that the occurrence of a GVH reaction depended on the type of MiHA present in the recipient (Bril and Benner, 1985; Benner, 1985; Perkins, 1987). From these experiments one may conclude that not the mere difference of these MiHA is important, but that additional factors must play a role.

\section{Etiology of acute graft-versus-host disease.}

After the demonstration that lymphoid cells of the donor are responsible for the induction of an acute GVH reaction (Billingham et al. 1962 ; Gowans 1962, 1962), improvement of the basic knowledge of cellular and humoral immune reactions was necessary before the mechanisms of the acute $\mathrm{GVH}$ reaction could be understood more precisely (Klein, 1982). After the exposure of 'T lymphocytes, as the mediators of the cellular effector arm in immunology, it was soon thereafter accepted that these cells induced the acute GVH reaction (Cerottini $e t$ al, 1971 ; reviewed by Sullivan, 1986). Elimination of mature T lymphocytes from the graft indeed reduced the incidence of an acute GVH reaction substantially (Rodt et al., 1974 ; Korngold and Sprent, 1978 ; Halle-Panenko et al., 1985).

The identification of different $T$ cell subsets ( $T$ helper (Th) cells and T killer/suppressor (Tk/s) celiss) by monoclonal antibodies (MAB) allowed to look more closely at the role of these T cell subsets in eliciting acute GVH reactions. This topic has been extensively reviewed by Korngold and Sprent (Korngold and Sprent, 1987). However, there is still no conclusive agreement on the precise role of the different $T$ cell subsets in the induction of acute GVH disease.

In principle, after irradiation and transplantation across a full MHC difference or MHC class II differences, Th lymphocytes can induce le thal GVH disease (Piguet, 1985; Korngold and Sprent, 1985). On the other hand, if class I antigens constitute the only histocompatibility barrier, Tk/s cells alone are sufficient for eliciting acute GVH disease (Mason, 1981 ; Sprent et al., 1986). However, recently Sprent et al. have demonstrated that a small number of Th cells can markedly augment acute GVH disease over class I barriers in mice (Sprent et al., 1988).

In contrast, however, in a $P \Rightarrow F 1$ model in mice, an acute GVH reaction could only be elicited provided a difference in both class II and class I antigens was present. Analysis of acute GVH reactions in this $P \Rightarrow F 1$ model has demonstrated that the acute phase is due to Ts cells, and that the activation of these cells is preceded by a short period in which activated Th lymphocytes are demonstrable (Pals et al., 1984).

In case of acute GVH reactions across MiHA, the situation is even more complex. Most evidence favours a role for $\mathrm{Tk} / \mathrm{s}$ in eliciting acute GVH disease, as established in studies in mice (Sprent and Korngold, 1981; Kindred 1983). However, more recent observations have demonstrated that the subset of $\mathrm{T}$ cel $\rrbracket s$ involved in eliciting acute 
GVH reactions across MiHA barriers largely depends on the strain combination of mice used. In four out of six combinations $\mathrm{Tk} / \mathrm{s}$ celis were mainly responsible for inducing disease whereas in two out of six combinations Th cells were the most potent inducers of acute GVH reactions (Korngold and Sprent, 1987). Therefore, the experimental data of reports using only one strain should be interpreted with caution.

In addition to the experiments designed to analyze the role of $T$ lymphocytes in eliciting acute GVH, the occurrence of acute GVH reactions after transfer of spleen cells from nude (thymusless) mice has also been described. Although no mature T lymphocytes are present in these mice, cells of these animals could elicit clear, although somewhat delayed acute GVH reactions (O'Kunewick et al., 1981, 1985). Therefore, this observation does not fit with the idea that mature $T$ cells in the BMT inoculum are solely responsible for the acute GVH reaction, and other mechanisms may also be capable to induce a similar reaction (Reinherz et al., 1979).

How lymphocytes finally induce the pathology observed in a GVH reaction is not yet clear. Lymphocytes have several different anti-host activities that may contribute to the GVH pathology, including alloantibody forming cells, host-specific cytotoxic activity (Cerottini et al., 1971) and delayed type hypersensitivity reactivity (reviewed by Benner et al., 1985). However, the precise mechanisms that produce GVH pathology are not known. Common immunological in vitro assays such as donor anti-recipient cytotoxic $T$ cell assays and mixed-lymphocyte cultures have yielded inconsistent results and are not predictive for the occurence of acute GVH disease (reviewed by Gale, 1985). Only one test has been reported to have prognostic value with respect to the development of acute GVH disease. In this test donor lymphocytes are sensitized in primary cultures against recipient lymphocytes. Next, the primed lymphocytes are cocultured with recipient skin. Induction of histological lesions comparable to acute GVH lesions in the skin explant after a short period of co-culture correlated well with the development of clinical GVH disease (Vogelsang et al., 1985).

Other investigators have suggested a role for natural killer (NK) cells in acute GVH reactions (Parkman et al., 1980 ; Dokhelar et al., 1981 ; Roy et al., 1982 ; Ghayur, 1987). NK cell involvement might explain the histological lesions detected in acute GVH disease (see below), since NK cells are believed to react against "fetal-like" antigens (Roder, 1982). These antigens might be more frequently present in organs with a high turnover of cells such as the skin and the gastrointestinal tract.

More recently, a role for tumour necrosis factor (TNF) in the pathogenesis of acute GVH disease has been suggested (Piguet, 1987). In this study, it emerged that treatment of mice with rabbit antibody directed against recombinant mouse TNF-alpha almost completely prevented the lesions of acute GVH disease in the skin and gastrointestinal tract, and substantially reduced mortality. Large granular lymphocytes (including $\mathrm{K}$ cells) might be responsible for the production of TNF, since these cells are known to be producers of TNF (Peters et al., 1986) and have been noticed to participate in acute GVH reactions (Guillien et al., 1986). 
Surveying these experimental data, it is thus far not possible to conclude which immunocompetent cells elicit the acute GVH reaction. Although mature T lymphocytes probably play the most prominent role, other cell types might be involved as well. Different effector subsets of $\mathrm{T}$ cells seem to be present in different models, i.e. the $\mathrm{P} \Rightarrow \mathrm{F} 1$ model yields results completely different from those obtained in models using irradiated recipients.

\section{Pathology of acute graft-versus-host disease.}

The pathology of acute GVH disease in the rat has been extensively described by Stastny and Beschorner (Stastny, 1963 ; 1965 ; Beschorner et al., 1982). The lymphoid organs show a marked hypocellularity, which has been ascribed by these authors to suppression of reconstitution, rather than to destructive mechanisms directed against host cells. Based on this atrophy of the lymphoid organs and the pancytopenia observed in the peripheral blood of mice undergoing acute GVH disease, Gleichman has referred to this phase of GVH disease as the "suppressive phase" (Gleichman, 1984).

In the non-lymphoid organs mononuclear cell infiltration, interstitial edema and necrosis of target cells are the predominant morphological changes. The earliest abnormalities may be found in the tongue. Other organs consistently involved in acute GVH disease are the skin, exocrine pancreas, liver, and intestines. Organs incidentially involved are the bronchial mucosa, serous salivary glands, lacrimal glands, conjuctivae, renal pelvis, urinary bladder, and heart.

In man, the triad of skin rash, liver dysfunction, and diarrhea identifies GVH disease clinically. Histological lesions due to a GVH reaction can be observed in the skin, liver, gastrointestinal tract, spleen, lymph nodes, kidney, heart, and tongue. Severall lesions, including cellular infiltrations, can be observed in the lungs, however, it is difficult to distinguish these lesion from those due to primary infections. The predominant lesions observed in human non-lymphoid organs are similar to those observed in rats and consist of mononuclear cell infiltrations and necrosis of predominantly epithelial cells, leaving "mummified bodies" - being necrotic cells - which represent a constant morphological feature of acute GVH disease. Lymph-nodes and spleen may show marked atrophy, as observed in rodents (Kruger et al., 1971 ; Slavin and Santos, 1973).

\section{Etiology of chronic graft-versus-host disease.}

In contrast to the vast evidence that acute GVH disease is caused by mature immunocompetent cells of the donor, little data are available on the cellular mechanisms leading to chronic GVH disease. Two possibilities have been suggested in the literature: 1) chronic GVH disease is caused by long living lymphocytes of donor origin which have been sensitized against unknown, possibly MiHA antigens of the host (Graze and Gale, 1979 ; van Rood et al., 1987) and 2) chronic GVH disease is elicited by immunocompetent donor cells that differentiate in the recipient from the bone marrow inoculum 
(Parkman et al., 1980). The first hypothesis is largely based on the clinical observations that acute GVH disease is the most valuable factor predicting chronic GVH disease, and that chronic GVH disease is most often seen as a continuum of acute GVH disease (Graze and Gale, 1979). However, with respect to the hypotheses described above, no clear experimental evidence is available to decide whether the immunocompetent cells involved in chronic GVH disease derive from donor stem cells or are persisting, longlived donor lymphocytes.

Many studies on functional activities of lymphocytes in chronic GVH disease have been performed by the group of Tsoi and Thomas. They observed deposition of IgM antibodies and complement in the skin of patients with chronic GVH disease, suggesting participation of humoral factors (Tsoi et al., 1978). Most evidence, however, indicates that abnormal cellular reactions lead to chronic GVH disease. First, proliferative responses of lymphocytes from patients with chronic GVH disease against non-HLA antigens presented by cryopreserved, pre-BMT recipient lymphocytes have been documented. In BMT treated patients without chronic GVH disease no such responses could be detected (Tsoi, et al. 1980). It should be noticed that in this study donor and recipient were selected for MHC identity and that a bidirectional mixed lymphocyte culture yielded no reaction. Comparable data were obtained in mice with chronic GVH disease, in which autoreactivity of chimeric $T$ helper cells could be demonstrated (Parkman, 1986).

Second, a cytotoxic reaction against cultured host fibroblast could be demonstrated in patients with chronic GVH disease. Again, this reaction was not detectable in patients without chronic GVH disease (Tsoi et al., 1981).

In addition to these observations on cellular proliferative and cytotoxic activities, decreased "specific" suppressor mechanisms have also been documented in patients with chronic GVH disease. No specific suppressor activity was demonstrable in MLR, when donor lymphocytes of patients with GVH disease and TNP-labeled, cryopreserved recipient lymphocytes were combined. On the other hand, patients without chronic GVH disease did show such suppressive activity (Tsoi et al., 1981). The authors suggested that patients without chronic GVH disease maintain a stable GVH tolerance by such suppressor cells, and therefore escape disease. Failure of this graft-versus-host tolerance may elicit chronic GVH disease (Tutschka, 1981).

In the studies mentioned above it is not known whether the lymphocytes responsible for the observed GVH reactions differentiated in the recipient's thymus or were long-lived donor lymphocytes. The discussion whether the active lymphocytes matured in the recipient or not appears to be important for the understanding of the immunological mechanisms leading to chronic GVH disease. It is known that after BMT, "education" of lymphocytes to tolerate "self-antigens" occurs within the thymus; after lethal X-irradiation and BMT a "recapitulation of ontogeny" occurs (Tustchka, 1986). Therefore, if active $T$ cells differentiate in the recipient's thymus, but still attack the host, this implies that tolerance induction has failed. If so, the target antigens can either be host specific antigens (i.e. MiHA) or antigens shared by host and donor ("autoantigens"). In this respect the function of the thymus after BMT is important. The thymus 
is known to be a target organ of the acute GVH reaction (Seddik et al., 1978, 1980 ; Muller-Hermelink et al., 1987), and damage of the thymus may consequently lead to a failure to induce tolerance to (auto)antigens in T lymphocytes (Boland, 1985). If so, this might be an explanation for the relation of acute GVH disease and chronic GVH disease (Storb et al., 1983 ; Ringden et al., 1985). Howewer, attempts to prevent chronic GVH disease by administration of thymic hormone, thymus transplants, or thymic epithelial cells have failed thus far (Atkinson et al., 1982; Boland et al., 1985)

Apart from the association of acute GVH disease and chronic GVH disease mentioned above, factors including increasing age of the recipient, administration of donor buffy coat cells and cytomegalovirus infections have been noticed to increase the risk for the development of chronic GVH disease (Storb et al., 1983 ; Ringden et al., 1985 ; Lonnquist et al., 1984 ; Jacobsen $e t$ al., 1986). How these factors increase the incidence of chronic GVH disease is not known. An attempt to increase the incidence of (chronic) GVH disease in rats, by the use of a rat cytomegalovirus, was, however, not successful (Bos 1989, and unpublished observations).

In conclusion, there is evidence for involvement of both humoral and cellular factors in the development of chronic GVH disease, and increased proliferative and cytotoxic activity of lymphocytes as well as abnormal suppressor activity has been documented.

At this point it should be mentioned that because of the lack of evidence that chronic GVH disease is due to persisting donor cells, the term chronic GVH is an operational one, merely descriptive for the pathology observed in the different models. Only when chronic GVH disease can be demonstrated to be due to persisting donor lymphocytes the term chronic GVH disease is correct in the immunological sense. How donor cells should be designated that originated from the donor, but which have been educated in the thymus of the recipient, is not debated in the literature. If the latter cells are responsible for the pathology because of a failure of the thymus to educate them to tolerate recipient antigens, the term auto-immunity might be more appropriate to describe the immunological processes in chronic GVH disease.

\section{Pathology of chronic graft-versus-host disease.}

Chronic GVH disease was first described in man by Mathe $e t$ al. The presence of multiple foci of infiltration of the intestines observed at autopsy of the first patient who underwent a BMT were thought to be due to a chronic GVH reaction (Mathe, 1965). Thereafter, several reports have been published that have documented chronic GVH disease after BMT in man with a prevalence of $20-40 \%$ in patients surviving the first 3 months after BMT (Thomas et al. 1975; Thomas, 1979 ; Storb et al. 1976; Shulman et al., 1980). Chronic GVH disease has been noticed to develop in three clinically different fashions : 1) continuously with acute GVH disease, and progressing gradually into chronic GVH disease, 2) after acute GVH disease, separated by an asymptomatic period, and 3) de novo, without prior clinical or histological signs of acute GVH disease. 
The first two clinical courses are most frequently observed (Shulman et al., 1978, 1980). A clinical report on 20 patients with chronic GVH disease was published in 1980 by Shulman et al. This report demonstrated that chronic GVH disease is a beterogeneous disease involving a variety of organs. The skin was the organ most frequently involved ( $90 \%$ of patients), whereas abnormalities of the minor salivary glands, mouth, eyes, lungs, liver or gastrointestinal tract were observed in approximately $50 \%$ of the patients. The musculo-skeletal system was less frequently involved, but myositis, serositis, and arthritis were incidentially documented. Several patients fulfilled the criteria for systemic lupus erythomatodes (Shulman et al., 1980). Later, also rarer diseases like myastenia gravis, diffuse fasciitis, and interstitial pneumonia have been related to chronic GVH disease (Perreault et al., 1985 ; Bolger et al., 1986 ; van de Bergh et al., 1987).

The pathology of the skin has been described in detail by Shulman et al. They distinguished two categories of patients, one with a generalized, and another with a localized type of chronic GVH disease of the skin. Histologically, in the early phase of the generalized form eosinophilic bodies (mummified cells), and necrotic keratinocytes were observed, with degeneration of the basal layer of the epidermis. In the late phase fibrosis and destruction of the adnexal structures, fibrosis of the dermis and subcutaneous fat and loss of elastic fibers were the most prominent features. In the localized form the most remarkable changes occurred in the dermis, including progressive fibrosis of the normal collagen bundles. In the late phase this localized form is indistinguishable from the late phase in generalized chronic GVH disease (Shulman et al. 1978 ; Graze and Gale 1979). The prognosis of the patients with chronic GVH disease is highly variable, depending on the severity of skin disease and the inwolvement of other organs as well as a possible immunodeficiency (Shulman et al., 1980).

The pathology of chronic graft-versus-host diseases in rodents shows strong similarities to pathology in man described above. The pathology of chronic GVH disease in these rodents will be further discussed below.

\section{Syngeneic and autologous graft-versus-host reactions.}

Not only as a consequence of the classical GVH reaction, observed after BMT across major or minor histocompatibility barriers, but also after BMT using identical twins as donors and recipients, or even after autologous BMT, GVH-like pathology may develop (Rappaport et al., 1979 ; Oaks and Cramer, 1985 ; Hood et al, 1987 ; Einsele, 1988).

Identical twins are supposed to be genetically identical (syngeneic), which excludes immune reactions to HA. In the case of autologous BMT donor and recipient are even identical. Hence, from an immunological point of view GVH reactions must be excluded. Occurrence of GVH reactions in these situations would violate the second "law" of Billingham defining induction of a GVH reaction (the presence of transplantation antigens in the recipient that are not present in the donor), unless neo-antigens, 
possibly induced by treatment, could be identified in the recipient. Therefore, unless these neo-antigens can be identified, the term GVH reaction should not be applied to these clinical or experimental models.

The factors leading to the GVH-like pathology after autologous or syngeneic BMT are, however, unknown. As mentioned above, a "recapitulation of ontogeny" takes place after BMT : lymphocytes have to learn to discriminate self and non-self. Possibly, due to the treatment of the recipients during the BMT procedure, including the administration of immunosuppressants, this process might be disturbed, leading to an autoimmune reaction. Furthermore, a disbalance in regulatory $\mathrm{T}$ lymphocytes might account for this reaction (Marcos et al., 1988; Hess et al., 1989)

Two examples of such reactions, induced by the combination of (sub-)lethal X-irradiation, syngeneic or autologous BMT, and/or the administration of immunosuppressants will be described in more detail in the following paragraph.

\section{Cyclosporine-A- and cyclophosphamide/busulphan- induced syngeneic graft-wersus-host/autoimmune reactions.}

As stated above, GVH-pathology may also develop when bone marrow is transplanted to an identical twin or after autologous BMT in man and rodents.

In 1983, Glazier and co-workers described the occurrence of GVH disease after lethal X-irradiation, BMT and the administration of cyclosporine-A (CyA) for 3 to 6 weeks in rats. Surprisingly, $2-4$ weeks after wiihdrawal of $\mathrm{CyA}$, a disease developed which clinically mimicked acute GVH disease occurring after allogeneic BMT (Glazier et al., 1983). This disease was called acute syngeneic graft-versus-host disease or CyAinduced autoimmune disease (CyA-AI). The possibility that this reaction is due to different MiHA present in these inbred strains could be excluded, since the same manifestations were observed after autologous BMT. (In the rat autologous BMT is performed by lethal $X$-irradiation excluding one limb by shielding with lead. The bone marrow of this paw is sufficient for hematological recovery.) In addition to lethal irradiation, sublethal irradiation might suffice to induce the disease, although in that case it develops somewhat slower (Sorokin et al., 1986). The thymus plays a crucial role in this phenomenon since protection of the thymus from X-irradiation prevents the development of CyA-AI (Glazier et al., 1983). Furthermore, thymectomy before BMT prevents CyA-AI (Sorokin et al., 1986). The development of CyA-AI has been explained by inadequate learning of "self" by (pre-)T lymphocytes derived from bone marrow stem cells; a process that normally (re)occurs in the thymus after BMT (Tutschka, 1986). Immunological mechanisms leading to CyA-AI are not well understood. As in acute GVH disease, the development of CyA-AI requires the presence of T cells (Sorokin $e t$ al., 1986; Korngold and Sprent, 1987). A role for cytotoxic T lymphocytes in eliciting CyAAI has been suggested by Hess and co-workers. They showed that after withdrawal of CyA cytotoxic T cells directed against public class II antigens, including self class II antigens, developed (Hesset al., 1985). In order to study the cells involved in CyA-AI, adop- 
tive transfers of cells from animals undergoing $\mathrm{CyA}-\mathrm{Al}$ to secondary recipients were performed. By this procedure similar clinical pictures were induced in these secondary recipients, provided total $T$ cell populations or purified $T$ helper $(\mathrm{Th})$ lymphocytes were transferred, but not by transfer of T killer/suppressor (Tk/s) cells (Sorokin et al. 1986). Since the latter data do not fit with the suggestion of Hess et al. that Tk/s cells are responsible for eliciting CyA-AI, no definitive conclusion on the cellular mechanisms essential for the development of CyA-AI can be drawn.

The animals undergoing $\mathrm{CyA}-\mathrm{Al}$ in the studies published so far all died because of this syndrome or were killed on purpose during the acute phase of the disease. Only in one report a remark has been made that approximately $30 \%$ of the animals survived CyA-Al and recovered (Sorokin et al., 1986). How the disease progressed in these animals has not been published.

The second observation of syngeneic GVH disease in rats has been documented by Oaks and Cramer. They observed that BMT in certain inbred rat strains conditioned with cyclophosphamide and busulphan led to GVH disease (Oaks and Cramer, 1985). In these animals symptoms of chronic GVH disease were observed $6-12$ months after BMT. Again, this GVH-like disease could be provoked after autologous BMT as well. Therefore, also in this model other factors than histocompatibility barriers must account for the reaction.

More recently, the presence of chronic GVH disease-like skin abnormalities have also been documented in animals about 3 weeks after adoptive transfer of autoreactive cells from rats undergoing CyA-AI. However, no clear evidence for scleroderma-like abnormalities was presented (Beschorner et al., 1988).

The interest in the development of chronic GVH disease or scleroderma-like disease in these models will be clear from the following paragraphs explaining the similarity of classical chronic GVH disease and scleroderma. The model of Oaks and Cramer for induction of syngeneic chronic GVH disease could unfortunately not be used in the studies presented in this thesis, since the appropriate rat strains were not available reared under specific pathogen-free conditions.

Since referral to this syndrome as syngeneic graft-versus-host disease might be confusing (see above), the term cyclosporine-induced autoimmune disease (CyA-Al) will be further used in this thesis. 


\section{CHRONIC GRAFT VERSUS-HOST DISEASE AND SCLERODERMA.}

\section{Association of chronic graft-versus-host disease and scleroderma in man.}

The pathology of chronic $G \mathrm{VH}$ disease described above has been noticed to resemble the pathology of some so-called autoimmune diseases in man (Nisbet and Heslop, 1962; Lawley et al. 1977). The abnormal fibrosis of the skin and other organs in chronic GVH disease is similar to the pathology of patients with scleroderma (Siimes et al., 1977). Furthermore, lesions of the minor salivary glands in chronic GVH disease occasionally cause a sicca syndrome quite similar to the lesions and symptoms of Sjögren disease. Other patients with chronic GVH disease show clinical signs and symptoms similar to those observed in patients with systemic lupus erythematodes (Sullivan et al., 1981).

Apart from the studies of Shulman and Gale referred to in the previous paragraph, several case studies have been published on patients developing chronic GVH disease after BMT showing clinical and histological symptoms akin to those described for patients with scleroderma (Lawley et al., 1977 ; Furst et al., 1979 ; Herzog et al., 1980). Furst et al. have compared a group of six patients with chronic GVH disease to a group of 49 patients with scleroderma. Symptoms like a hidebound skin with histologically proven atrophy of the epidermis and adnexae, fibrosis of the dermis sicca syndrome, pulmonary function abnormalities, and arthralgias were similar in the two groups. Although histological similarities between skin biopsies of patients with scleroderma and patients with chronic GVH disease have been noticed by several authors, discrepancies exist as well. Differences concern the topography of the infiltrate, localization of active dermoblasts, and the deposition of collagen, mainly restricted to the upper third part of the dermis in chronic GVH disease. These differences may histologically discriminate chronic GVH disease from scleroderma (Janin-Mercier et al., 1981).

Cardiac and renal abnormalities as well as Raynaud's phenomenon were also observed in patients with chronic GVH disease, although less frequently than in patients with scleroderma. There are few similarities of the laboratory findings in both groups of patients. Patients with chronic GVH disease show elevated plasma concentrations of immunoglobuline- $\mathrm{G}(\mathrm{IgG})$ and $\operatorname{lgG}$ immune complexes, which are not (or less prominently) present in scleroderma (Furst et al., 1980; Herzoget $a_{*, 1} 1980$ ). Although antinuclear antibodies with several specificities occurred in patients with chronic GVH disease, these lacked the pattern of specificity of anti-nuclear antibodies present in the serum of patients with scleroderma (Lister et al., 1987).

An important difference hampering comparison of the two groups is the period available for follow-up. Scleroderma is often present for many years, whereas patients with chronic GVH disease often die within 1 - 3 years after BMT due to complications as a consequenc of an immunosuppressed status. Therefore, some symptoms of scleroderma may not have been observed in patients with chronic GVH disease because of the limited follow-up period (Furst et al., 1979; Herzog et al. 1980). 
In conclusion, chronic GVH disease and scleroderma have been noticed to have many features in common, although several differences exist as well. It is believed by many authors that study of the pathogenesis of chronic GVH disease might shed some light on the etiology of scleroderma.

\section{Similarity of pathology associated with chronic graft-versus-host disease in rodents and scleroderma in man.}

Because of the similarities between chronic GVH disease and scleroderma in terms of skin pathology, there has been great interest in models of chronic GVH disease in animals. In the rat, chronic GVH disease has been described in several experimental models, and the similarity of its associated pathology with that of scleroderma in man has been mentioned even before the first clinical observations on the association of scleroderma and chronic GVH disease in man (Stastny et al., 1963). Assuming that several human diseases such as connective tissue diseases are due to immunological reactions against auto-antigens, Stastny attempted to simulate these diseases by introducing GVH disease in a random bred recipient rat strain. In the future recipients neonatal tolerance for lymphoid cells from an inbred donor rat strain was established; after tolerance had been demonstrated by acceptance of donor-type skin grafts, lymphoid cells of the donor were injected. In the acute phase, skin abnormalities resembling those associated with SLE develloped, whereas later thickening of the skin, scaling, and alopecia were observed. Microscopically, there was increase of collagen in the dermis, with atrophy of the epidermis and skin adnexes. Ultimately, these abnormalities progressed to extreme atrophy of the epidermis with marked hyperkeratosis, disappearance of the appendages and a marked increase of collagen, yilelding a histological picture resembling scleroderma. Additional abnormalities were observed in the joints, heart, kidney and lymphoid organs (Stastny et al., 1965).

In other rat models, similar observations on chronic GVH disease were made after lethal X-irradiation and $\mathrm{BMT}$ using donors incompatible for the $\mathrm{MHC}$, or after syngeneic BMT (Beschorner et al., 1982 ; Jaffee and Claman, 1983; Oaks and Cramer, 1985). In the study of Beschorner et al. skin abnormalities were similar to those described by Stastny et al, and again demonstrated striking similarities to scleroderma in man. In the model of Oaks and Cramer, however, atrophy of the dermis was a more prominent sign of disease, and increased sclerosis was not always present (Cramer, personal communication). Furthermore, abnormalities of the liver, salivary glands, and esophagus were described. These organs can also be affected in patients with systemic scleroderma (see above).

In conclusion, experimental models in rats exist that induce chronic GVH disease wich may be associated with skin and other organ pathology resembling that characteristic for scleroderma in man. 


\section{SUMMARY}

\section{Is chronic graft-versus-host disease an adequate model for scleroderma?}

As outlined above, there is substantial overlap between scleroderma and chronic GVH disease. In a recent review, Mekori and Claman have discussed the validity of chronic GVH disease in animal models as a model for scleroderma in man. They concluded that, although some histological discrepancies do exist, experimental chronic GVH disease can be a valuable model to study pathogenetic mechanisms relevant for scleroderma. However, they did not mention the presence of vascular pathology in this model (Mekori and Claman, 1987). As described in this chapter, vascular pathology is one of the hallmarks in scleroderma in patients, leading to severall complications such as Raynaud phenomenon and ulceration of the skin due to inadequate blood flow. In addition, the vascular abnormalities have been destined an essential role in several theories on the etiology of scleroderma. In some studies, the Raynaud's phenomenon has also been observed in patients with clinical evidence of chronic GVH disease after BMT, although less frequently than in patients with spontaneous scleroderma (Furst $e$ t al., 1980). No patients with chronic GVH disease have been described with skin ulcerations due to inadequate blood flow of the skin.

In reports on the experimental models reviewed in this chapter no data have been presented on vascular pathology in animals with chronic GVH disease. However, if experimental chronic GVH disease is an adequate model for scleroderma, vascular pathology should be demonstrable. 


\section{REFERENCES TO CHAPTER I}

Alarcon-Segovia D, R Palacios, and G Ibanex de Kasep (1981) Human postthymic precursor cells in health and disease. VII. Immunoregulatory circuits of the peripheral blood mononuclear cells from patients with progressive systemic sclerosis. J Clin Lab Immun 5:143w148

Andrews BS, GJ Friou, RJ Barr, GR Mirlck, M Berman, C Sandborg, and P Ross (1986) Loss of epidermall Langerhans cells and endothelial cell HLA-DR antigen in the skin in progressive sclerosis. I Rheumatol 13-2:341-348

Atkinson K, R Storb, HD Ochs, S Goehle, KM Sullivan, RP Witherspoon, LG Lum, M-S Tsol, JE Sanders, M Parr, J Stewart, and ED Thomas (1982) Thymus transplantation after allogeneic bone marrow graft to prevent chronic graft-versus-host disease in humans. Transplantation 33:168-173

Barnett AJ (1974) Scleroderma (progressive systemic sclerosis) .C Thomas, Springfield

Beatty PG, RA Clift, EM Mickelson, BB Nisperos, N Flournoy, PJ Martin, JE Sanders, P Stewart, D Buckner, R Storb, ED Thomas, and JA Hansen (1985) Matrow transplantation from related donors other than HLA-identical siblings. New Eng J Med 313:765-771

Bekkum van DW, and O Vas (1957) Immunological aspects of homo- and hetterologous bone marrow transplantation in irradiated animals. J Cell Comp Physiol 50:139

Bekkum van DW (1985) Graft-versus-host discase. In: Bone marrow transplantation (van Bekkum and Lowenberg eds) Marcel Dekker inc, New York and Basel pp. 147-212

Benner R (1985) Regulation of delayed type hypersensitivity to host histocompatibility antigens during graft-versus-host reactions. Immunol Rev 88:25-58

Bergh van den V, G Tricot, G Fonteyn, R Dom, and J Bulcke (1987) Diffuse fasciitis alter bone marrow transplantation. Am J Pathol 83:139-143

Bernstein RM, JC Steigerwald, and EM Tan (1982) Association of antinuclear and antinucleolar antibodies in progressive systemic sclerosis. Clin Exp Imm 48:43-51

Beschorner WE, PJ Tutschka, and GW Santos (1982) Sequential morphology of graft-versus-hosi disease in the rat radiation chimera. Clin Immunol Immunopathol 22:203-224

Beschorner W, PJ Tutschka, and GW Santos (1982) Chronic graft versus host disease in the rat radiation chimera. Transpllantation 33-4:393-399

Beschorner WE, AD Hess, CA Shinn, and GW Santos (1988) Transfer of cyclosporine-associated syngeneic graft-versus-host disease by thymocyles. Resemblance to chronic graft-versus-host disease. Transplantation 45:209-215

Billingham RE, and L Brent (1959) Quantitative studies on tissue transplantation immunity. IV. Induction of tolerance in newborn mice and studies on the phenomenon of runt disease. Philos Trans Royal Soc Londen 242:439-477

Billingham RE, V Defendil, WK Silvers, and D Steinmuller (1962) Quantitative studies on the induction of tolerance of skin homografts and on runt disease in neonatal rats. J Natl Canc Inst 28:365-404

Billingham RE (1967-1968) The biology of graft versus host reactions. Harvey Lect 62:21-78

Boland J, K Atkins on, T Bodinnar, and J Biggs (1985) Does thymic epithelial cell insulficiency predispose to chronic graft versus host disease after bone marrow transplantation? Transplant Proc 17:1709-1.720

Bolger GB, KM Sullivan, AM Spence, F R Appelbaum, R Johnston, JE Sanders, HJ Deeg, R Withers poon, KC Doney J Nims, ED Thomas, and R Storb (1986) Myasthenia gravis after allogeneic bone marrow transplantation: relationship to chronic graft-versus-host disease. Neurology 36:1087-1091 
Bollinger A, K Jager, Sqier, A Geser (1979) Microangiopathy in scleroderma ewaluated by dynamic fevorescence videomicroscopy. Microvase Res 17:\$164

Bolinger A, J Frey, K Jager, J Furrer, J Seglias, and W Siegenthater (1982) Patterns of diffusion through skim capillaries in patients with long-term diabetes. New Eng J Med 307:1305-1310

Boillinger A, J Frey, K Jager, UK Franzeck (1983) Diffusion through skin capillaries in patients with long term diabetes, scleroditerma, and chronic wenous incompetence. Inter Angio 2:159-165

Bollinger A, $\mathbf{K}$ Jager, and W Siegenthaler W (1986) Microangiopathy of progressive systemic sclerosis (PSS) cvaluated by dynamic fluorescence videomicroscopy. Arch Int Med 146:1541-154.5

Dos GMJ, GD Majoor, CA Bruggeman, G Grauls, M-JWH wan de Gaar, and PJC wan Breda Vriesman (1989) Rat cytomegalovirus can be tiransferred by bone marrow cells but does not affect the course of acute graft-wersus-host disease. Transplant Proc In press.

Botstein GR, and EC LeRoy (1981) Primary heart disease in systemic sclerosis (scleroderma) : Advances in clinical and pathologic features, pathogenesis, and new therapeutic approaches. Am Heart I 102:91.3919

Botstein GR, GK Sherer, and EC LeRoy (1982) Fibroblast selection in scleroderma. An alternative model of fibrosis. Arthr Rheum 25:189-195

Bril H, and R Benner (1985) Graft-vs-host reactions : Mechanisms and contemporary theories. CRC Crit Rew Clin Lab Sci 22:43-94

Brown GE, and PA O'Leary (1925) Skin capillaries in scleroderma. Arch Int Med :73-88

Campleell PM, and EC LeRoy (1975) Pathogenesis of systemic sclerosis : A vascular hypothesis. Sem Arthr Rheum 4:351-368

Cerottini J-C, AA Nordin, and KT Brunmer (1971) Cellular and humoral response to transplantation antigens. 1. Development of alloantibody-forming cells and cytoloxic lymphocytes in the graft-versus-hosi reaction. JExp Med 134 :553-564

Cheney RT, and J Sprent (1985) Capacity of Cyclosporine to induce auto-graft-versus-host disease and impair intrathymic T cell differentation. Transplant Proc 17:528-531.

Cohen S, AR Johnson, and E Hurd (1983) Cytotoxicity of sera from patients with scleroderma. Effects on human endothelial cells and fibroblasts in culture. Arthr Rheum 26:170-178

Congdon CC, and $1 \mathrm{~S}$ Urso (1957) Homologous bone marrow in the treatment of radiation injury in mice. J Exp Med 33:749-762

Counce S, P Smith, R Barth, and GD Snell (1956) Strong and weak histocompatibility gene differences in mice and their role in the rejection of homografts of tumors and skin. Ann Surg 144:447-465

Curzio C (Translated by R Watson) (1754) An account of an extraordinary disease of the skin, and its cure. Plillos Trans Roy Soc Lond 48:579-587

D'Angelo WA, JF Fries, AT Masi, and LE Shulman (1969) Pathologic observations in systemic sclerosis (Scleroderma). A study of fifty-eight autopsy cases and fifty-cight matched controls. Am J Med 46:428* 440

Deeg HJ (1985) The biology of chronic graft-versus-host disease. Exp Haemat S17 13:128-130

Dinkler M (1891) Zur Lehre von der Sklerodermic. Deutsch Arch Klin Med 44:581.

Dokhelar M-C, J Weils, M Lipinski, C Tetaud, A Devergie, E Gluckman, and T Tursz (1981) Natural killer cell activity in human bone marrow recipients. Transplantation 31:61-65

Drenk F, and HRG Deicher (1988) Pathophysiological effects of endothelial cytotoxic activity derived from sera of patients with progressive systemic sclerosis. J Rheumatol 15:468-474 
Dustoor MM, MM Mclnerney, DJ Mazanec, and MK Cathart (1987) Abnormal lymphocyte function in scleroderma: A study on identical twins. Clin Inmunol Immunopathol 44:20:30

Einsele H, G Ehninger, EM Schneider, GFR Kruger, A Vallbracht, R Dopfer, H Schnidt, HD Waller, and CA Muller (1988) High frequency of graft-versus-host like syndromes following syngenaic bone marrow transplantation. Transplantation 45:579-585

Fleischmajer R, and JS Perlish (1983) The vascular, inllammatory, and fibrotic component in scletoderna skin. In : Connective tissue disease BM Wagner (ed). Williams \& Wilkins, London pp.40-49

Fleischmajer R, V Damiano, and A Nedwich (1971) Scleroderma and the subcutaneous tissue. Science 171:1019-1021

Furst DE, PJ Clements, P Graze, R Gale, and N Roberts (1979) A syndrome resembling systemic sclerosis after bone marrow transplantation. Arthr Rheum 22:904-910

Gale RP (1985) Graft-versus-host disease. Immunol Rev 88:193-214

Ganczarczyk ML, P Lee, and SK Armstrong (1988) Nailfold capillary microscopy in polymyosilis and dermatomyositis. Arthr Rheum 31:116-119

Ghayur T, TA Seemayer, PAL Konshavn, JG Gartner, and WS Lapp (1987) Graft-versus-host reachions in the beige mouse. An investigation of the role of host and donor natural killer cells in the pathogenesis of graft-versus-host disease. Transplantation 44:261-267

Glazier A, PJ Tutschka, ER Farmer, GW Santos (1983) Graft versus host disease in cyclosporin-A treated rats after syngeneic and autologous bone marrow transplantation. J Exp Med 158:1-8

Glazier A, PJ Tutschka, and E Farmer (1983) Studies on the immunobiology of syngeneic and autologous graft-versus-host disease in cyclosporine-treated rats. Transplant Proc 15:3035-3041

Giteichman E, ST Pals, AG Rolink, T Radaskiewicz, and H Gleichman (1984) Graft versus host reactions: clues to the etiopathology of immunological diseases. Immunol Today $5: 324-332$

Goetz RH (1945) Pathology of progressive systemic sclerosis (generalized scleroderma) with special reference to skin changes. Clin Proc ( $S$ Afr) 4:337

Goulmy E, J-W Gratama, E Blokland, FE Zwaan, and JJ van Rood (1983) A minor transplantation antigen detected by MHC-restricted cytotoxic T-lymphocytes during graft-wersus-host disease. Nature 302:159-161

Gowans JL, DD MeGregor, DM Cowen, and CE Ford (1962) Initiation of immune responses by small lymphocyles. Nature 196:651-655

Gowans JL (1962) The fate of parental slrain small lymphocytes in F1 hybrid rats. Ann New York Acad Sci $99: 432-455$

Graze PR, and RP Gale (1979) Chronic graft wersus host disease: A syndrome of disordered immunity. Am J Med 66:611-620

Guillen FJ, J Ferrara, WW Hancock, D Messadi, E Fonferko, S Burakeff, and GF Murphy (1986) Acute cutaneous graft-versus-bost disease to minor histocompatibility antigens in a murine model. Lab Invest 55:35-42

Guldner HH, C Szostecki, HP Vosberg, HJ Lakomek, E Penner, and FA Bautz (1986) Scl 70 autoamtibodies from scleroderma patients recognize a $95 \mathrm{kD}$ a protein identified as DNA topoisomerase 1 . Chronosoma $94: 132-138$

Halle-Panenko O, LL Pritchard, M Bruley-Rosset, L Berumen, and R Motta (1985) Parameters involved in the induction and abrogation of the lethal graft-versus-host reaction directed against non-H-2 antigens. Immunol Rew 88:59-86 
Hendel L, T Aumitzboll, K Dirksen, and M Petri (1984) Collagen in the esophageal mucosa of patients with progressive systemic sclerosis. Acla Derm Vener 64:480-484

Herzog P, PJ Clememts, NK Roberts, DF Furst, CE Johson, and SA Feig (1980) Case report : progressive systemic sclerosis-like syndrome after bone marrow Iransplantation. Clinical, immunological, and pathological findings. J Rheumatol 7:56-64

Hess AD, L Horwitz, WE Beschorner, and W Santos (1985) Development of Graft-versus-host diseaselike syndrome in cycllosporin-treated rats after syngeneic bone marrow transplantation. J Exp Med 161:718-730

Hess AD, AC Fischer, WE Beschorner, and GB Vogelsang (1989) Syngeneic graft-wersus-host disease. Inbalance of autoregulatory and autocytotoxic mechanisms. Transplant Proc In press

Hochberg MC, PA Holt, MG Kane, FC Arnett, and MB Stevens (1980) Survival in systemic sclerosis (scleroderma). Arthr Rheum 23:689-690

Holzman H, S Sollberg, und P Altmeyer (1987) Einteilung der progressiven systemischen Sklerodermic. Hautartet 38:253-257

Hood AF, GB Vogelsang, LP Black, ER Farmer, and GW Santos (1987) Acute grafl-versus-host disease. Development following autologous and syngeneic bone marrow transplantation. Arch Dermatol 123:745750

Horslev-Petersen K, T Ammitzbohl, A Engstrom-Laurent, K Bernsten, P Junker, G Asboe-Hansen, and I Lorenzen (1988) Serum and urinary aminoterminal type II procollagen peptide in progressive systemic sclerosis : relationship to sclerodermal involvement, serum hyaluronan and urinary collagen metabolites. J Rheumatod 15:460-467

Houtman PM, COM Kallenberg, AA Wouda, and TH The (1985) Decreased nailfold capillary density in Raynaud's phenomenon : a reflection of immunologically mediated local and systemic vascular disease ? Ann Rheum Dis 44:603-609

Hughes GRV (1987) Connective tissue disease. Blackwell scientific publications, Oxford pp. 150-171

Inoshita T, TL Whiteside, GP Rodnan, and FH Taylor (1981) Abnormalities of T lymphocyte subsets in patients with progressive sclerosis (PSS, scleroderma). J Lab Clin Med 97:264-277

Jablonska S (1975) Scleroderma and pseudoscleroderma. Polist Medical Publishers Warsaw pp. 1-632 Jacobs MJHM, PJ Breslau, DW Slaaf, RS Reneman, and JAJ Lemmens (1987) Nomenclature of Raynaud's phenomenon : A capillary microscopic and hemorheologic study. Surgery 101:136-145

Jacobsen N, HK Andersen, P Skinhoj, LP Ryder, P Platx, D Jerne, and V Faber (1986) Correlation between donor cytomegalovirus immunity and chronic graft versus host disease after allogeneic bone marrow transplantation. Scand J Haematol 36:499-506

Jaffee BD, and HN Claman (1983) Chronic graft-versus-host disease as a model for scleroderma. I. Description of models. Cell Immunol 77:1-12

Janevski BK (1982) Angiography of the upper extremity. Martinus Nijhotf publishers, The Hague, The Netherlands pp : 210-212

Janin-Mercier A, J Saurat, M Bourges, J Sohiter, LJ Didier, and E Gluckman (1981) The lichen planuslike and sclerotic phases of the graft versus host disease in man : An ultrastructural study of six cases. Acta Derm Vener 61:187 193

Johnson RL, and M Ziff (1976) Lymphokine stimulation of collagen accumulation. J Clin Invest 58:240252

Kahaleh MB, GK Sherer, and EC LeRoy (1979) Endothelial injtry in scleroderma. J Exp Med 149:13261335 
KahaJeh MB, and EC LeRoy (1983) Endothelial injury in scleroderma : A protease mechanism. J Lab Clin Med 101:553-560

Kallenberg CGM, AA Wouda, and TH The (1980) Systemic involvement and immunologic findings in patients presenting with Raynaud's phenomenon. Am I Med 69:675-680

Kallenberg CGM , E Vellenga, AA Wouda, and TH The (1982) Platelet activation, fibrinolytic activity and circulating immune complexes in Raynand's phenomenon. J Rheumatol 9:878-884

Kallenberg CGM, GW Pastoor, AA Wouda, and TH The (1982) Antinuclear antibodies in patients with Raynaud's phenomenon : clinical significance of anticentromere antibodies. Ann Rheum Dis 41.382 .387 Kallenberg CGM, AA Wouda, and TH The (1985) Systemic involvement and immunologic findings in patients presenting with Raynaud's phenomenon. An J Med 69:675-680

Keystone EC, C Lau, DD Gladman, S Wilkinson, $S$ Lee, and A Shore (1982) Immunoregulatory T cell subpopulations in patients with scleroderma using monoclonal antibodies. Clin Exp Immunol 48:443-488 Kindred B (1983) H-2-restricted Graft-versus-host reaction : Foreiga determinants and restriction elements. Immunogenetics 18:57-63

Klein (1982) Immunology. The science of self and non-self discrimination. John Wiley and Sons, New York Korngold R, and J Sprent (1978) Lethal graft-versus-host discase after bone marrow transplantation across minor histocompatibility barriers in mice. Prevention by removing mature $\mathrm{T}$ cells from marrow. $J$ Exp Med 148:1687 1698

Korngold R, and J Sprent (1985) Surface markers of T cells causing lethal graft-ws-host disease to class I us class II H-2 differences. J Immunol 135:3004-3010

Korngold $\mathbf{R}$, and J Sprent (1987) 'T cell subsets and graft-yersus-host disease. Transplantation 44:335-339 Korngoid R, and J Sprent (1987) Variable capacity of L3T 4 + T cells to cause lethal graft-versus-host disease across minor histocompatibility bariers in mice. J Exp Med 16:1552-1564

Krieg Th, and M Meurer (1988) Systemic sclerosis. Clinical and pathophysiologic aspects. I Am Acad Dermatol 18:457-481

Krieg T, I Langer, H Gerstmeier, J Keller, H Mensing, G Goerz, and R Timpl (1986) Type III collagen animopropeptide levels in serum of patients with progressive systemic scleroderma. J Invest. Dermatol 87:788-791

Kristensen JK (1978) Reactive hyperemia in cutaneous tissue in generalized scleroderma. J Invest Dermatol 71:269-273

Kristensen JK (1981) Blood flow in fingers in generalized scleroderma with Raynaud's phenomienon : in: lluence of arterial blood pressure reduction and proximal vasodilatation. JI Invest Dermatol 77.373 376

Kristensen JK (1979) Local regulation of digit al blood flow in generalized scleroderma. J Invest Dermàtol 72:235-240

Kruger GRF, CW Berard, RA DeLellis, RG Graw, RA Yankee, BG Leventhal, GN Rogentine, GP' Herzig, RH Halterman, and ES Henderson (1971) Graft-versus-host disease. Morphologic variation and differential diagnosis in 8 cases of HLA matched bone marrow transplantation. Am J Pathol 63:179-196

Lawley Th J, GL Peck, H Moutsopoulos, AA Gratwohl, AB Deisseroth (1977) Scleroderma, Sjogren-like syndrom, and chronic graft-kersus-host disease. Ann Int Med 87:707-709

LeRoy EC (1982) Pathogenesis of scleroderma. J Invest Dermatol S1:875-89s

LeRoy EC, C Black, R Fleischmajer, S Jablonska, T Krieg, TA Medsger, N Rowell, and F Wollheim (1988)

Scleroderma (systemic sclerosis) : classification, subsets, and pathogenesis. J Rheumatol 15:202-205

Lever WF, and G Schaumburg-Lever (1983) Skin pathology. Lippincott, Philadelphia Pp. 461.-471 
Lister d, H Messner, E Keystone, R Miller, and MJ Fritzler (1987) Autoantibody analysis of patients with graft versus host diseatere. $J$ Clin Lab Immunol 24:19-23

Livingston JZ, ThE Scott, FM Wigtey, GJ Auhalt, WB Bias, RH Mclean, and MC Hochberg (1987) Syslemic sclerosis (scleroderma) : Clinical, genetic, and serologic subsets. I Rheumatol 14:512-518

Lonnquist $\mathbb{B}_{3}, \mathrm{O}$ Ringden, B Wahren, G Gahrton, and G Landgren (1984) Cytomegalovirus infection associated with and preceding chronic graft-versus-host disease. Transplantation 38:465-468

Luderschmidt C, S Schollz, E Mehlhaff, $\mathbf{G}$ Konig, and E Albert (1987) Association of progressive systemic scleroderma to several HLA-B and HLA-DR alleles. Arch Dermatol 123:1188-1.191

Lynch Chd, G Singh, ThL Whiteside, GP Rodnan ThA Medsger, and BS Rabin (1982) Histocompatibility antigen in progressive systemic sclerosis (PSS ; scleroderma). J Clin Inmunol 2:314-31.8

Marcos MAR, M-L Toribio, A de la Hera, C Marquez, and C Martinez-A (1988) Mutual cell interactions and the selection of immune repertoires. Implication in autoimmunity. Immunol Today 9:204-207

Maricq HR, and LC LeRoy (1973) Patterns of tinger capillary abnormalities in connective tissue disease by wide field microscopy. Arthr Rheum 16:619-628

Maricq HR, G Spencer-Green, and EC LeRoy (1976) Skin capillary abnormatities as indicators of organ involvement in scleroderma (systemic sclerosis), Raynaud's phenomenon and dermatomyositis. Am J Med $61: 862-869$

Maricq HR, EC LeRoy, WA D'Angelo, TA Medsger, GP Rodnan, GC Sharp, and JF Wolfe (1980) Diagnostic potential of in wivo capillary microscopy in scleroderma and related disorders. Arthr Rheum 23:183187

Maricq HR, AB Weinberger, EC LeRoy (1982) Early detection of scleroderma-spectrun disorders by in wiwo capillary microscopy: a prospective study of patients with Raynaud's phenomenon. $J$ Rheum 9:289291

Mason DW, and MJ Dallman (1981) Role of thynus-derived and thymus-independent cells in murine skin allograft rejection. Transplantation 32:221-223

Mathe G, KL. Amiel, L Schwarzenberg, A Cattan, M Schneider, MJ de Vries, M Tubiana, C Lalanme, JL Binet, M Papiernik, G Seman, M Matsukura, AM Mery, V Schwarzmann, and A Flaisller (1965) Succesful allogenic bone marrow transplantation in man : Chimerism, induced specific tolerance and possible anti-leukemic effects. Blood 25:179-196

Maxwell DB, CA Grotendorst, GR Grotendorst, and EC LeRoy (1987) Fibroblast heterogeneity in scleroderma: Clg Situdies. J Rheumatol 14:756-759

Medsger TA, and AF Masi (1979) Epidemiology of progressive systemic sclerosis. Clin Rheum Dis : 15-25 Mekori YA, and HN Claman (1986) Is grafl-wersus-host disease a reliable model for scleroderma? La Ricerca Clin Lab 16:509-514

Moneta G, M Brulisaurer, K Jager, and A Bollinger (1987) Infrared fluorescence videomicroscopy of skin capillaries with indocyanine green. Int J Microcirc Clin \& Exp 6:25-34

Muller-Herntelink HK, GE Sale, B Borisch, and R Storb (1987) Pathology of the thymus after allogeneic bone marrow transplantation. Am J Pathol 129:242-256

Murphy JB (1916) The effect of acult chicken organ grafts on the chick enbryo. J Exp Med 24:1-10

Nisbet NW, and BF Heslop (1962) Runi disease. Br Med J 27:206-213

Nishioka K, Y Kobayashi, K Ichiro, C Takijiri (1987) Mast cell numbers in diffuse scleroderma. Arch Dermatol 123:205-208

Oaks MK, and DV Cramer (1985) Chronic graft-versus-host disease in rats after syngeneic bone marrow transplantation. Transplantation 39:504-510 
Oaks MK, and DV Cramer (1985) The genetics of bone marrow transplantation in the rat. Transplantation 39:69-76

O'Kunewick J, RF Meredith, RB Raikow, BJ Bnozovich, and K Maglier (1981) Fatal response suggestive of graft-versus-host reaction following transplantation of spleen cell from allogeneic athymic (nude) mice. Transplantation 31:201-204

O'Kunewick JP, WE Beschorner, MJ Buffo, and DL Kociban (1985) Histopathology of a possible graftversus-host reaction induced by nude mouse spleen cells. Transplantation 39:447-448

Osial TA, TL Whiteside, RB Buckingham, G Singh, E Barnes, JM Pierce and GP Rodnan (1983) Clinical and serologic study of Sjogrens syndrome in patients with progressive systemic sclerosis. Arthr R heum 26:500-508

Pals ST, T Radaskiewicz, and E Gleichman (1984) Allosuppressor and allohelper T cells in acute and chronic graft -ws - host disease. IV. Activation of donor allosuppressor cells is confined to acute GVHD. J Immunol 132:1669-1678

Parkman R (1986) Clonal analysis of murine graft-vs-host disease. I. Phenotypic and functional analysis of T lymphocyte clones. J Immunol 136:3543-3548

Parkman R, J Rappeport, and F Rosen (1980) Human graft wersus host disease. „IInwest Dermatoll 74:276279

Pelltonen L, A Palotie, R Myllyla, T Krieg, and A Oikarinen (1985) Collagen biosynthesis in systemic scleroderma : regulation of posttranslational modifications and synthesis of procollagen in cultured fibroblasts. J Invest. Dermatol 84:14-18

Perkins DL, J Michaelson, RM Glaser, and A Marschak-Rothstein (1987) Selective elimination of nonIpr lymphoid cells in mice undergoing lpr-mediated graft-vs-hosi disease. J Immunol 139:1406-1413

Perreault C, S Ousineau, G D'angelo, M Gyger, F Nepveu, J Boileau, Y Bonny, M Lacombe, and R Lavalle (1985) Lymphoid interstitial pneumonia after allogenic bone marrow transplantation. A possible manile station of chronic graft versus host disease. Cancer 55:1-9

Peters PM, JR Ortaldo, MR Shalaby, LP Svedersky, E Nedwin, TS Bringman, PE Hass, BB Aggarwal, RB Herberman, DV Goeddel, and MA Palladino Jr (1986) Natural killer-sensitive targets stimulate production of TNF-a but not TNF-b (lymphotoxin) by highly purified human peripheral blood large granular lymphocytes. J Immunol 137:2592-2598

Piguet P-F, and P Vassalli (1983) Fate of T-lymphocytes injected into immunodeficient allogeneic nude or semi-allogeneic F1 mice : correlation with manifestations of grafl-versus-host reaction. Immunol Today $73: 71-86$

Piguet P-F (1985) GVHR elicited by products of class I of class II loci of the MHC: analysis of the response of mouse T lymphocytes to products of class 1 and class 11 loci of the MHC. I Immunol 135:163\% 1643

Piguet P-F, GE Grau, B Allet, and P Vassalli (1987) Tumor necrosis factor/cachectin is an elfector of skin and gut lesions of the acute phase of graft-vs-host disease. J Exp Med 166:1280-1289

Postlethwaite AE, and AH Kang (1984) Pathogenesis of progressive systemic sclerosis. I Clin Lab Mcd $103 \div 506-509$

Ranft J, T Lammersen, and H Heidrich (1987) th wo capillary microscopy findings compared to opthalmoscopy findiggs in scleroderma patients. Arthr Rheum 30:1173-1175

Rappaport H (1979) Histopathologic sequence of events in adult mice undergoing lethal graft wersus host reaction developed across $\mathrm{H}-2$ and/or non $\mathrm{H}-2$ histocompatibility barriers. Am Assoe Pathol 96:121-142 
Rappaport J, M Mihm, E Reinherz 8 Lopansri, and R Parkman (1979) Acute graft-wersus-host disease in recipicnts of bone marrow transplants from identical twin donors. Lancet II:717-720

Reinherz EL, R Parkman, J Rappaport, FS Rosen, and SF Schlossman (1979) Abberations of suppres sor T cells in human graft-versus-host disease. New Engl J Med 300:1061-1068

Ringden O, T Paulin, B Lonnqvist, and B Nilsson (1985) An analysis of factors predisposing to chronic graft wersus host disease. Exp Haematol 13:1062-1067

Roder JC and HW Pross (1982) The biology of the human natural killer cell. J Clin Immunol 2:249-263

Rodnan (3P, and TG Benedek (1962) A thistorical account of the study of progressive systemic sclerosis (diffuse seleroderma). Ann Int Med 57:305-319

Rodt H, S Thierfelder, and $\mathbf{E}$ Eulitz (1974) Anti-lymphocyte antibodies and marrow transplantation. III. Effect of heterologous anti-brain antibodies on acute secondary disease in mice. Eur J Immunol 4:25

Rolink AG, T Radaskiewicx, ST Pals, WGJ van der Meer, and E Gleichman (1982) Allosuppressor and allohelper $T$-cells in acute and chronic graft versus host disease. I. Alloreactive suppressor cells rather than killer cells appear to be the decisive effector cells in lethal GVHD. J Exp Med 155:1501-1522

Rolink AG, and E Gleichman (1983) Allosuppressor and allohelper T-cells in acute and chronic graft versus host diseasc. III. Different Lyt subsets of donor T cells induce different pathological syndromes. J Exp Med 158:546-556

Rood JJ van, E Goulmy, and A van Leeuwen (1987) The immunogenetics of chronic graft versus host disease and its relevance for the graft verstus leukemia effect. In : Cellular immunotherapy of cancer. Alan $R$ Liss Inc New York. pp. $433-438$

Rosenau W, and HD Moon (1961) Lysis of homologous cells by sensitized lymphocytes in tissue culture. J Natl Canc Inst 27:471-483

Rossi GA, PB Bitterman, SI Rennard, VJ Ferrans, and RG Crystal (1985) Evidence for chronic inflammation as a component of the interstitial lung disease associated with progressive systemic sclerosis. Am Rev Resp Dis 131:612-617

Roumm AD, ThL Whiterside, ThA Medsger, and GP Rodnan (1984) Lymphocytes in the skin of patients with progressive systemic sclerosis. Quantitation, subtyping, and clinical correlations. Arthr Rheum 27:645-653

Rowell NR (1980) Vasculitis in connective tissue disease In :Vasculitis (Wolff and Winkelman eds) Major problems in dermatology, Vol 10. Lloyd-Luke London pp. 203-217

Roy C, T Ghayur, PA Kongshavn, WS Lapp (1982) Natural killer activity by spleen, lymph-node and thymus cells during graft versus host reaction. Transplantation 34:144-146

Seddik M, TA Seemayer, and WS Lapp (1980) T cell functional defect associated with thymic epithelial cell injury induced by a graft versus host reaction. Transplantation 29:61-66

Seddik M (1978) Thymic epithelial functional deficit in chronic graft versus host reactions. Transplant Proc 11:967-969

Seenayer TA (1979) The graft versus host reaction: A pathogenetic mechanism of experimental and human disease. Prospective in pathology. Vol 5 Fudenberg el al (eds). Mason, New York pp. 93-133

Seibold JR, and JN Harris (1985) Plasma beta-thromboglobulin in the differential diagnosis of Raynaud's phenomenon. J Rheumatol 12:99-103

Sheldon WB, DP Lurie, HR Maricq, MB Kahaleh, FA DeLustro, A Gibofsky, and EC LeRoy (1981) Threc siblings with seleroderma (systemic sclerosis) and wo with Raynaud's phenomenon from a single kindred. Arthr Rheum 24:668-676 
Shero JH, B Bordwell, NF Rothfield, WC Earnshaw (1986) High titers of autoantibodies to Topoison* erase I ( $\mathrm{SCL}-70$ ) in sera from scleroderma patients. Science 231:737-740

Shulman FM, GE Sale, KG Lerner, A Barker, PL Weiden, K Sullivan, Galluci, ED Thomas, and R Storb (1978) Chronic cutaneous graft-versus-host disease in man. Am J Pathol 91:545-570

Shulman HM (1980) Chronic gxaft versus host syndrome in man. A long term chinicopathological study of 20 Seatle patients. Am J Med 69:204-217

Simis MA, E Johanson, and J Rapala (1977) Scleroderma-like graft-versus-host disease as late consequence of bone marrow grafing. Lancet II:831-832

Simonsen M, J Bullnan, A Gammeltoft, F Jensen, and K Jorgenson (1953) Biological inconnpatibility in kidney transplantation in dogs. I. Experimental and morphological investigations. Acta Pathol Microbiol Scand 32:1-16

Simonsen M (1957) The impact on the developing embryo and newborn animal of aduht homologous cells. Acta Pathol Microbiol Scand 40:480-500

Simonsen M (1962) Graft versus host reactions. Their natural history, and applicability as tools of research. Prog Allergy 6:349-461

Simonsen M (1985) Graft-versus-host reactions: the history that never was, and the way things happened to happen. Immunol Rev 88:5-24

Slavin RE, and GW Santos (1973) The graft versus host reaction in man after bone marrow transplanta* aion : pathology, pathogenesis, clinical features, and implications. Clin Inmunol Inmunopathol 1:472-498 Snover DC (1984) Acute and chronic graft versus host disease: histopathological evidence for two dist inct pathogenetic mechanisms. Hum Pathol 15:202.205

Sorokin R, H Kimura, K Schroder, DH Wilson, and DB Wilson (1986) Cyclosporin-induced autoinumunuity. Conditions for expressing disease, requirements for intact thymus, and potency estimates of atbloimmune lymphocytes in drug-treated rats. J Exp Med 164:1615-1625

Sprent J, and $\mathbb{R}$ Korngold (1981) Irmuzunogenetics of graft wersus host reactions to minor histocompatibility antigens. Immunol Today 2:189-195

Sprent J, M Schaeffer, D Lo, and R Korngold (1986) Properties of purified T cell subsets. II. In wiwo responses to class I vs class II H-2 differences. J Exp Med 163:998-1011

Spremt J, M Schaefer, E-K Gao, and R Korngeld (1988) Role of T cell subsets in lethal graft-versus-host disease (GVHD) directed to class I versus class II H-2 differences. I Exp Mcd 167:556-569

Stastny P, VA Stembridge, T Vischer, and M Ziff (196.3) Homologous discase in the adult rat, a model for antoimmune disease. 1. General features and cutaneons lesions. I Exp Med 1186.635

Stastry P, VA Stembridge, T Vischer, and M Zifr (1965) Homologous discase in the adult rat, a model for attoimmune disease. II. Findings in the joints, heart and other tisswes. J Exp Med 122:681

Steen VD, GL Ziegler, GP Rodman, and TA Medsger (1984) Clinical and laboratory associations of anticentromere antibody in patients with progressive systemic sclerosis. Afthr R heum 27:125-131

Steen VD, GR Owens, GJ Fino, GP Rodnan, and TA Medsger (1985) Pulmonary involvement in systemic sclerosis (scleroderma). Arthr Rheun 28:759-767

Stet RJM (1987) Graft versus host reactions in the rat. An experimental study. Thesis. Groningen, The Netherlands pp. 99-137

Storb R, ED Thonas, PL Weiden, CD Buckner, RA Clif, A Fefer, LP Fernando, ER Giblet, BW Goodell, FL Johnson, KG Lerner, PE Neiman, and JE Sanders (1976) Aplastic ancmia treated by allogencic bone marrow transplantation: A report on 49 new cases from Scattle. Blood 48:817-841 
Storb R, RL Prentice, JA Hansen, and ED Thomas (1983) Association between HLA-B antigen and acute graft-versus-host disease. Lancet 11 816-819

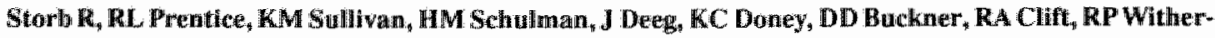
spoon, FA Appelbaum, JE Sanders, PS Stewart, and ED Thomas (1983) Predictive factors in chronic graft-versus-host disease in patients with aplastic anemia treated by marrow transplantation from HLAidentical siblings. Ann Int Med 98:461-466

Storb R, RL. Prentice, CD Bucknier, RA Clift, F Appelbaum, J Deeg, K Doney, JA Hansen, M Mason, JE Sanders, J Singer, KM Sullivan, RP Witherspoon, and ED Thomas (1983) Graft versuls host disease and survival in patients with aplastic anemia treated by marrow grafts from HLA-identical siblings. New Engl J Med 308:302-307

Storb R (1985) Marrow transplantation : The Seatle experience. Tokai J Exp Clin Med 10:75-83

Subcommittee for scleroderma criteria of the American rheumatism association diagnostic and therapeutic eriteria committee (1980) Preliminary criteria for the classification of systemic sclerosis (scleroderma), Arthr Rheum 23:581-590

Sullivan KM, HM Sluliman, R Storb, PL Weiden, RP Witherspoon, GB McDonald, MM Schubert, K Atkinson, and ED Thomas (1981) Chronic graft-wersus-host disease in 52 patients :Adverse matural course and succesful treatment with combination of immunosuppression. Blood 57:267-276

Sullivan KM (1986) Acute and chronic graft-versus-host dlisease in man. Int J Cell Cloning 4 s1:42:93

Takkehara K, Y Moroi, and Y Ishibashi (1985) Antinuclear antibodies in the relatives of patients with systemic sclerosis. Br J Dermatol 112;23-33

Tan EM, GP Rodman, I Garcia, Y Morol, MJ Fritzler, and C Peebles (1980) Diversity of antinuclear antibodies in progressive systemic sclerosis. Anti-centromere antibody and its relanionship to CREST syndrome. Artlar Rheum 23:61.7-625

Thomas ED, R Storb, RA Clift, A Fefer, FL Johnson, PE Neiman, KG Lerner, H Glucksberg, and CD Buckner (1975) Bone marrow transplantation. New Engl I Med 292:832-843

Thomas ED, CD Buckner, RA Clift, A Fefer, FL Johnson, PEE Neiman, GE Sale, JE Sandiers, JW Singere, HM ShuIman, R Storb, and PL Weiden (1979) Marrow transplantation for acute nomlymphoblastic leukemiá in first remission. New Eng J Med 301:597-599

Thompson RP, Harper FE, JC Maize, SK Ainsworth, EC LeRoy, and HR Maricq (1984) Nailfold biopsy in scleroderma and related disorders. Arthr Rhoum 27:97-103

Trostle DC, CD Bedett, VD Steen, MR Al-Sabbagh, Z Zee, and TA Medsger (1988) Renal vascular histology and morphometry in systemic sclerosis. Arthr Rheum 31:393-400

Tsoi MS, R Storlb, E Jones, PL Weiden, H Schulman, R Witherspoon, K Atkinson, and ED Thomas (1978) Deposition of $\mathrm{IgM}$ and complement at the dermo-epidermal junction in acute and chronic cut aneous graftvs-host discase in man. J Immunol 120:1485-1492

Tsoi MS, R Storb, S Dobbs, L Medill, and ED Thomas (1980) Cell-mediated immunity to non-HLA antigens of the host by donor lymphocytes in pat ients with chronic graft-vs-host disease. I Immunol 125:22582262

Tsoi MS, R Storb, E Dobbs, E Santos, and ED Thomas (1981) Specific suppressor cells and immune response to host antigens in long-term lumnan allogeneic marrow recipients : Implications for the mechanisms of graft-host tolerance and chronic GVHD. Tranplant Proc 13:237-240

Tsoi MS, R Storlb, S Dobbs, and ED Thomas (1981) Specific suppressor cells in graft -host tolerance of HLA-identical marrow tramplantation. Nature 292:355-357 
Tutschka PJ, AD Hess, WE Beschorner, and GW Santos (1981) Suppressot cells in tramsplantation toler ance. I. Suppressor cells in the mechanism of tolerance in radiation chimeras. Transplantation 32:203-209 Tutschka PJ (1986) Induction of tolerance with cyclosporin A. Transplantation : Approaches to Graft Rejection. Alan $\mathbb{R}$ Liss Inc New York. pp. 209.226

Unna PG (1894) The histopathology of the diseases of the skin. Translated by N Walker. The Macmillan Company New York pp.1100

Venrooij van WJ, SO Stapel, H Houben, WJ Habets, CGM Kallenberg, E Penner, and LB wan de Putte (1985) Scl-86, a marker antigen for diffuse scleroderma. J Clin Invest 75:1053-1060

Vogelsang GB, AD Hess, AW Berkman, PJ Tutschka, ER Farmer, PJ Converse, and GW Santos (1985) An in witro predictive test for graft versus host disease in patients with genolypic HLA-identical bone imarrow transplants. New Eng J Med 313:645-650

Vries de RRP, and JJ wan Rood (1982) Het HLA-systeem; een functiomele benadering. Ned $T$ Gemeeskunde 12:150-161

Wagner DD, and VJ Marder (1983) Biosynthesis of von Willebrand protein by human endothelial cells. J Biol Chem 258:2065-2067

Wagner HH, and K Alexander (1985) Der differentialdiagnostische Stellenwert des Handarteriograms beim primaren und sekundaren Raynaud-syndrom. Fortschr Rontgenstr 142:10-18

Weiner ES, WC Earnshaw, J-L Senecal, B Bordwell, P Johnson, and Rothfield NF (1988) Clinical associations of anticentromer antibodies and antibodies to topoisomerase I. Arthr Rheum 31:378-385

Whiteside TL, JG Worrall, RK Prince, RB Buckingham, and GP Rodnan (1985) Soluble mediators from mononuclear cells increase the synthesis of glycosaminoglycan by dermal fibroblast cultures derived from normal subjects and progressive systemic sclerosis patients. Arthr Rheum 28:188-197

Whiteside TL, Y Kumagai, AD Roumm, R AImendinger, and GP Rodnan (1983) Suppressor cell function. and $T$ lymphocyte subpopulations in peripheral blood of patients with progressive systemic sclerosis. Arthr Rheum 26:841-847

Winkelmann RK (1976) Pathogenesis and staging of scleroderma. Acta Dermatovenerol 56:83-92

Wysenibeek AJ, L Leibovici, S Cohen, and A Weinberger (1988) Nailfold capillary microscopy in essential mixed cryoglobulinemia : A report of several cases. J Vasc Dis 552-555

Young RH, and GJ Mark (1978) Pulmonary vascular changes in scleroderma. Am J Med 64:998-1004 

CHAPTER II

\section{INTRAVITAL VIDEOMICROSCOPY OF THE PHYSICALLY INTACT} RAT SKIN MICROCIRCULATION 



\section{INTRODUCTION}

In order to study the possible presence of microvascular pathology in rats with scleroderma-like skin disease elicited by a graft-versus-host reaction, a model had to be developed to study the microcirculation of the skin in rats. As has been outlined in the previous chapter (chapter $\mathbf{I}$ ), the presence of microvascular pathology in rats with histologically proven, scleroderma-like skin disease would be an additional argument to accept this model as a model for scleroderma in man. Intravital microscopy of the finger nailfold has proven to be a valuable method for the evaluation of microvascular pathology associated with progressive systemic sclerosis and Raynaud's phenomenon in man (Brown and O'Leary, 1925 ; Maricq and LeRoy, 1973). For the rat no suitable system has been described to study the microcirculation of the skin in a non-manipulated animall, and to do functional test of blood cell velocities such as a reactive hyperemia.

This chapter describes a model to study the non-manipulated rat skin by intravital microscopy, allowing the analysis of the morphological pattern of skin vessels, the measurement of blood cell velocity, and the testing of vascullar reactivity. This model can be used to evaluate whether skin vessel pathology similar to the microvascular pathology of patients with scleroderma exists in the above mentioned animal model of chronic graft-versus-host disease, as will be described in detail in chapter III.

\section{MATERIALS AND METHODS}

\section{Animals}

Male and female Lewis rats aged 12 to 16 weeks were used. The weight of the female rats varied between 220 and $250 \mathrm{~g}$ and that of the male rats from 280 to $430 \mathrm{~g}$. The animals were anesthetized with $40-50 \mathrm{mg} / \mathrm{kg}$ ketamine $\mathrm{HCl}$ (Vetalar ${ }^{(\text {it) }}$ ) intramuscularly and with $0.02 \mathrm{ml} / \mathrm{kg}$ xylazine HCL $2 \%$ (Rompun ${ }^{(3)}$ ) subcutaneously. The body temperature of the rats was kept at $37^{\circ} \mathrm{C}$ using an infra-red lamp connected to a rectal thermoanalyzer system. Room temperature was $23 \pm 1{ }^{\circ} \mathrm{C}$ during the experiments.

\section{Intravital videomicroscopy.}

Intravital microscopy was performed with a Leitz Orthoplan microscope. Three Leitz objectives ( $4 x$, numerical aperture $(\mathrm{NA})=0.14 ; 10 \mathrm{x}, \mathrm{NA}=0.25$ and $\mathrm{L} 20, \mathrm{NA}=0.32$ ) were used. The image was projected onto a television-camera (Philips LDH; Newvicon XQ $1275,2 / 3$ inch tube). The sensitive surface of the camera was situated directly at the intermediate image of the objective. The camera was rotatable with respect to its optical axis. Final magnification at the camera surface was $5 \mathrm{x}, 12.5 \mathrm{x}$ and $25 \mathrm{x}$, respectively. 
Television images were displayed by a monitor (Philips LDH $2122 ; 12$ ") and stored on tape (Sony Betamax SL-C9). A video timer was used to record the time course (Fig. 1). To test for optimal resolution and contrast of the microscope images incident illumination or transillumination was performed using a $150 \mathrm{~W}$ xenon lamp, a $200 \mathrm{~W}$ mercury $(\mathrm{Hg})$ lamp or a $100 \mathrm{~W}$ halogen lamp. Incident illumination was performed with two fiber optic light guides (Volpi) or by using an incident fluorescence illuminator (ploemopak 2.1; magnification $1.25 \mathrm{x}$ ) and a POL-cube. The POL-cube consisted of a $50 \%$ mirror in a 45 degree position with respect to the optical axis of the microscope with a polarizer in the illumination pathway and a crossed analyzer in the image forming pathway. Neutral density filters were used to obtain optimal light intensity at the camera and a heat absorbtion and a heat reflection filter were used to protect the preparation against local temperature increase caused by the incident light. The area of the skin to be inspected was covered with a thin layer of paraffin oil to improve its transparency (Fig. 1).

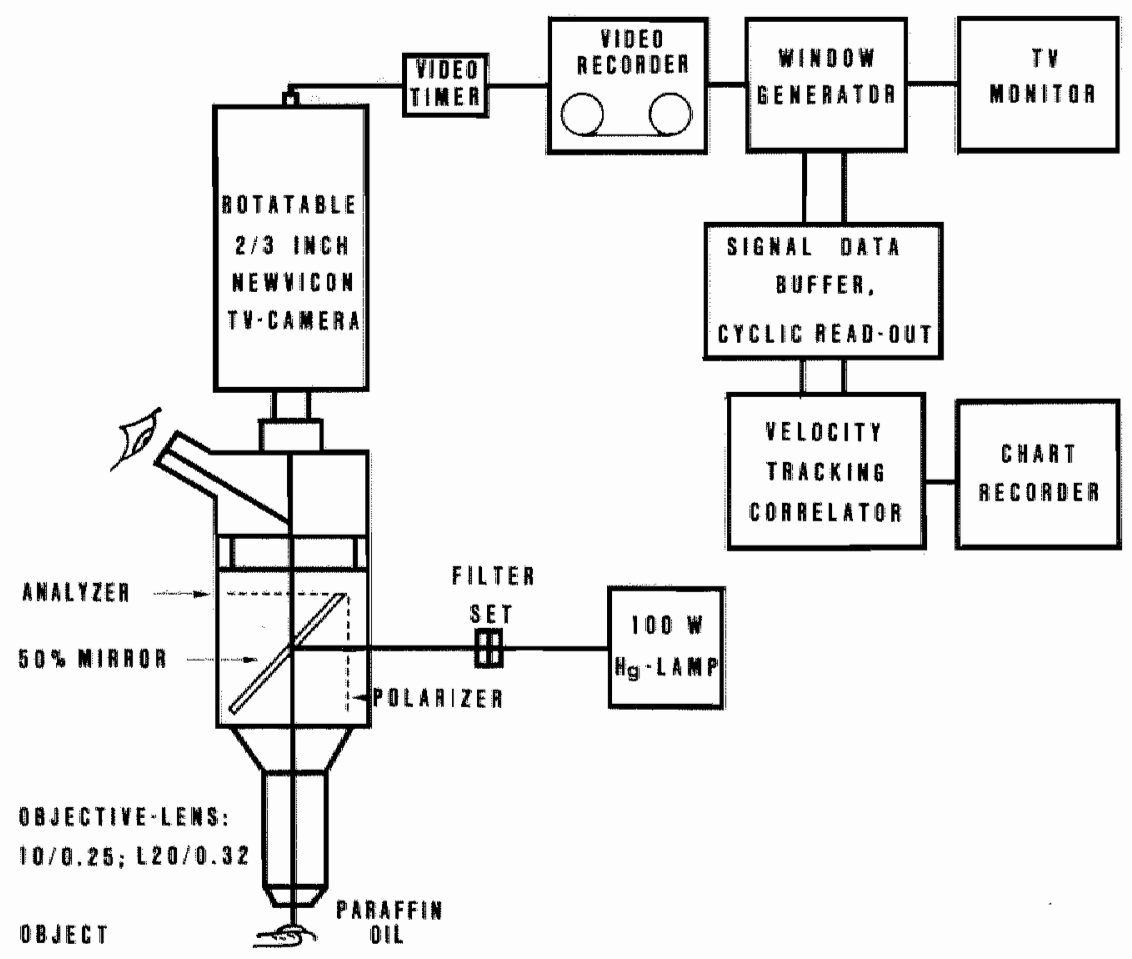

FIGURE 1: Schematic drawing of the microscopic systen and the set-up to measure blood cell velocity in microvessels. 
Blood cell velocity.

Blood cell $(B C)$ velocity was measured in skin vessels of a toe of a hind paw in the control situation (Vc) and during reactive hyperemia (RH) to test for vascular reactivity. Blood circulation in the skin vessels was arrested by inflating a cuff placed around the paw and RH was induced by deflating the cuff after 180 seconds of flow arrest. BC velocity was recorded continuously during $\mathrm{RH}$ and the peak $\mathrm{BC}$ velocity during $\mathrm{RH}(\mathrm{Vp})$ was determined.

$\mathrm{BC}$ velocity was measured using the videometric dual window method (Fagrell et al., 1977). Most of the experiments were performed with the L20 objective. The moving $\mathrm{BCs}$ and plasma gaps generated approximately the same signals in both windows, but with a certain time-delay. These two signals were fed into a cross-correlator [velocitytracking correlator (IPM) (Slaaf et al, 1984)] and the delay was assessed. To obtain optimal adjustment of the correlator, both signals were fed into a dual-memory loop with a maximum timespan of 20 seconds (built in our own labaratory) and subsequently fed into the cross-correlator in a cyclic way. The use of a dual-memory loop gives the opportunity to registrate the blood cell velocity immediately after releasing the cuff (Fig. 1). The output signal of the cross-correlator was calibrated for total magnification and window distance, and recorded as an instantaneous function of time on a physiological recorder. Our video window generator has the required facility to move the windows with any fixed interdistance and mutual orientation in all directions.

Because the maximum $\mathrm{BC}$ velocity that can be measured with this technique is limited, only vessels with a relatively low Vc were used to evaluate the arterial occlusion test. Data is expressed as mean \pm one standard deviation (SD). Statistical correlation between $\mathrm{Vc}$ and $\mathrm{Vp}$ was determined with a linear regression test.

\section{RESULTS}

\section{Observation of rat skin microvasculature.}

The most suitable area to study the vessels of the skin turned out to be the hairless area of a toe adjacent to the nail. In both the fore- and hind-foot visualization of the skin vessels can be achieved. The hind-foot, however, is larger and therefore application of the cuff was easier and no disturbing influence of breathing (yielding irregular movements of the fore-foot) occurred. The best image quality of the skin vessels was obtained by covering the skin with paraffin oil and using a combination of the Hg-lamp and the ploemopak-system equipped with the POL-cube as an incident illuminating system. Using the $10 \mathrm{x}$ objective, the area under observation (about $0.3 \times 0.8 \mathrm{~mm}$ ) encompassed 2 or 3 arteriolar inputs which bifurcated several times and ended in capillaries. The capillary network drained into a profuse venular system (Figs. 2 and 3 ). Capillary loops 


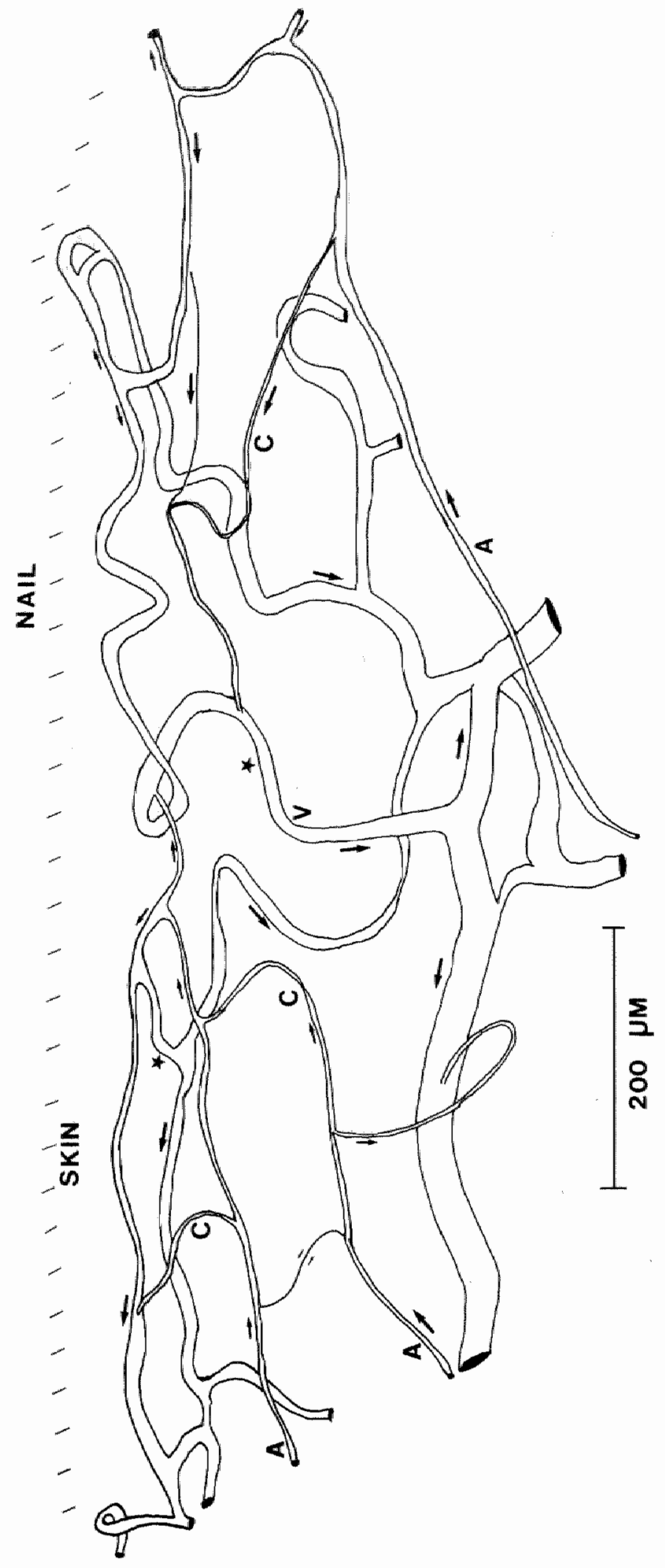




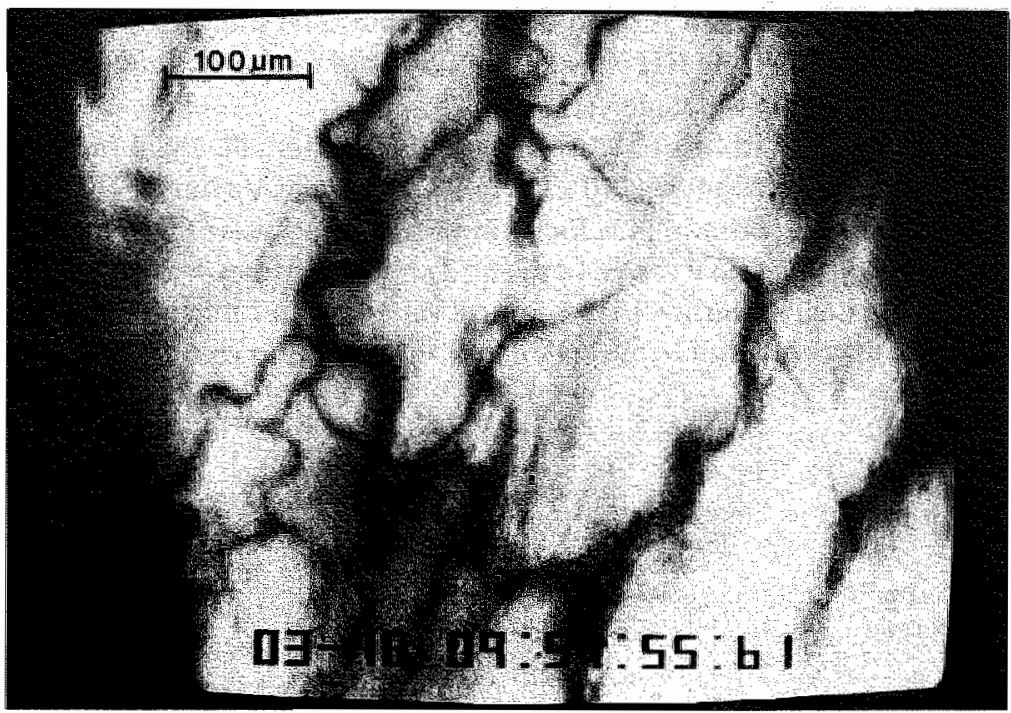

FIGURE 2: Microvessels in the rat skin adjacent to the nail as recorded by intravital microscopy. (Bar = $100 \mu n)$

typical of human dermal papillae were not observed. During successive observations over a period of at least 4 weeks it was possible to identify the same vessels in one animal.

\section{Measurement of venular reactive hyperemia.}

First to third order venules defined according to Strahler (Strahler, 1952) downstream of a capillary were used to measure BC velocity (Fig. 3). In these vessels $V_{c}$ ranged from $30 \mu \mathrm{m} / \mathrm{s}$ to over $500 \mu \mathrm{m} / \mathrm{s}$. To test for vascular reactivity vessels with a $V / \mathrm{c} \mathrm{smaller}$ than $150 \mu \mathrm{m} / \mathrm{s}$ were selected. Changes in these vessels are considered to be representative of changes in capillary $B C$ velocity. In Fig. 4 a typical registration of $V_{c}$ and post-occlusion RH is shown.

In Fig. 5 the reproducibility of the method is shown in 4 experiments, performed on 2 different vessels $(A$ and $B$ ) of one animal. $V c$ and $V p$ were determined two times in vessel $A$ and vessel $B$ (Experiment A1, A2, B3, and B4, respectively). The interval be-

FIGURE 3. Schematic drawing of the morphology of a representative are of the rat skin microcirculation in a toe. $A=$ arteriolar input. $C=$ capillary. $V=$ venule. The border of the skin as well as the nail area are indicated. The arrows indicate flow direction. * indicates where control velocily and peak velocily during reactive hyperemia can be measured according to our criteria. Scalle does not apply to the vessel diameter in detail. 
tween $\mathrm{A} 1$ and $\mathrm{A} 2$ and between $\mathrm{A} 2$ and $\mathrm{B} 3$ was 10 min. The time between $\mathrm{B} 3$ and $\mathrm{B} 4$ was 17 min V $\mathrm{c}$ and $\mathrm{Vp}$ during RH were of the same order of magnitude when the experiment was repeated on the same vessel.

A total of 18 experiments on 11 vessels was done in 4 female and 4 male rats. The mean $V_{c}$ in the selected vessels was $70 \pm 31 \mu \mathrm{m} / \mathrm{s}$. The mean Vp during RH was $655 \pm$ $124 \mu \mathrm{m} / \mathrm{s}$ and the mean increase in velocity in these vessels was $585 \pm 115 \mu \mathrm{m} / \mathrm{s}$. The time to peak after onset of flow varied between 3 and $10 \mathrm{~s}$ (Mean $=6.3 \pm 3.0$ ). In most experiments BC velocity returned to the control value within 1 min after release of the cuff. No significant correlation between $\mathrm{Vp}$ and $\mathrm{Vc}$ was found (correlation coefficient $=0.39, \mathrm{p}>0.1)$.

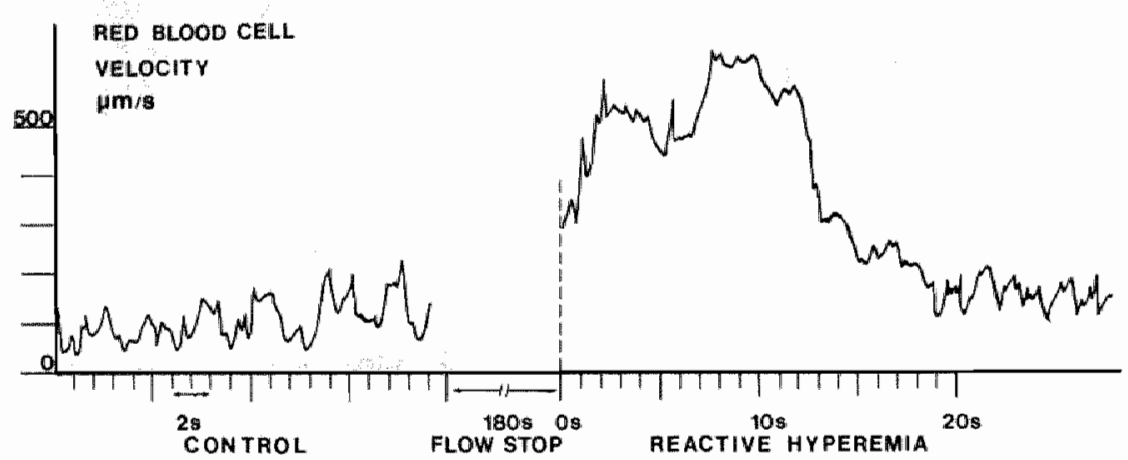

FIGURE 4: Recording of the blood cell velocity in a venule in the control situation and during post-occlusion reactive hyperemia. Blood cell velocily can be determined almost immediately after releasing the cuff. Dashed line marks onset of flow. 


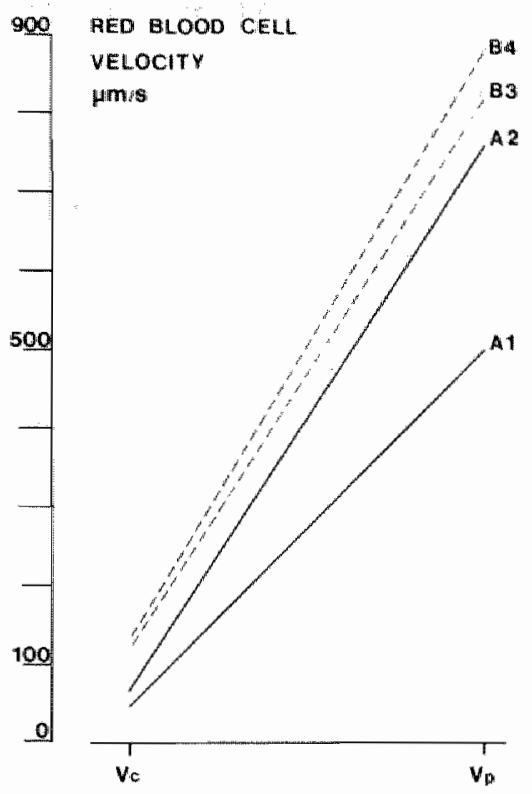

FIGURE 5: Relation between blood cell velocity in the control situation (VC) and peak velocity during reactive hyperemia $\left(V_{p}\right)$ in 4 experiments performed in one animal indicating reproducibility of the method.

\section{DISCUSSION}

In this chapter a model is presented to study the microcirculation of rat skin nontraumatically, using video microscopy. In this model several parameters of importance to evaluate nutritive skin microcirculation in normal and pathological situations can be studied. Studies of total digital blood flow are inadequate for assessing nutritional circulation, since only a small part of the total digital blood flow passes through the skin capillaries (Coffman, 1972). Using video capillaroscopy, however, direct observation of the nutritive circulation of the skin is possible.

Other models employed to study skin microcirculation in the rat require manipulation for optimal visualization of micro-vessels (Hertel, 1984). In the area of the toe adjacent to the nail the skin is relatively thin and is hairless, thus enabling the observation of the vessels without any physical manipulation, possibly interfering with pathophysiological mechanisms. Other areas of the rat skin tested for adequate visualization of 
the microvessels were the tail and the ears. However, hair growth, thickness of the epidermis, and/or irregular movements due to breathing of the animals hampered adequate visualization of the vessels and/or blood cell velocity measurements.

The best image quality of the vascular bed was obtained with the use of incident illumination through the POL-cube in combination with a mercury lamp. Transparency of the skin was improved by application of a thin layer of paraffin oil to the skin. The incident light is polarized by the POL-cube. Light reflected from the oil is extincted by the crossed analyzer. Light reflected from within the tissue is depolarized by multiple scattering, passes the analyzer and forms a bright background. The blood cells appear as dark spots on the bright background because they preferentially absorb the light. The optimal results obtained with the mercury lamp are ascribed to the favorable position of the emission peaks with respect to the absorption spectrum of hemoglobin. The use of the ploemopak system also allows this set up to be used for fluorescence microscopy. Fluorescence microscopy yields additional possibilities to study pathophysiological mechanisms in skin microcirculation (Bollinger et al, 1982), and by using this technique, the study of vascular permeability in rats undergoing a delayed-type hypersensitivity reaction in the skin was posssible (Wijsbek et al., 1988). Though this technique was not further used in the work presented in this thesis, it might be worthwile in further studies in rats with experimental scleroderma.

The morphology of skin vasculature in the rat is not the same as in human skin where capillary loops can be seen by intravital microscopy (Fagrell et al., 1977). This difference in morphology may be explained by the absence of papillary structures, vascularized by a capillary network, that are typical for human skin (Greenfield, 1983).

Beside morphological changes a disturbed reactive hyperemia response has been shown in patients with progressive systemic sclerosis (Kristensen, 1978). Because of the similarity of the histological changes in these patients - fibrosis of the media and hypertrophy of the intima (Wolf and Winkelman, 1980) - and in animals with scleroderma-like skin disease, disturbed reactive hyperemia responses may also be anticipated in these animal models. Therefore, we studied the possibility to measure reactive hyperemia in this model.

To be able to determine peak velocity during reactive hyperemia, microvessels were selected with a low control blood cell velocity. Such vessels had to be chosen because of the upper limit of blood cell velocity that can be measured with the video dual-window technique. The upper limit of blood cell velocity is determined by three factors. Firstly, the frame rate of the video recording system. Secondly, the interdistance of the windows imposed by the architecture of the vessels. Thirdly, lack of contrast and, hence, an insufficient signal-to-noise ratio at higher blood cell velocity. We selected first to third order venular branches downstream of a capillary with a low control velocity to measure peak velocity during reactive hyperemia. It was expected that the peak blood cell velocity in these vessels would be within the limits of the system. These branches were not part of the venular plexus yet, so the measured velocity can be considered to be representative of capillary blood cell velocity. Since the assessment of the blood cell velocity is only feasible with both windows properly placed over the vessells, movements 
of the tissue should be minimal. To prevent movement of the paw due to releasing of the pressure cuff, the rat was anaesthetized. Although the anaesthesia might be of influence on the absolute value of the blood cell velocity and reactive hyperemia pattern, the results still can be used in a comperative study either in different groups of animals or in long term experiments.

Since we can identify the same vessels in one rat at successive observations, changes in a certain vessel over a prolonged period of time can be monitored.

Because the videometric dual-window method allows for monitoring of rapid changes in blood cell velocity at relatively low light levels we have chosen this method to determine control velocity and peak velocity during reactive hyperemia. Careful adjustment of the correlator is required to measure blood cell velocity continuously during reactive hyperemia. This can be achieved by storing the signals in a dual-memory loop and feeding them into the correlator in a cyclic way, preventing zero velocity. In this way the correlator can lock in on the signals directly after onset of flow in the post-occlusion period and provides an output during a complete reactive hyperemia period. Minor displacements of the paw after deflating the cuff made it necessary that the two windows could be moved in any direction with a fixed interposition to keep them positioned above a vessel under investigation.

Measurements of blood cell velocity and reactive hyperemia were made under controlled room- and body temperature. Since the model was developed to study diseased animals, it can be argued that blood cell velocity and reactive hyperemia should be assessed at the spontaneous skin temperature and concommitant blood cell velocity, rather than at an induced skin temperature. The results in the present study show that the peak velocity during reactive hyperemia is not related to the control velocity in the microvessels selected for low control velocity. This observation suggests that there is a maximum flow carrying capacity in the microcirculatory bed under investigation.

In conclusion, in this chapter an animal model is presented that allows the non-invasive investigation of physically intact skin microcirculation morphology and of functional parameters. This model can be used to study in vivo microvascular changes in animal models with scleroderma-like pathology, as is described in the following chapters. 


\section{REFERENCES TO CHAPTER II}

Bollinger A, J Frey, K Jager, J Furrer, J Seglias, and W Siegenthaler (1982) Patterns of diffusion through skin capillaries in patients with long-term diabetes. New Eng J Med 307:1305-1310

Brown GE, and PA OLeary (1925) Skin capillaries in scleroderma. Arch Intern Med 73-88

Coffnan JD (1972) Total and nutritional blood flow in the finger. Clin Science 42:243-250

Fagrell B, A Fronek, and M Intaglletta (1977) A microscope-telewision system for studying flow velocity in human skin capillaries. Am J Physiol 233:H318-H321

Greenfield ADM (1983) The circulation through the skin. In:Handbook of physiology, Circulation II, Chapter 39. Waverly \& Son Inc. Baltimore, USA.

Hertel RF (1984) Kutane Mikrozirkulation in Aurikel: möglichkeit der kontinuierlichen Analyse des wachsenden und alternden Individuums. Manuskriptsammlung 8. Jahrestagung Ges. Mikrozirk. Wurzburg, p.20 (abstract).

Kristensen JK (1978) Reactive hyperemia in cutaneous tissue in generalized scleroderma. J Invest Dermatol $71: 269-273$

Maricq HR, and EC LeRoy (1973) Patterns of finger capillary abnormalities in connective tissue disease by wide field microscopy. Arthr Rheum 16:619-628

Slaaf DW, T Arts, TJM Jeurens, G-J Tangelder, and RS Reneman (1984) Electronic measurements of blood cell velocity and volume flow in microvessels. In:Investigative microtechniques in medicine and biology. Volume 1.J Chayen and L Bitensky (eds.) Marcel Dekker, Inc. New York.

Strahler AN (1952) Hyposometric (area altitude) analysis of erosional topology. Bull Geol Soc Am 63:1117-11:42

Wolf R, and RK Winkelman (1980) Vasculitis. Major problems in dermatology, vol 10. Lloyd-Luke Londen.

Wyjsbek AMW, GMJ Bos, DW Slaaf, GJ Tangelder, and GD Majoor (1988) In wivo assessment of vascular permeability during delayed-type hypersensitwity reaction in the rat. Int J Microcirculation Clin \& Exp 7:S75 (abstract) 
CHAPTER III

\section{IN VIVO DEMONSTRATION OF MICROVASCULAR PATHOLOGY \\ IN EXPERIMENTAL SCLERODERMA}


$\therefore \quad: \quad+\quad=$

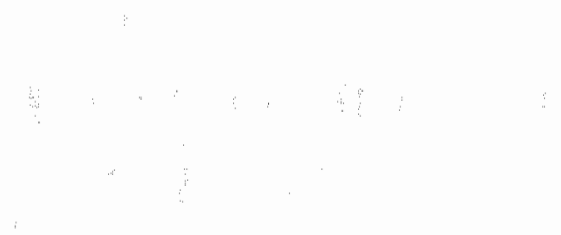

$\ldots$ 


\section{INTRODUCTION}

As has been outlined in chapter $I$, scleroderma in man is characterized by increased sclerosis of the skin and vascular pathology. Intravital microscopic observation of the nailfold in man shows aneurysm-like capillary dilatations, sometimes in combination with avascular area's, in the majority of patients, indicating the vascular pathology (Brown and O'Leary, 1925 ; Maricq and LeRoy, 1973 ; Jacobs, 1985). The etiology of scleroderma is not known, nor the pathogenesis of the vascular lesions. The finding that scleroderma is histologically characterized by an excessive deposition of collagen (Winkelman, 1971; Hughes, 1987) and the presence of vascular pathology have led essentially to two hypotheses : scleroderma is primarily a collagen disease (Stuart, 1976; Cathcart and Krakauer, 1981), or is primarily a vascular disease (Kahaleh et al., 1979 ; LeRoy, 1982). In both hypotheses autoimmune pathophysiological mechanisms have been purported to play a key role (Seibold et al., 1982 ; Sternberg, 1985).

In patients the study of the etiology is difficult because, at the time clinical signs become manifest, important early events may have waned. Therefore, several investigators have sought an experimental model to study the etiology of scleroderma. Since chronic graft-versus-host (GVH) disease after bone marrow transplantation (BMT) shares several characteristics with scleroderma, this disease has been proposed as a model for scleroderma (Stastny et al., 1963; Shulman et al., 1978; Beschorner et al., 1982 ; Jaffee and Claman, 1983). However, unlike in man, in vivo microvascular pathology has not been documented in this experimental model (See chapter I for a more detailed description of chronic GVH disease).

This chapter describes the assessment of microvascular pathology in rats with chronic GVH disease by intravital microscopy. This observation extends the validity of chronic GVH disease as a model for scleroderma, and opens the possibility to study early pathogenic events, including the relationship between microvascular and collagen pathology.

\section{MATERIALS AND METHODS}

\section{Animals.}

Female inbred Lewis (LEW; RT1 ${ }^{1}$ ) rats were derived from our own breeding stock and female Dark Agouti (DA ; RT ${ }^{\text {a }}$ ) rats were purchased from the Zentralinstitut für Versuchstiere, Hannover, FRG. Rats from both strains were used at 2 months of age. 
Bone marrow transplantation (BMT).

DA rats were used as donors for allogeneic BMT to induce chronic GVHD in irradiated LEW recipients. Syngeneic ( $L E W \Rightarrow L E W$ ) BMT's were performed as controls. Bone marrow donors were killed on day 0 by cervical dislocation under ether anaesthesia. Tibias and femurs were collected, freed from attached tissue and decontaminated by immersion in $70 \%$ ethanol. Head of bones were cut off and the marrow cavity was perfused with cold ( $4^{\circ} \mathrm{C}$ ), sterile Dulbecco's balanced salt solution (DBSS) supplemented with $2 \%$ heat-inactivated newborn calf serum, penicilin (100 IU/ml) and streptomycin $(100 \mu \mathrm{g} / \mathrm{ml})$. Cell aggregates were disrupted by passage through injection needles of decreasing internal diameter $(0.8,0.7,0.6$, and $0.5 \mathrm{~mm}$, respectivelly). Recipients were lethally irradiated (Philips-Müller MG 320 X-ray machine ; $9.6 \mathrm{~Gy}$ at $0.7 \mathrm{~Gy} / \mathrm{min}$ ) on day -1 and reconstituted intraveneously with $6 \times 10^{7}$ allogeneic DA or syngeneic LEW vital bone marrow cells in $1.0 \mathrm{ml}$ DBSS on day 0. Since acute GVHD was expected to occur in recipients of allogeneic BMT, all bone marrow recipients received $6 \mathrm{mg} / \mathrm{kg}$ of the immunosuppressant cyclophosphamide (Endoxan ${ }^{\text {, }}$, Degusa Pharma Gruppe, Bielefeld, FRG) subcutaneously (s.c.) on day 1, 4, 7, and 10 to prevent lethal disease. In addition, for selective decontamination of the gut Gentamycin (A.U.V., Cuijk, The Netherlands; $2.5 \mathrm{mg} / \mathrm{kg} /$ day) was injected s.c. from day -2 to day 8 and Duoprim (Coopers Agrovet, Weesp, The Netherlands ; $1.0 \mathrm{ml} / \mathrm{kg} /$ day) intraperitoneally from day 3 to day 8.

\section{Determination of chimaerism.}

Chimaerism was determined using rat monoclonal antibodies (MAB's) against RT.1A (Howard et al., 1980) and RT.1A (Hemmi et al., 1985) major histocompatibility complex (MHC) class I antigens. To assess chimaerism of leukocytes, white blood cells isolated from peripheral blood were first incubated with either of both MAB's and, after extensive washing, with a mouse MAB specific for rat immunoglobulin (Ig) kappa light chains. It should be noted that this second antibody also reacts with approximately $90 \%$ of the B lymphocytes, since in rats only about $10 \%$ of the B lymphocytes carry lambda light chains. In normal rats, however, the relative number of B lymphocytes in peripheral blood is low, ranging from $5-15 \%$ of all lymphocytes as determined by incubation with the second and third antibodies only. As a third antibody, fluorescein iso-thiocyanate (FITC)-conjugated goat F(ab') anti-mouse IgG (heavy and light chain specific) was used (Cappel Laboratories, Cochranville, CA, USA). This third antibody does not cross-react with rat IgG. FITC-positive and -negative cells were quantitated on a fluorescence-activated cell sorter (FACS IV, Beckton-Dickinson, Sunnyvale, CA, USA) by analyzing $10^{4}$ leukocytes/sample.

Chimaerism of red blood cells (RBCs) from BMT recipients was determined in a dextran-facilitated hemagglutination assay (Günther and Stark, 1977). 


\section{Skin biopsy.}

Skin biopsies were taken 9 and 12 months after BMT. Formaldehyde-fixed and paraffin-embedded tissue samples were cut at $4 \mu \mathrm{m}$. Sections were stained routinely with hematoxylin and eosin (HE) and with the Giesson (EVG) stain for visualization of collagen and elastin fibers.

\section{Intravital microscopy.}

The equipment for intravital microscopic study of skin vessel morphology and its application to observe the microvasculature of the rat skin have been described in detail in the previous chapter, and has been published before (Bos et al., 1987). In short, microvessels of the skin can be visualized in an anaesthetized rat in a hairless area close to the nail of a toe of a hind paw. A Leitz Orthoplan microscope, a mercury lamp, an incident illuminator (ploemopak 2.2) equiped with a $50 \%$ mirror (installed at 45 degrees with respect to the optical axis), a polarizer-analyzer system (POL-cube), and immersion oil applied to the skin to improve its transparency yield optimal conditions for this purpose ((Bos et al., 1987; Slaaf et al., 1987). Images were recorded through a $2 / 3$-inch videocamera placed directly at the intermediate image. Two different objectives were used (10x; NA $=0.25$ and $\mathrm{L} 20 ; \mathrm{NA}=0.32$, Leitz, Wetzlar, $F R G$ ), yielding an effective interline distance of approximately 2 and $1 \mu \mathrm{m} / \mathrm{line}$, respectively. This microscope configuration allows for visualization of the superficial microcirculation of the skin. Images are formed by the red cell columns, due to the preferential absorption of light by RBCs. The system does not depict vascular walls. The same microvessels can be studied in a single animal over a prolonged period of time (chapter II).

\section{Assessment of capillary dimensions.}

Diameters of capillary RBC columns were measured directly from the TV-monitor using a pair of calipers. An image enhancement system was used to improve the contrast of the images stored on tape. For normal capillaries the RBC column was measured at 7 points, equally distributed over the full length of the capillary, being defined as a vessel segment between the last bifurcation and the first point of confluence. The point at the arteriolar end of the capillary was designated point 1 , and the point at the venular end point 7. In capillaries with an obvious widening, the point where the RBC column reached its maximum width was determined and taken as the mid-point. From there, three equally distributed measuring points towards both the arteriolat and venullar end of the vessel were taken. Widths of RBC columns were expressed as relative values as compared to the RBC column width at the measuring point closest to the venule ( = point 7 ) according to the formula :

\section{RBC column width at point $N$}

$\mathrm{RBC}$ column width at point 7

Ratio's of over 1.5 were arbitrarily taken as indicating abnormal capillary dilatation. 


\section{Vascular reactivity.}

Vascular reactivity was measured in first to third order venules. The procedure for quantitation of vascular reactivity has been described in detail (chapter II). Briefly, offline measurement of $R B C$ velocity was performed by analysis of video images made prior to and during reactive hyperemia (RH). A cuff around a hindpaw was inflated above systolic blood pressure (to approximately $180 \mathrm{mmHg}$ ) resulting in cessation of flow. After a period of $180 \mathrm{~s}$, RH was induced by release of pressure in the cuff. Velocity was measured with the use of a dual-window system in combination with a crosscorrelator and by assessing the time required for the RBCs to cover the known distance between the windows (Slaaf et al., 1984).

\section{RESULTS}

\section{Chimaerism.}

Leukocytes from allogeneic BMT recipients were analysed for expression of MHCmarkers, $3(n=8)$ and 56 weeks $(n=6)$ after BMT. Three weeks after BMT, in each rat most leukocytes bound the anti-RT.1A ${ }^{\text {at }} \mathrm{MAB}$ (range $68-98 \%$ ), indicating preponderance of leukocytes of donor origin. Fifty-six weeks after BMT, $71-85 \%$ of the leukocytes could be demonstrated to be of donor origin, in the absence of recipient leukocytes. However in one animal (nr. 2, Table 1) $9 \%$ of the leukocytes were stained using the anti-RT.1A MAB, whereas $6 \%$ of the cells were stained using the second and third antibodies only (B lymphocytes). Therefore, the presence of leukocytes (3\%) of recipient origin could not be excluded in this animal.

RBC phenotypes were assessed by hemagglutination, 3 and 8 weeks after BMT. RBCs from all recipients of allogeneic BMT were agglutinated by the anti-RT.1A MAB 3 and 8 weeks after transplantation, indicating the presence of RBCs of donor origin. $\mathrm{RBCs}$ from one recipient of allogeneic BMT were agglutinated by the antiRT.1A MAB 3 weeks after transplantation, but not at 8 weeks after BMT. RBCs from all recipients of syngeneic $B M T$ were agglutinated by the anti-RT.1A $M A B$, but not by the anti-RT.1 $\mathrm{A}^{\mathrm{a}} \mathrm{MAB}$.

The data demonstrate that the BMT protocol applied, established complete chimaerism in all but one rat. However, also in the only recipient in which full chimaerism could not be proven, leukocytes were predominantly of donor origin. 
Table 1. Association of abnormalities in recipients of allogeneic BMT

\begin{tabular}{lcccc}
\hline RAT & $\begin{array}{c}\text { ACUTE GVH } \\
\text { NO. }\end{array}$ & ALOPECIA & $\begin{array}{c}\text { HISTOLOGICAL } \\
\text { ABNORMALITIES }\end{array}$ & $\begin{array}{c}\text { MICROVASCULAR } \\
\text { DILATATIONS }\end{array}$ \\
\hline 1 & + & ++ & $++^{\mathrm{a})}$ & + \\
$2^{\mathrm{b})}$ & + & ++ & $++^{\mathrm{a}}$ & + \\
3 & + & + & + & + \\
4 & + & - & + & + \\
5 & + & + & - & - \\
6 & + & + & - & - \\
7 & + & - & - & - \\
8 & - & - & - & \\
\hline
\end{tabular}

a) Decrease of elastin fibers observed with EVG staining

b) Three $\%$ of leukocytes possibly of recipient origin 56 days after BMT.

c) Perivascular infiltration only.

d) Three months after transplantation slight alopecia which disappeared over time.

TABLE I: The association of clinical, histological, and microvascular abnomalities in a group of 8 recipients of allogeneic bone marrow transplantation is shown. Hislological abnormalities refer to chronic scheroderma-like changes 6-9 months after BMT. For a detailed description of the signs of acute graff-versuswhost (GVH) disease, clinical alopecia, histological abnombalities, and microvascular dilatations, see thext.

\section{Clinical observations.}

One out of 10 allogeneic, and one out of 10 syngeneic BMT recipients died within the first 8 days after transplantation. Symptoms of acute GVH disease including hyperemia of the skin, alopecia, dermatitis, epidermiolysis, and edema of the skin developed in $8 / 9$ recipients of allogeneic BMT, 10 to 14 days after BMT. Recipients of syngeneic BMT did not show any clinical abnormalities. During the period of acute GVH disease, recipients of allogeneic BMT lost weight as compared to recipients of syngeneic BMT ( $p<0.01$; Wilcoxon rank test). The disease was progressive during the first 4 weeks after BMT. Notwithstanding immunosuppressive therapy one recipient of allogeneic BMT died due to acute GVH disease 3 weeks after transplantation. Four weeks after BMT 5/8 animals clearly showed alopecia. After this period in all rats suffering from acute GVH disease most clinical symptoms appeared to diminish. However, in two animals (nrs. 1 and 2, Table 1) there was still marked alopecia $6-12$ months after transplantation, indicating continuous skin pathology (Fig. 1). Two other animals (nrs. 3 and 5 , Table 1) showed recovery, although slight alopecia was still present $6-12$ 

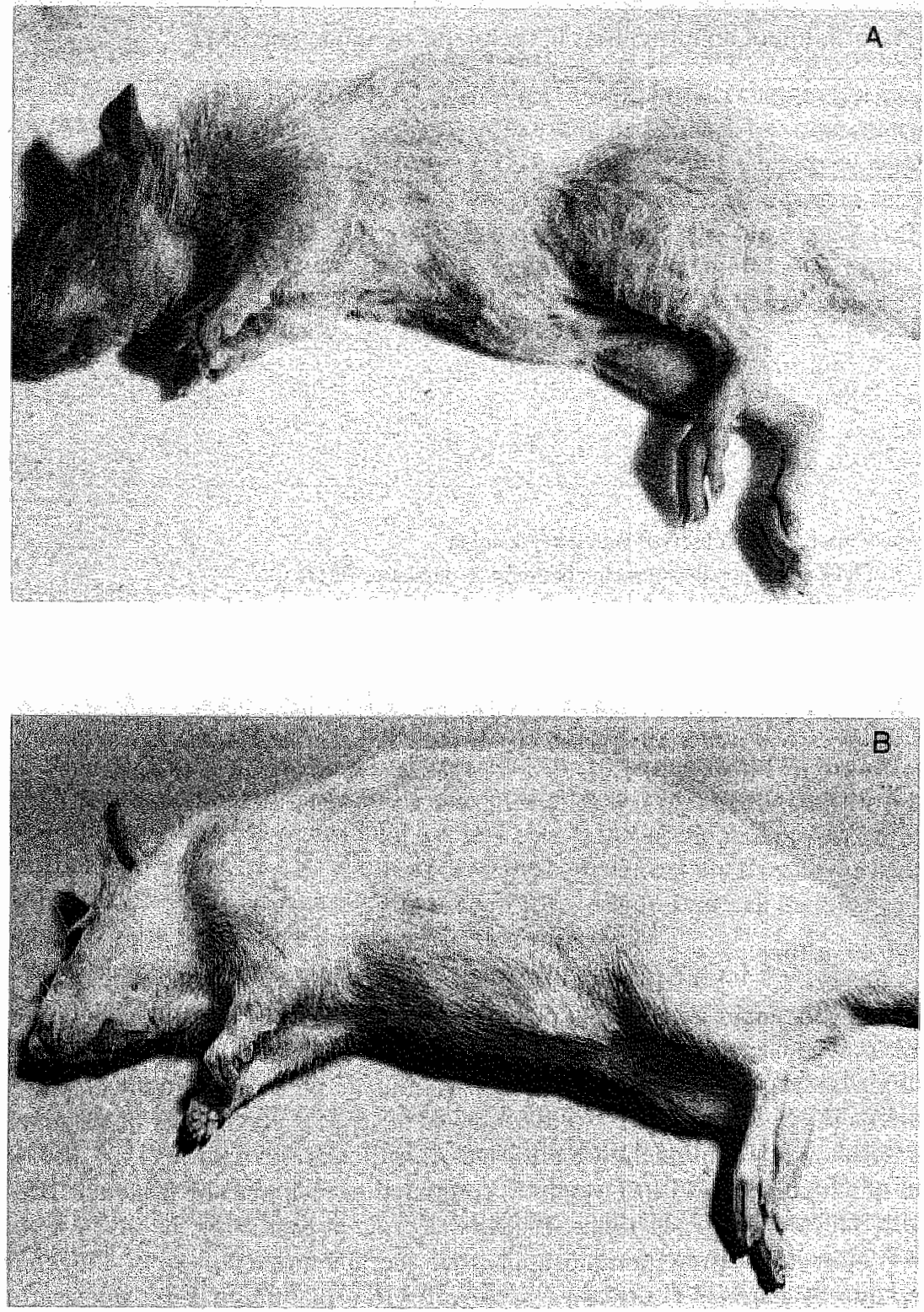

FIGURE 1: Panel A : Clinical aspect of a rat with chronic grafi-versus-host disease, seven months after allogeneic bone marrow transplantation. Clear alopecia is present on the lateral side of the paws, the head, and the breast: This rat is designated No. 1 in Table 1.

Panel $B:$ Rat, six months after syngeneic bone marrow tronsplastation. 
months after BMT. In one animal (nr, 6, Table 1) alopecia was no longer present 3 months after BMT. Clinically abnormal areas were found mainly on the paws, head, breast, and the caudal part of the back.

\section{Histology.}

Skin biopsies were taken 9-12 months after BMT from clinically suspect areas of allogeneic BMT recipients and from corresponding areas of syngeneic BMT recipients as controls. Three out of 8 experimental rats showed scleroderma-like, chronic graft-versus-host pathology on histological examination of HE-stained skin sections, including loss of adnexae, homogenized collagen, and replacement of subcutaneous fat by homogenized collagen (Fig. 2). In 2 rats (nrs. 1 and 2 , Table 1) mononuclear cell infiltrations were observed and in one animal (nr. 4, Table 1) only one perivascular mononuclear cell infiltration was seen. EVG-staining showed loss of elastin fibers, mainly from the upper part of the dermis, in two animals (nrs. 1 and 2, Table 1).

No histological abnormalities were observed in biopsies taken from control animals.

\section{Intravital microscopy and vascular reactivity.}

Intravital microscopy was performed 9-12 months after BMT on all animals. In each of 3 toes of both hindfeet an area of approximately $1.5 \mathrm{~mm}^{2}(3 \mathrm{~mm} \times 0.5 \mathrm{~mm})$ of the skin adjacent to the nail was examined. Normal capillaries widen gradually towards the venular end of the vessels. In 10 control vessels of recipients of syngeneic BMT, the RBC-column diameter at the arteriolar end was 0.8 (range 0.5 to 1.0 ) times that on the venular side (Fig. 3). In only one out of the 9 recipients of syngeneic BMT an abnormally dilated vessel (maximum width 2.4) was found. On the other hand, in recipients of allogeneic BMT, 5 out of 8 rats showed marked, aneurysm-like dilatations of some skin capillaries (Fig. 4). The diameters of the venular ends (point 7) were the same or larger in dilated vessels as compared to normal capillaries. As judged by our criterion (maximum width $>1.5$ ), 2-5 abnormal capillaries per rat were found in 6 toes of each of these 5 animals. Measurement of diameters of RBC columns of capillaries selected at sight as being abnormal confirmed local dilatation (Fig. 3). The median maximum value (point 4) of 16 abnormal vessels measured was 2.5 (range $1.6-3.9$ ). This median maximum value was significantly different from the median mid-vessel value of 10 control vessels taken from 4 control rats (point 4 ; median $=1.0$; range $=0.75-1.4$ ) at the level $\mathbf{P}<0.001$ (Wilcoxon rank test). In dilated vessels the relative capillary $\mathrm{RBC}$ column diameter at the arteriolar end does not differ from that of control capillaries, indicating that the dilations as described above are local, and aneurysm-like. Avascular area's or extravasations of red blood cells were not observed. 

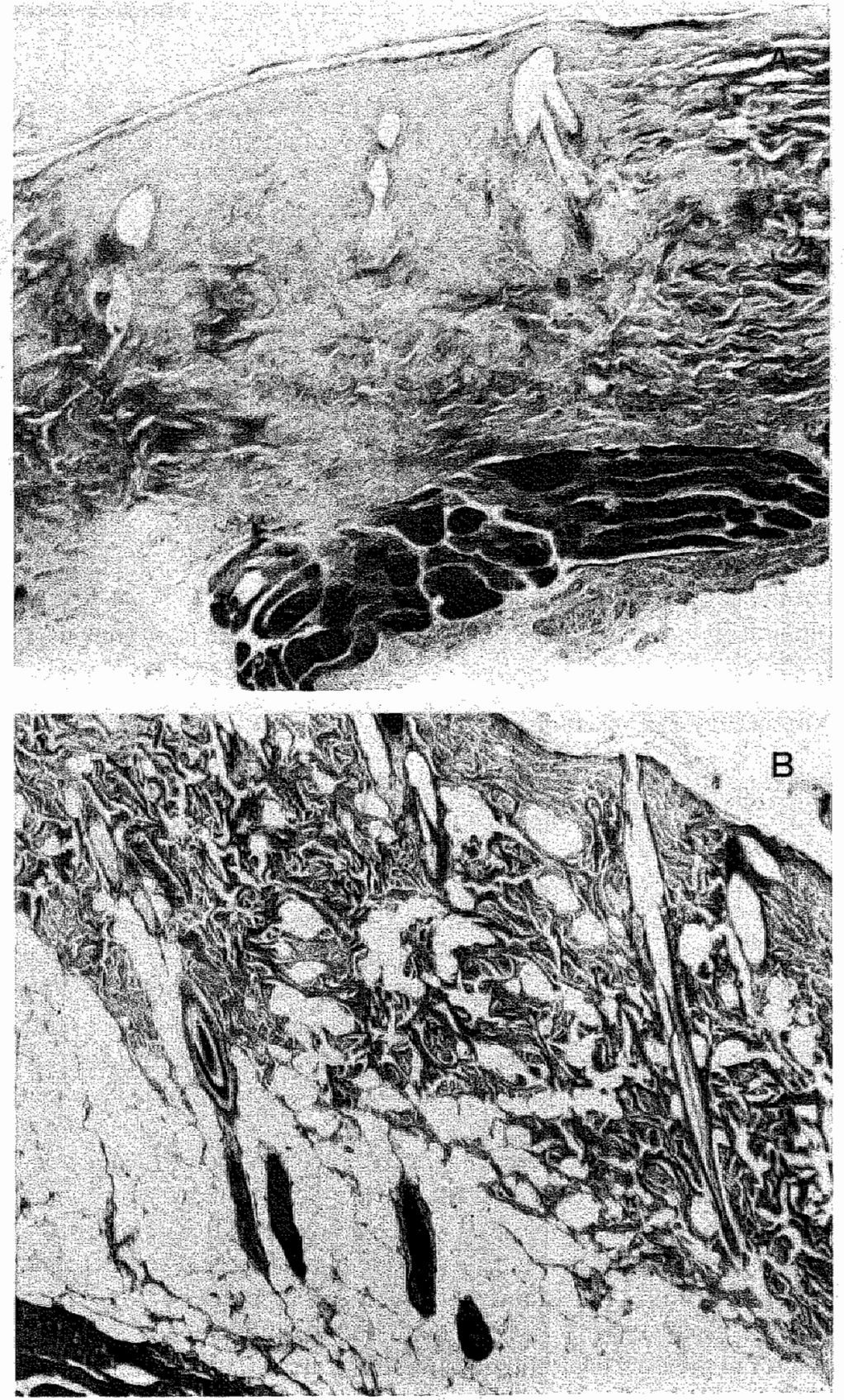

FIGURE 2: Panel A : Skin biopsy from recipient of allogeneic bonte mantow transplantation, 9 months after lethal irradiation and transplantation (see Fig. 1). Note marked alopecia, replacement of subcutanteous fat by collagen and homogenized collagen. Panel $B:$ Skin biopsy from a recipient of syngeneic bone marrow iransplantation, 9 months after lethal irradiation and transplantation (HE staining). 
RBC-velocity patterns during RH were measured in 5 recipients of allogeneic BMT. In 4 of these 5 animals morphologically abnormal capillaries had been detected before. Peak RBC-velocities and times to reach the peak did not differ from those measured in non-treated rats in an earlier study (Bos et al., 1987; chapter II).

\section{Association of abnormalities.}

The association of abnormalities in recipients of allogeneic BMT as observed clinically, histologically, and by intravital microscopy are shown in Table 1. All 4 animals with histological abnormalities, including the 2 rats with severe alopecia, showed abnormal microvessels, as observed by intravital microscopy. In one animal abnormal vessels were found although no scleroderma- like lesions were observed histologically. Three animals displayed no abnormalities up to 12 months after allogeneic BMT.

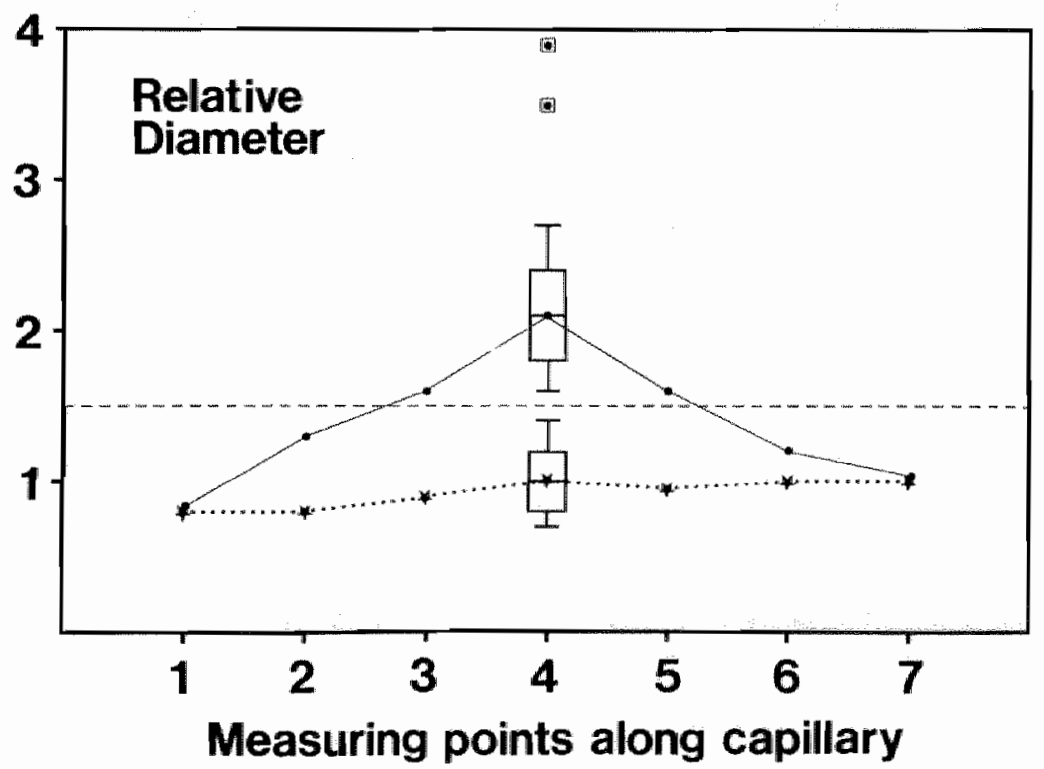

FIGURE 3 : Median diameters of red blood cell columns. For a detailed description see Methods section. In short, seven points per capillary were measured and data are expressed as relative values as compared to point 7. Point $I$ is the arteriolar end of a capillary and poin 7 the vesular end. : Mean values of 10 capillaries in 4 recipients of syngeneic bone marrow transplantation. o: Mean values of 10 selected capillanies in 5 rats after allogeneic bone marrow transplantation. With the box median values, interquartile ranges, and ranges are expressed. Indicate stray values. 

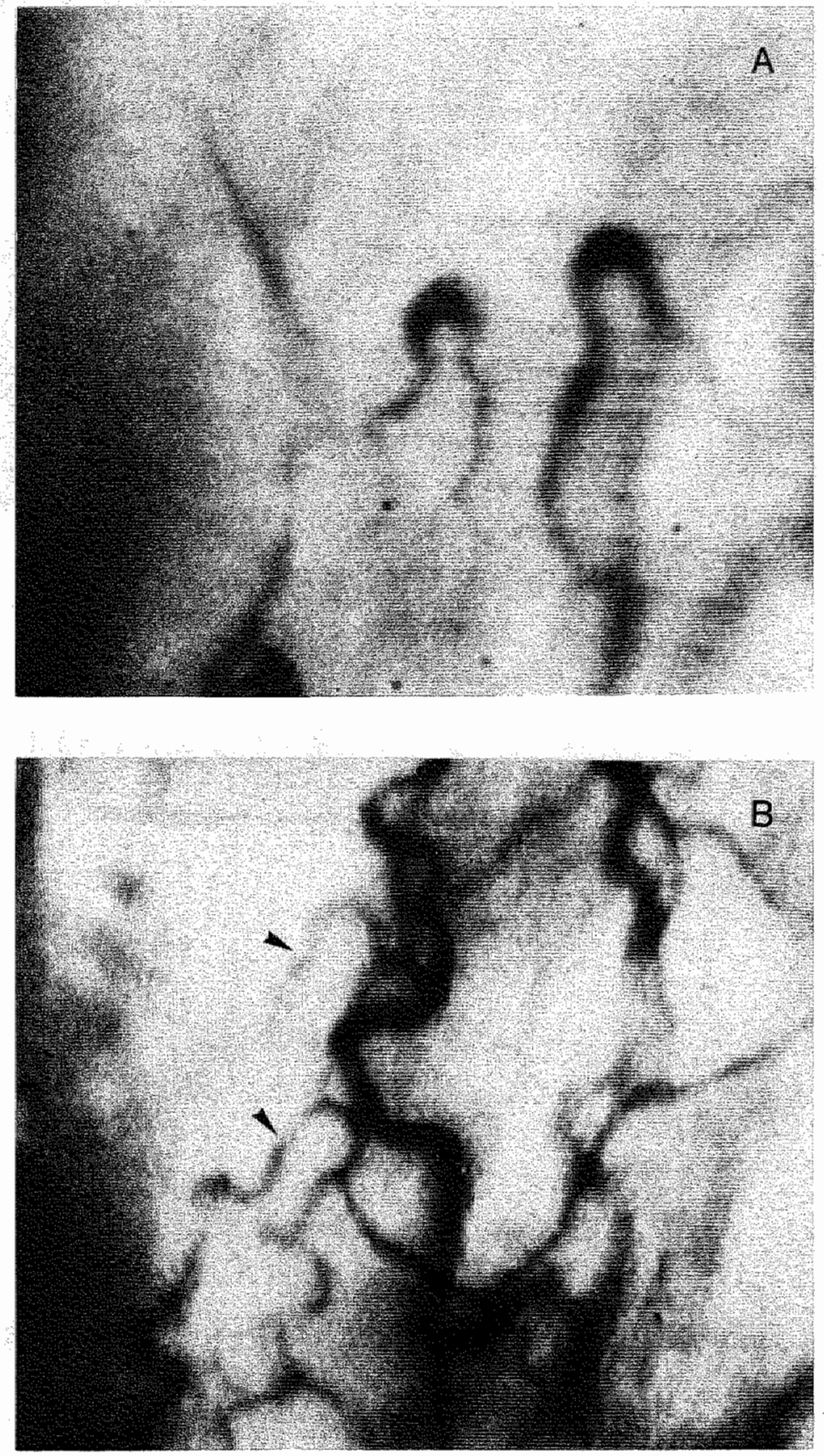

FIGURE 4: Panel A: Two aneurysm-like dilatations of capillaries of the skin. These vessels were observed in a rat (nr. 2, Table 1) 9-12 months affer allogeneic bone marrow transplantation. Panal B: Nomal skin capillaries (arrows) of a rat skin. 


\section{DISCUSSION}

Chronic graft-versus-host disease has been proposed as a model for scleroderma on the basis of clinical and histological similarities. It should be realized however, that pathogenetic mechanisms might be different in these two diseases. The present study establishes the existence of in wivo detectable, enlarged capillaries using intravital microscopy of the skin in rats with experimentally induced chronic graft-versus-host disease, indicating the presence of microvascular pathology in these rats. The capillary abnormalities detected in rat skin $9-12$ months after allogeneic bone marrow transplantation are akin to those seen in patients with scleroderma, e.g. aneurysm-like dilations of capillaries. The number of abnormal capillaries, observed by intravital microscopy, found in each rat with chronic graft-versus-host disease, is quite low ( $2-5$ in 6 toes of each experimental rat). However, in all investigated areas per rat, in total onlly about 60 capillaries were found, so the ratio of abnormal to normal capillaries ranged from about $1: 12$ to about $1: 30$. In a study on 15 patients with scleroderma Houtman found. a median of 2 enlarged capillaries per $5 \mathrm{~mm}$ of the nailfold, and 39 capillaries per $5 \mathrm{~mm}$ of the nailfold in these patients, yielding a ratio of about $1: 20$ (Houtman, 1985). Therefore, the ratio of abnormal to normal capillaries in rats with chronic graft-versus-host disease is comparable to that established for patients with scleroderma.

Whereas human nailfold intravital microscopy almost exclusively detects capillaries, intravital microscopy of the rat skin also detects many venules. Incidentally, apart from abnormal capillaries, dilated venules can be seen in the skin of recipients of allogeneic bone marrow transplantation as well (data not shown). Although venular abnormalities have not been described in scleroderma, the presence of both capillary and venular abnormalities might be important for the pathogenesis of the microvascular abnormalities in chronic graft-versus-host disease (Wolff and Winkelman, 1980).

Although the number of animals examined is small, in rats with chronic graft-versus-host disease an association was found between scleroderma-like skin pathology and microvascular changes, as observed by intravital microscopy. It should be pointed out that since histological sections will not show any capillary abnormalities in chronic graftversus-host disease, intravital microscopy is superior to routine histology to detect abnormalities in single capillaries. Interestingly, in one experimental animal microvascular changes occurred without concomitant development of histological sclerodermalike lesions. Clinical studies have established that the presence of Raynaud's phenomenon and/or abnormally enlarged nailfold capillaries can preceed the development of scleroderma (Maricq et al., 1986; Kallenberg et al, 1986). Recording of the sequence by which pathology evolves in subsequent animal experiments might shed some light on the pathogenesis of scleroderma. In this study all animals with histological abnormalities also displayed capillary enlargements. As in patients, the presence of abnormal microvessels might also be a sensitive parameter of scleroderma-like clisease in rats. 
In contrast to the conmon observation in patients with scleroderma, no avascular areas or extravasation of red blood cells was noted in the skin of experimental rats. In patients, the presence of avascular areas depends on the clinical stage of the scleroderma and the number of abnormal capillaries is related to the clinical condition, especially the number of organs involved in progressive systemic sclerosis (Maricq et al., 1976 ; Houtman, 1985). Decreased capillary density prevails more frequently in patients with socalled "diffuse cutaneous systemic sclerosis" than in patients with "limited cutaneous scleroderma" in whom avascular are usually absent (LeRoy et al., 1988). Therefore, the absence of avascular area's might represent an analogue of "limited cutaneous scleroderma" in the rats.

It should be mentioned, that in the course of studying the microcirculation in a group of older control animals ( $>1$ year) capillary dilatations similar to those described in rats with experimental scleroderma were found (data not shown in this chapter). This observation indicates that the pattern of abnormalities is not specific for scleroderma. The same holds true in man, where similar microvascular abnormallities can be observed in other diseases than scleroderma (Wysenbeek et al., 1985; Ganzarczyk et al., 1988). Whether the development of enlarged capillaries in man is associated with ageing is less clear. In clinical studies on scleroderma control persons with a lower age are frequently used (Carpentier et al., 1988). On the other hand, the study of older persons does not reveal a great number of scleroderma-like microvascular changes (Maricq, personal communication). In contrast, however, in the conjunctival vascular bed capillary changes can be observed as a consequence of ageing (Maurel et al., 1988).

Diminished cutaneous reactive hyperemia responses (indicating arterial disease) have been detected in patients with scleroderma using a 133-Xenon washout technique (Kristensen, 1978). In the present study, off-line measurements of red blood cell velocities did not reveal diminished reactive hyperemia responses. A possible explanation for this discrepancy is, that in the experimental animals the duration of the disease has not been long enough to induce changes at the arteriolar level, which may give rise to abnormal reactive hyperemia responses. In patients the abscence of a cutaneous hyperemic reaction correlated with both duration and severity of the disease. In patients with a disease duration of 2 to 3 years normal hyperemia responses could still be observed (Kristensen, 1978). In addition, intravital microscopy may not be the most appropriate method to establish changes in reactive hyperemia responses, since by this technique only red blood cell velocity (but not flow) is measured and in just one capillary per observation. Therefore, additional techniques should be applied to rats with chronic graftversus-host disease to decide whether the reactive hyperemia response is normal or diminished.

Others have earlier drawn attention to the histological similarity of skin pathology associated with chronic graft-versus-host disease and scleroderma, although there is no full conformity (Mekori and Claman, 1986). Since microvascular abnormalities are an important parameter of scleroderma in man, the present dernonstration of microvascu- 
lar abnormalities by intravital microscopy in rats with chronic graft-versus-host disease is considered an additional argument in favour of the acceptance of experimental chronic graft-versus-host disease as a model for scleroderma.

\section{REFERENCES TO CHAPTER III.}

Beschorner WE, PJ Tutschka, and GW Santos (1982) Chronic graft wersus host disease in the rat radia* tion chimera. Transplantation $33: 393-399$

Bos GMJ, DW Slaaf, GD Majoor, G-J Tangelder, and RS Reneman (1987) A model for chronic study of vascular morphology and reactivity of physically intact rat skin microcirculation. Int J Microcirc Clin Exp $6: 371-380$

Brown GE, and PA O'Leary (1925) Skin capillaries in scleroderma. Arch Int Med $36: 73-88$

Carpentier PH, E Michoud, F Sarrot-Reynauld, and A Franco (1988) Diagnostic potental of nailfold fluorescein capillary microscopy. Int J Microcirc Clin \& Exp 7:S36 (abstract)

Cathcart MK, and RS Krakauer (1981) Immunologic enhancement of collagen accumulation in progressive systemic sclerosis. Clin Immunol Immunopathol $21: 128-133$

Ganczarczyck ML, P Lee, and SK Armstrong (1988) Nailfold capillary microscopy in polymyositis and dermatomyositis. Arthr Rheum 31:116-119

Günther E, and O Stark (1977) The major histocompalibility system of the rat (Ag-B or H-1 system). The Major Histocompatibility System in Man and Animals. D Götze (ed.) Berlin, Springer-Verlag p. 215

Hemmi S, M Fenner, H Binz, J Winterhalter, and H Wigzell (1985) Studies of monoclonal antibodies specific for major histocompatibility complex products of the rat. I. Production and characterization of monoclonal antibodies. Scand J Immunol 21 : $549-563$

Houtman N (1985) Microvascular and immunological studies in Raynaud's phenomenon. Thesis, University of Groningen, Groningen, The Netherlands pp.41-56

Howard JC, GW Butcher, DR Licence, G Galfre, B Wright, and C Milstein (1980) Isolation of six monoclonal alloantibodies against rat histocompatibility antigens : clonal competition. Immunollogy $41: 131-141$ Hughes GRV (1987) Connective tissue disease. Third edition. Oxford, Blackwell Scientific Publications pp.150-171

Jacobs MJHM (1985) : Capillary microscopy and hacmorheology in vesospastic and ocelusive vascular disease. Thesis, University of Limburg, Maastricht, The Netherlands pp.37.51

Jaffee BD, and HN Claman (1983) Chronic graft-versus-host discase as a model for scleroderma. I. Description of models. Cell Immunol $77: 1-12$

Jayson J (1984) Systemic sclerosis : a collagen or microvascular diseasc. Brit Med J $288: 1855-1857$

Kahaleh MB, GK Shearer, and EC LeRoy (1979) Endothelial injury in scleroderma. J Exp Med 149: 13261335

Kallenberg CGM, TH The, and AA Wouda (1986) Raynaud's phenomenon : factors of prognostic significance for the development of connective tissue disease. Relevance of vascular and immunological tests. Neth J Med 29:386-392

Kristensen JK (1978) Reactive hyperemia in cutaneous tissue in generalized scleroderma. J Invest Dermatol $71: 269-273$

LeRoy EC (1982) Pathogenesis of scleroderma. II linvest Dermatol 7951:875-895 
LeRoy EC, C Black, R Fleischmajer, 5 Jabloniska, T Kirieg, TA Medsger, N Rowell, and F Wollheim (1988) Scleroderma (systeraic sclerosis) : classificication, subsets, and pathogenesis. I R heumatol 15:202-205

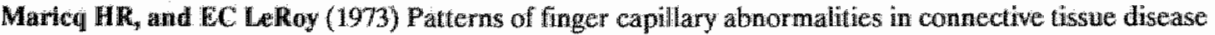
by wide field microscopy. Arthr Rheum 16:619-628

Maricq HR, G Spencer-Green, and EC LeRoy (1976) Skin capillary abnormalities as indicators of organ involvement in scleroderma (systemic sclerosis), Raynaud's phenomenon and dermatonnyositis. Am J Med $61: 862-869$

Maricq HR, AB Weinllerger, and EC LeRoy (1982) Early detection of scleroderma-spectrum disorders by in wivo capillary microscopy : a prospective study of patients with Raynaud's phenomenon. J Rheumatol 9:289-291

Maurel A, P Hamon, and G Lagrue (1988) Conjunctival angioscopy : normal features and wariations according to age and vascular risk factors. Int J Microcirc Clin \& Exp 7:S105 (abstract)

Mekori YA, and HN Claman HN (1986) Is graft-wersus-host disease a reliable model for scleroderma?

La Ricerca Clin Lab 16:509-514

Seibold JR, TA Medsger Jr, A Winkelstein, RH Kelly, and GP Rodnan (1982) Immune complexes in progressive systemic sclerosis. Arthr Rheum 25:1167-1173

Shulman HM, GE Salle, KG Lerner, A Barker, PL Weiden, K Sullivan, B Gallueü, ED Thomas, and $\mathbb{R}$ Storb (1978) Chronic cutancous graft-versus-host disease in man. Am J Pathol 91:545-570

Siminovitch K, M Klein, W Pruzanski, S Wilkinson, P Lee, S Yoon, and JE Keystone (1982) Circulating immune complexes in patients with progressive systemic sclerosis. Arthr Rheum 25:1174-1179

Slaaf DW, T Arts, TJM Jeurens, G-J Tangelder, and RS Reneman (1984) Electronic meastrement of red blood cell velocity and wolune flow in inicrowessels. In Investigative Microtechniques in Medicine and Biology. Vollume I. J Chayen and L Bitensky (eds) New York, Marcel Dekker pp.327-369

Slaaf DW, G-J Tangelder, RS Reneman, K Jager, and A Bollinger (1987) A versatile incident illuminator for intravital microscopy. Int J Microcirc Clin Exp 6:321-332

Stastny P, VA Stembridge, T Visecher, and M Ziff (1963) Homologous disease in the adult rat, a model for autoimmune disease. 1.General features and cutaneous lesions. J Exp Med 118:635-648

Sternberg EM (1985) Pathogenesis of scleroderma: the interrelationship of the immune and vascular hypotheses. Surv Immunol Res 4:69-80

Stuart JM (1976) Evidence for cell-mediated immunity to collagen in progressive systenic sclerosis. J Lab Clin Med 88:601-607

Winkelman RD (1971) Classification and pathogenesis of scleroderma. Mayo Clin Proc 46:83-91 Wolf K, and RK Winkelman (1980) Vasculitis. Major problems in Dermatology, Vol $10 \mathrm{pp}$. $31-48$ Wysenbeek AJ, L Lelbovicic, S Cohen, and A Winberger (1985) Nailfold capillary microscopy in essential mixed cryoglobulinemia : A report of all cases. I Wasc Dis 552.555 
CHAPTER IV

\section{CHRONIC CYCLOSPORINE-INDUCED AUTOIMMUNE DISEASE IN THE RAT : A NEW EXPERIMENTAL MODEL FOR SCLERODERMA}




\section{INTRODUCTION}

Similarity of lesions of scleroderma in man, and those observed in chronic graft-versushost disease following allogeneic bone marrow transplantation (BMT) in man as well as in rodents, has been documented. Hence, chronic graft-versus-host (GVH) disease has been proposed as a model for investigation of the pathogenesis of scleroderma in man (Stastry et al., 1963; Siimes 1977; see chapter 1). The presence of capillary abnormalities in the skin of rats with chronic GVH disease, analogous to those observed in patients with scleroderma, has been taken as an additional argument to accept experimental chronic GVH disease as a model for scleroderma in man (chapter III ; Bos et al., 1988).

The pathogenesis of scleroderma in man is unknown, but autoimmune phenomena might play an important role (Postlethwaite and Kang, 1984). However, from an immunological point of view, chronic GVH disease is not synonymous with autoimmune disease. Therefore, we have explored a new, autoimmune model of chronic autoimmune disease in rats, for concurrent development of scleroderma.

Recently an acute GVH-like syndrome has been described in rodents elicited by a combination of X-irradiation, autologous or syngeneic BMT, and temporary administration of Cyclosporine-A (CyA) (Glazier et al., 1983). Since no genetic differences between bone marrow donors and recipients exist in this model, a classical graft-versushost reaction cannot be evoked. However, manipulation of the reconstitution of immunocompetent cells gives rise to an autoimmune-reaction in the recipient (Hess et al. 1989 ; Bos et al., 1988, chapter V).

Since chronic GVH disease is usually preceded by an episode of acute GVH disease, it was hypothesized that after the recovery of the acute phase of CyA-induced autoimmunity (CyA-AI), rats might develop pathology similar to chronic GVH disease. In this chapter the pathology of the acute and chronic phase of CyA-AI has been described.

Furthermore, animals were tested by intravital microscopy for the presence of capillary abnormalities in the skin as described in chapter III for the classical chronic GVH disease (Bos et al, 1988).

\section{MATERIALS AND METHODS}

\section{Animals.}

Female, specific pathogen-free Lewis (Lew ; RT1) rats were used as donors and recipients. Rats were derived from our own breeding stock (Department of animal facilities, Maastricht) or purchased from Charles River (Sulzfeld, West-Germany). Animals were used at the age of 2 months. 


\section{Bone marrow transplantation}

Syngeneic (LEW $\Rightarrow$ LEW) bone marrow transplantations (BMT) were performed. Bone marrow donors were sacrificed on day 0 by cervical dislocation under ether anaesthesia. Tibias and femurs were collected, freed from attached tissue and decontaminated by immersion in $70 \%$ ethanol for 10 seconds. Head of bones were cut off and the marrow cavity was perfused with cold sterile Dulbecco's balanced salt solution (DBSS) supplemented with $2 \%$ heat-inactivated newborn calf serum (NBCS), penicillin $(100 \mathrm{U} / \mathrm{ml})$ and streptomycin $(100 \mu \mathrm{g} / \mathrm{ml})$. Cell aggregates were disrupted by passage through injection needles of decreasing internal diameter $(0.8,0.7,0.6$, and 0.5 $\mathrm{mm}$ respectively). Marrow cells were counted in a hemocytometer using either Türk solution to count nucleated cells or Trypan Blue solution to discriminate between dead and viable cells. Recipient LEW rats were lethally X-irradiated on day -1 with 9,6 Gy at $0,7 \mathrm{~Gy} / \mathrm{min}$ using a Röntgen irradiator (Philips MG 320, Hamburg, W.-Germany). On day 0 , recipient rats received $4-6.10^{7}$ viable, syngeneic marrow cells in $1 \mathrm{ml}$ DBSS intravenously into a tail vein.

\section{Administration of $C y A$}

CyA, kindly donated by Sandoz Ltd., Uden, The Netherlands/Basle, Switzerland, was dissolved in olive oil at a concentration of $7.5 \mathrm{mg} / \mathrm{ml}$. The olive oil was heated to $60^{\circ} \mathrm{C}$ to improve dissolution. Injections of CyA were given subcutaneously. Control animals received the solvent only. CyA was given for a period of 40 to 80 days.

\section{Clinical scoring of pathology}

After withdrawal of CyA, rats were scored 1-2 times a week for the presence of signs of disease : hyperemia of the skin, dermatitis, and alopecia (Glazier et al., 1983). Scoring was performed by an observer not involved in this study, but familiar with the symptoms of the disease.

\section{Histology}

Skin biopsies were taken from the breast, back and/or paws of animals with clinical signs of CyA-AI. During life, skin biopsies were usually taken from the breast, since this area often exhibited clinical pathology. Moreover, the rats cannot destroy the sutures at this localization. Biopsies were taken both in the acute phase of disease ( $4-7$ weeks after withdrawal of CyA), and in the later phase, 3 to 8 months after withdrawal of CyA. When an animal had died, or at the end of the experiment at autopsy, in addition to biopsies from the skin, tissue samples were taken from several other organs including tongue, digestive tract, heart, lungs, kindney, liver, spleen, and salivary gland. 
Tissue samples were fixed in $0.1 \mathrm{M}$ phosphate-buffered $4 \%$ formaldehyde for $24-48$ hours at $4{ }^{\circ} \mathrm{C}$, and embedded in paraffine. Biopsies were cut at $4 \mathrm{um}$ and stained with hematoxilin / eosine, Azan, and toluidine-blue according to standard procedures. The Azan staining was applied to detect collagen and the toluidine-blue staining permitted the detection of mast cells.

\section{Microcirculation in vivo.}

The morphological pattern of the microcirculation of the skin of rats in the chronic phase of disease was studied by intravital microscopy as described in detail in chapter II (Bos et al., 1987).

\section{Control groups.}

Three different control groups were included in this study: Age-matched-control (AMC) rats treated with the CyA solvent only $(\mathrm{N}=4)$; AMCanimals given CyA $(\mathrm{N}=4)$; $\mathrm{X}$-irradiated and bone marrow transplanted-controls given CyA solvent only $(\mathrm{N}=8)$.

\section{RESULTS.}

\section{Development of clinical signs in CyA-induced autoimmunity.}

Results derived from two groups of animals transplanted in separate experiments. In the first group, CyA was given for 60 days $(\mathrm{N}=5)$. In the second group CyA was given for $40(N=19)$ or $80(N=5)$ days (Table 1). Since the duration of CyA administration did not influence the pattern of disease all data were pooled.

No clinical signs of disease were observed in animals during administration of CyA. The first sign of disease after withdrawal of CyA was frequently hyperemia of the skin, followed by the development of alopecia around the nose and on the chest. Thereafter, dermatitis was usually observed, and sometimes severe epidermiolysis. Apparantly, as concluded from scratching by the animals, pruritis accompanied the dermatitis. In the final stage alopecia was present all over the breast and the lateral side of the paws (Fig. 1). The back of the animals was less frequently affected, although some animals became completely nude. Approximately $65 \%$ of the animals treated with CyA developed such acute pathology, usually 3 weeks after withdrawal of the immunosuppressant (Table 1).

After the acute phase of disease, the affected animals clinically recovered although alopecia remained. The affected animals appeared to be vital, though their weight was reduced as compared to control animals. In the chronic phase, animals with CyA-AI were clinically indistinguishable from animals with chronic graft-versus-host disease 
Table 1: Clinical signs and symptoms of disease

\begin{tabular}{|c|c|c|c|c|c|c|}
\hline & \multirow[t]{2}{*}{$\mathbb{N}$} & \multirow[t]{2}{*}{$\begin{array}{l}\text { Distease } \\
\text { during } C y-A \\
\text { administration }\end{array}$} & \multicolumn{2}{|c|}{$\begin{array}{l}2-4 \text { weeks } \\
\text { after with- } \\
\text { drawal of CvA }\end{array}$} & \multicolumn{2}{|c|}{$\begin{array}{l}>4 \text { weeks } \\
\text { after with- } \\
\text { drawal of CVA }\end{array}$} \\
\hline & & & Doath & $(\mathrm{Cy} A-\mathrm{A}]^{\mathrm{A}}$ & Death & CyA-AI \\
\hline $\begin{array}{l}\text { Experinental group } \\
\text { (BMT + CyA) }\end{array}$ & 30 & $0 / 30$ & $8 / 30^{b}$ & $14 / 22$ & $2 / 22$ & $18 / 20$ \\
\hline Contralse & 16 & $0 / 16$ & $0 / 16$ & $0 / 16$ & $0 / 16$ & $0 / 16$ \\
\hline
\end{tabular}

a The presence of CyA-AI was established by lyperemia, dermatitis and alopecia

b Four $/ 8$ animals showed signs of CyA-AI

c This group includes bone-marrow grafted, non-CyA-trealted, non-bone-marrow grafted, CyA-treated, and non-CyA-treated controls

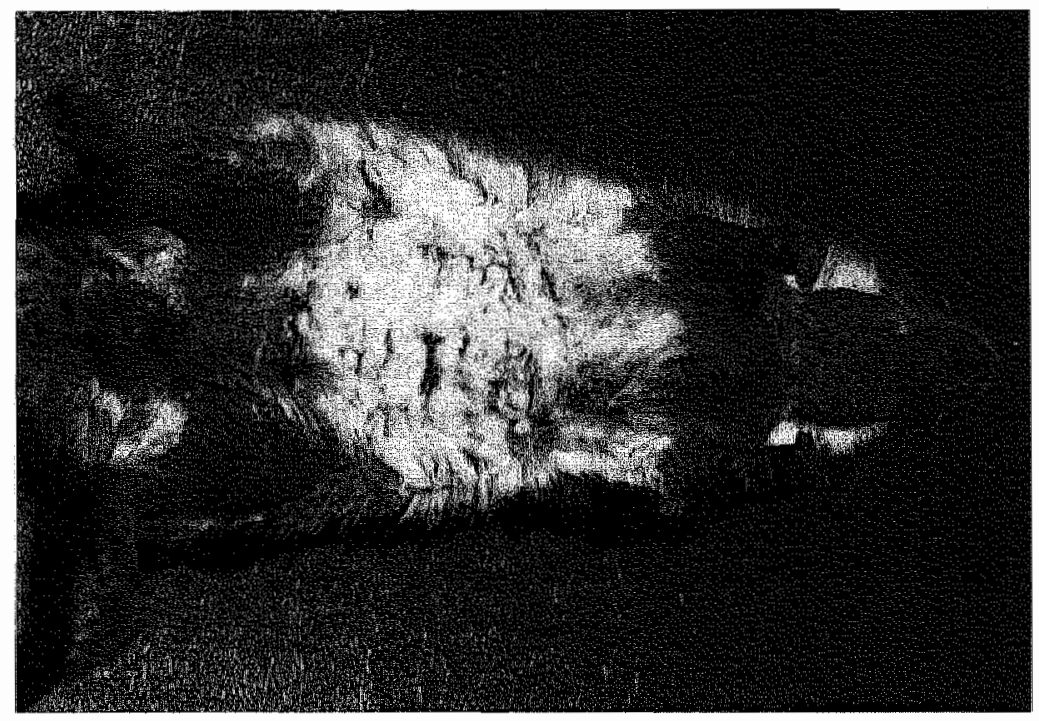

FIGURE 1: Rat with acute cyclosporine-induced autoinunune disease showing marked alopecia on breast and extremilies. 
after allogeneic BMT (Fig. 2). Usually, on the back of the affected animals the skin was tight, showed a "shiny" aspect and appeared to be thicker when compared to control animals. On the breast and paws there was an increase of skin folds. Hardening of the skin, as is the case in patients with scleroderma, however, could not be objectively assessed.

Of the group of eight animals not affected by $\mathrm{CyA}-\mathrm{AI}$ in the acute phase, two were killed inadvertedly during ether anaesthesia given in one of the technical procectures. Four more animals developed clinical alopecia between two and five months after withdrawal of CyA (Table 1).

None of the rats of the three control groups showed any clinical sign of disease during the course of the experiment, except for radiation pathology (weightloss and sometimes diarrhea) in the BMT controls in the first week after BMT.

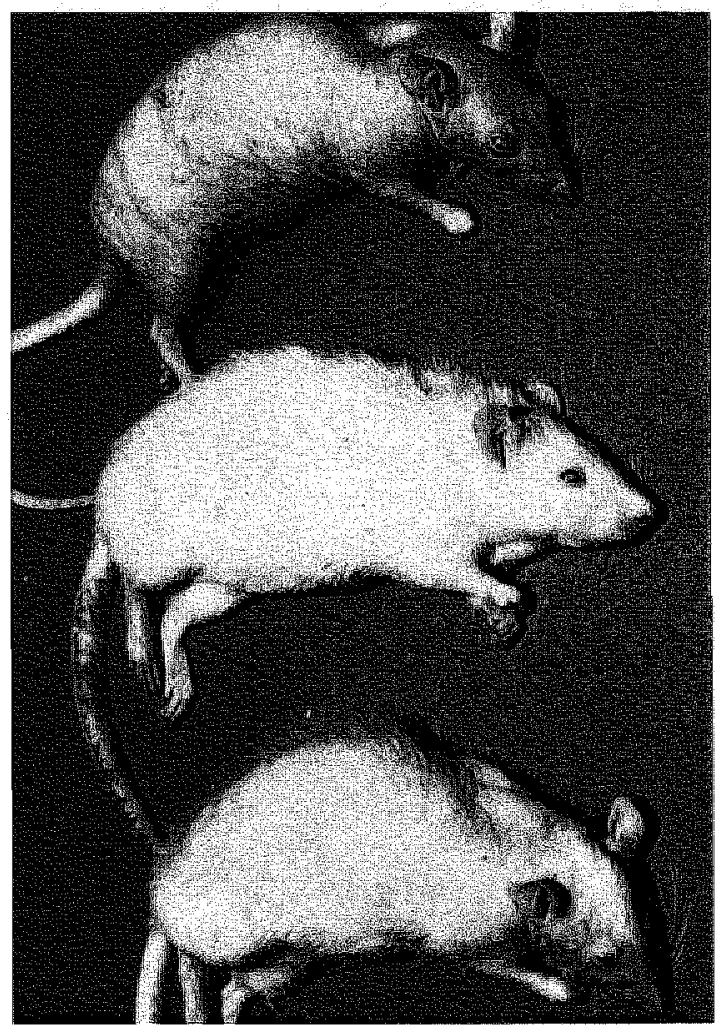

FIGURE 2: Rat with chronic cyclosporine-induced autoimnune disease (upper), heathy syngeneic bone matrow transplanted control (middle), and rat with chronic grafl-wersus-host disease after allogeneic bone marrow transplantation (lower). 


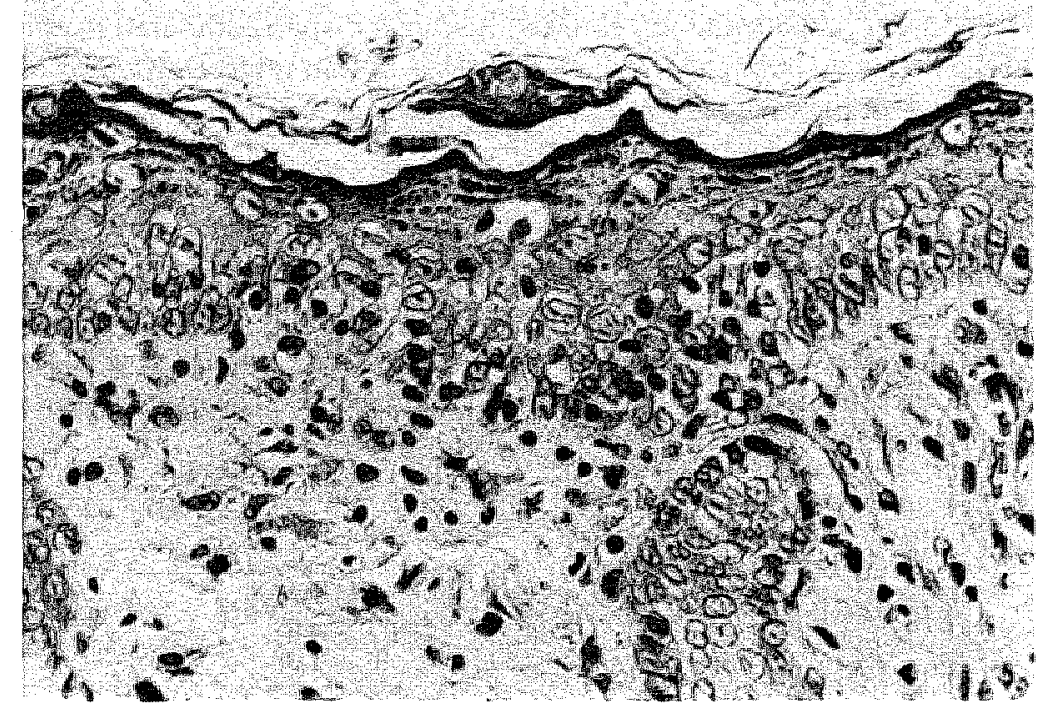

FIGURE 3: Skin biopsy taken during acute cyclosporine-induced autoimmune disease, showing infittration of mononuclear cells, destruction of the epidermis, and widening of the epidemis.

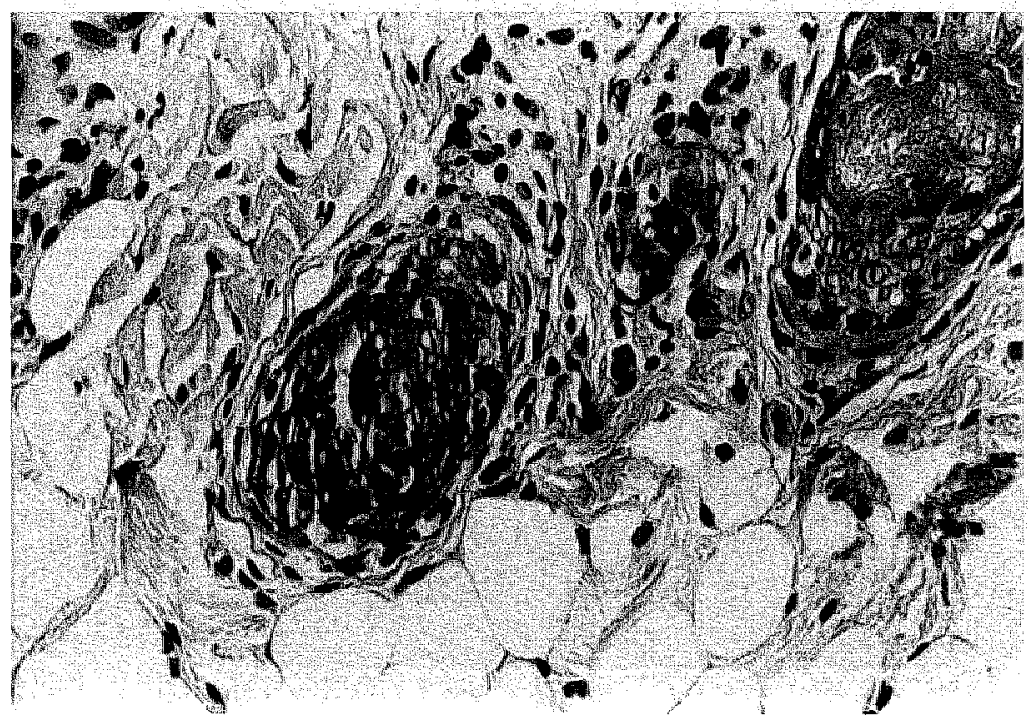

FIGURE 4: Skin biopsy taken during intermediate cyclosporine-induced autoimmune disease. Note persistent inflammation of hair follicles and increase of collagen deposition in the subdermal fat region 


\section{Histopathology prior to CyA withdrawal}

During the administration of CyA, 12 biopsies were taken from a total group of 8 bone marrow-transplanted and CyA treated animals. There was a marked decrease of subcutaneous fat in these animals compared to AMC rats. However, this reduction of subcutaneous fat was also noticed in animals that underwent BMT but were not treated with CyA (4/4). In two biopsies taken from different rats after 70 days of CyA administration a slight inflammatory reaction was observed, situated around a single hair follicle in both biopsies.

\section{Histopathology of the acute phase of CyA-AI.}

To study the histopathology of the skin in the acute phase of CyA-Al, biopsies of the skin were taken $4(\mathrm{~N}=5)$ and $7(\mathrm{~N}=8)$ weeks after withdrawal of Cy $\mathrm{A}$. Biopsies were taken from animals with clinical manifestations of CyA-AI only.

GVH-like pathology was present in all biopsies, although in varying degrees. This encompassed sparse, diffuse infiltrates of mononuclear cells in the dermis, especially around small hair follicles in the upper dermis, and at the dermal/epidermal junction. Local destruction of the epidermis with vacuolar degeneration of basal cells, and focal necrosis of keratinocytes, giving rise to Civatte bodies (eosinophilic cells) were seen as well (Fig. 3). In these biopsies the epidermis was wider compared to control animals, where it has one to two cell layers only. Acanthosis, as well as a hypergranular (coarse) stratum granulosum were usually observed. Furthermore, myositis was frequently observed in experimental but not in control animals.

In all biopsies taken at 7 weeks post CyA withdrawal, folliculitis was present as the most conspicuous abnormality. Folliculitis affected both small and large hair follicles in the dermis, and in the subdermal fat.

Fibrosis of the subdermal region usually developed around hair follicles with an inflammatory reaction. This fibrosis was rarely seen 4 weeks after withdrawal of CyA (1/5), but readily obserwed at 7 weeks after CyA withdrawal (7/8).

In the biopsies taken 7 weeks after withdrawal of CyA numerous mast cells could be obserwed. Mast cells were usually present in the lower dermis and in the subdermal fat, in those regions where increased fibrosis was observed as well.

In the control groups no typical lesions of "graft-versus-host-like" pathology were observed.

\section{Histopathology of the intermediate and chronic phase of CyA-Al.}

Biopsies were taken 11 to 36 weeks after withdrawal of CyA, at intervals of 6 - 8 weeks, to assess the histological changes in the intermediate and chronic phase of disease. 
In the intermediate phase ( $11-21$ weeks after CyA withdrawal), the epidermal abnormalities described above diminished. Occasionally a mild local mononuclear inflammation at the epidermal/dermal junction was still observed. The epidermis decreased to its normal thickness or remained only slightly thickened. Epidermal necrosis was no longer observed. The diffuse inflammation of the dermis decreased as well, but inflammation of the hair follicles persisted (Fig. 4). Remarkably, inflammation of the larger hair follicles, usually situated in the lower dermis or subdermal fat, was most prominent, whereas around the smaller follicles in the dermis an inflammatory reaction was usually absent. In the upper dermis, the number of hair follicles was reduced, and in those present, degeneration inclusive the absence of the hair(s) was seen.

In the dermis, hyperplasia of sebaceous glands was frequently observed. Furthermore, hypervascularisation was noticed, associated with markedly enlarged venules, mainly localized in the subdermal fat. An increased number of mast cells was still observed at the localization mentioned above. Also in this phase of disease the mast cells were situated in those areas where increased fibrosis was present.

As described above, an increase of fibrosis, usually starting around the larger hair follicles, could be observed from as early as 7 weeks after withdrawal of CyA. Fibrosis still progressed in the later phase of disease. As a consequence, the (remaining) subcutaneous fat often diminished. In the initial stage, the collagen fibers in the former subdermal fat region appeared very thin, but later their thickness increased. In the most conspicuous cases, subcutaneous fat was completely absent, being replaced by collagen

Table 2: Presence of GVH-like histopathological skin lesions ${ }^{\text {a }}$

\begin{tabular}{|c|c|c|c|c|c|}
\hline & \multirow{2}{*}{$\begin{array}{l}\text { During } \\
\text { Cy.A } \\
\text { adminim } \\
\text { stration }\end{array}$} & \multirow{2}{*}{$\begin{array}{l}\text { 4-7 weeks } \\
\text { after with- } \\
\text { drawal of } \\
\text { Cy-A }\end{array}$} & \multicolumn{3}{|c|}{ 6-8 months after withdrawal of $\mathrm{C} y-\mathrm{A}$} \\
\hline & & & no disease & $\begin{array}{l}\text { inflammatory } \\
\text { reaction and } \\
\text { increased } \\
\text { collagen }\end{array}$ & scleroderma \\
\hline $\begin{array}{l}\text { Experimental group } \\
\text { (BMT + CyA) }\end{array}$ & $2 / 12^{b}$ & $13 / 13$ & $2 / 11$ & $6 / 11$ & $3 / 11^{c}$ \\
\hline Controls $^{\text {d }}$ & $0 / 12$ & $0 / 12$ & $12 / 12$ & $0 / 12$ & $0 / 12$ \\
\hline
\end{tabular}

b 70 days of $C y-A$ administration

- All animals with scleroderma-like lesions also showed inflammatory changes at the intermediate phase of discase

a

This group includes bone-marrow grafted, non-CyA-treated, non-bone-marrow grafted, CyA-treated, and non-CyA-treated controls 
In the late and chronic phase of disease ( $6-8$ months post CyA withdrawal), three different patterns of dermal lesions were observed (Table 2). In the group exhibiting the first pattern there was a recovery of the inflammatory reaction observed earlier, and no signs of chronic disease were discernible $(\mathrm{N}=2)$. In biopsies taken from these rats, a reduced number of normal hair follicles was the only abnormality. In the second group, biopsies showed a spectrum of changes similar to that of the intermediate phase of disease : persistence of the inflammatory reaction, manifest as a folliculitis in the subdermal fat, and an increase of collagen in the subcutaneous region $(\mathrm{N}=6)$. Finally, in the third group, inflammatory reactions were no longer seen or had diminished. However, in these biopsies an increase of homogeneous collagen and complete absence of subcutaneous fat was present ( $\mathrm{N}=3$ ) (Fig. 5). In addition, in these biopsies there was also a decrease of normal, vital hair follicles. These biopsies showed striking similarities to the histopathology observed in the late phase of scleroderma in man.

The histological study of other organs revealed no pathology, except for the tongue. In this organ, severe inflammatory reactions were encountered in the acute phase of disease. In the later phases this inflammatory reaction persisted, and fibrosis became apparent.

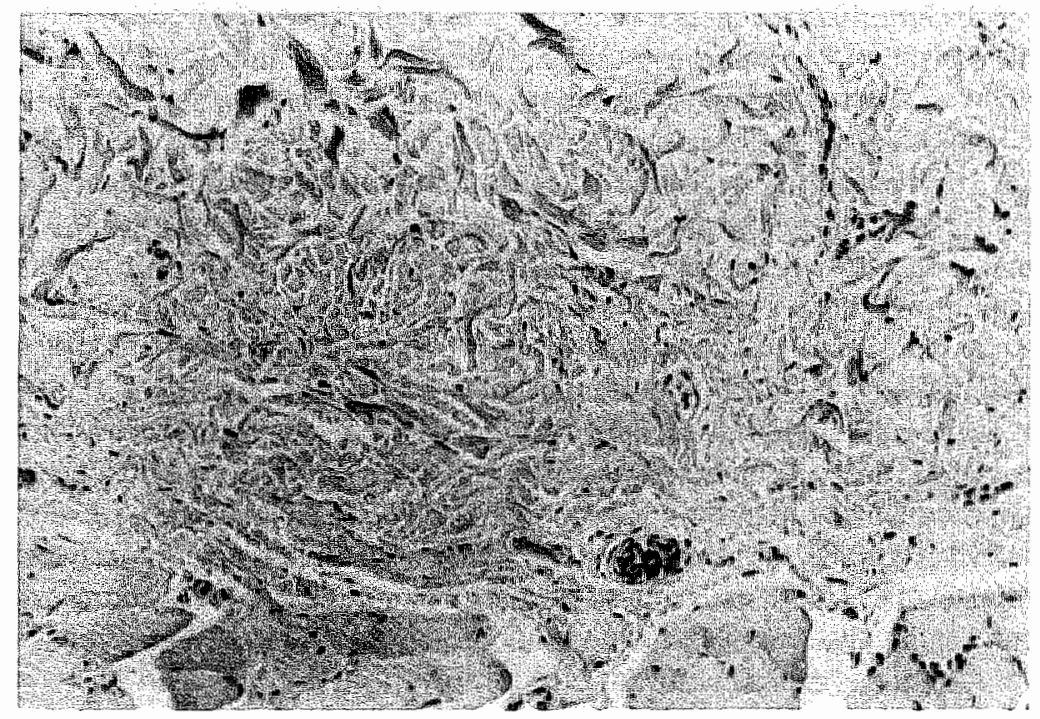

FIGURE 5: Skin biopsy raken during chronic cyclosporine-induced autoimumune disease. Marked increase of collagen deposition can be observed and as a consequence complete absence of subcutaneous fat. No inflammatory reaction can be observed anymore. 


\section{In viva microvascular investigations}

All rats with clinical signs of CyA-Al were screened three times by intravital microscopy, at 2 - 3 months intervals, for the presence of microvascular abnormalities in the skin. In every rat 3 toes of each hindfoot were studied. In only 3 animals microvascular enlargements of $1-3$ capillaries were observed in the last survey, at $30-36$ weeks after cessation of $\mathrm{Cy}$-A administration. However, microvascular changes were not observed in those rats exhibiting chronic disease and scleroderma-like lesion of the skin. However, at this time dilated capillaries could be observed in some control animals, possibly as a consequence of aging (see chapter II).

\section{DISCUSSION.}

In this chapter the clinical signs and symptoms and the histological skin lesions of the early, intermediate and late phases of Cyclosporine-induced autoimmune disease in the rat have been described. In this model, disease is elicited by a combination of lethal $\mathrm{X}$-irradiation, syngeneic bone marrow transplantation, and the administration of $\mathrm{Cy}-$ closporine-A for 40 to 80 days. A disbalance of regulatory cells normally preventing immune reactions to "self" antigens is likely to be the cause of disease in this model (Hess et al., 1989, Bos et al., 1988, chapter I and V).

After withdrawal of Cyclosporine-A, animals developed a clinical syndrome indistinguishable from acute graft-versus-host disease after allogeneic bone marrow transplantation. This syndrome has been previously described (Glazier et al., 1983). The thistopathological lesions of the skin described in this study in the acute phase were similar to those reported earlier in this model (Glazier et al., 1983) and were comparable to those described during an acute graft-versus-host reaction after allogeneic bone marrow transplantation (Beschorner et al., 1982). Histopathological abnormalities included a lichen planus-like inflammatory reaction in the epidermis and around small, dermal hair follicles as the most prominent signs.

After the acute phase of disease, which was lethal in a few animals, the animals recovered elinically. This is in contrast to the experience of others, in whose experiments most animals died during the acute phase of disease (Glazier et al., 1983). In only one report the survival of a substantial percentage of animals has been mentioned (Sorokin ef al. 1986). As in our studies, in this latter study "specific pathogen-free" animals were used. Therefore, the absence of concommittant infectious diseases might explain the high survival rate in our experiments.

In the chronic phase of disease animals showed clinical pathology comparable to that seen in animals with classical chronic graft-versus-host disease. The pattern of skin abnormalities in chronic graft-versus-host diseases has been suggested to be similar to scleroderma in man (Stastny et al., 1963 ; Oaks and Cramer, 1985 ; Beschorner et al., 
1982). However, apart from the observation of a thicker and lighter skin on the back of some animals, we could not objectively assess hardening of the skin of these rats as existing in patients with scleroderma.

The histopathological lesions developing after the acute phase were similar to those described in chronic graft-versus-host disease: a (slight) inflammatory reaction, decrease of adnexae, increased fibrosis, and the disappearance of subcutaneous fat. The latter phenomenon is known to be one of the most specific abnormalities in patients with scleroderma (Fleischmajer et al, 1971) One of the most prominent abnormalities noticed in our study was a marked folliculitis. This folliculitis has not been described in most of the studies on the pathology of graft-versus-host disease, although folliculitis has been mentioned as an aspect of this disease (Friedman et al. 1988; Beschorner, personal communication).

Increase of collagen fibers was noticed as early as 7 weeks after withdrawal of $\mathrm{Cy}$ closporine-A, and biopsies taken at this time showed signs of acute as well as of chronic disease. We did not observe an increase of collagen fibers in the subcutaneous region in biopsies taken 4 weeks after withdrawal of Cyclosporine-A, as documented earlier in a comparable study (Beschorner et al., 1988).

Based on histological similarities, chronic graft-versus-host disease has been suggested as a model for scleroderma by many authors (Stastny et al., 1963 ; Jaffee and Claman, 1983 ; Oaks and Cramer, 1985). However, substantial differences have been noticed as well (reviewed by Mekori and Claman, 1986). One of the main distinctions is the localization of increased sclerosis. In chronic graft-versus-host disease, increased sclerosis is often situated in the upper dermis, whereas in scleroderma in man, abnormal collagen deposition is usually restricted to the lower dermis and the subcutaneous region (Mekori and Claman, 1986). In the model described in this study, the increase of collagen was usually observed in the lower dermis and subcutaneous region, starting around the hair follicles. The subcutaneous fat was gradually replaced by collagen. Therefore, with respect to the localization of abnormal fibrosis, this model shows stronger similarity with scleroderma in man compared to classical chronic graft-versushost disease after allogeneic bone marrow transplantation.

It should be noticed that in most of the animals there was still a marked inflammatory reaction 6-8 months after withdrawal of Cyclosporin-A. Whether this reaction will further decrease to evolve into a more chronic phase of disease in more animals remains to be seen in a longer follow up period. In comparing Cyclosporine-induced autoimmune disease and scleroderma it is important to realize that "early" scleroderma involves a period of three years of disease (Hawkins et al., 1985). However, due to the life span of a rat, the follow-up period in this model is far less than duration of disease in patients with scleroderma. This difference may account for the low incidence of lesions analogous to those of late scleroderma.

Mast cells were prominently present from 7 weeks after withdrawal of CyA in most of the biopsies. These cells were usually seen around inflamed hair follicles, at the site of deposition of collagen. Both in patients with scleroderma, and in chronic graft-versus-host disease, mast cells have been related to abnormal sclerosis (Claman, 1985 ; 
Hawkins et al, 1985 ; Pearson et al., 1988). The role of mast cells in this model still has to be clarified, but their presence in association with the observed deposition of collagen suggests a causal relationship in this model as well.

Since apart from the skin, no other organs, known to be possibly involved in diffuse systemic sclerosis, showed any abnormalities in this model, the model appears to represent the "limited cutaneous scleroderma" subtype of scleroderma (LeRoy et al., 1988)

Attempts to demonstrate in vivo microvascular abnormalities in this model were not successful. This observation contrasts with that made in rats with classical chronic graftversus-host disease (chapter III). Possibly, permitted a prolonged follow-up period, these abnormalities might still develop. If so, it must be concluded that such lesions cannot play an initiating role in the pathogenesis of disease. It should be stressed, however, that the abscence of microvascular abnormalities from this model so far, constitutes an important discrepancy with scleroderma in man, since in man microvascular abnormalities are almost invariably present (LeRoy et al., 1988). However, larger groups of animals with scleroderma-like pathology have to be studied to establish conclusively the absence or presence of microvascular pathology in this model.

In conclusion, the induction of autoimmune disease by combination of lethal X-irradiation, syngeneic bone marrow transplantation, and temporary administration of $\mathrm{Cy}$ closporine-A yields histopathological lesions similar to those encountered in chronic graft-versus-host-disease. On one hand, the localization of collagen deposition in this model shows stronger similarity to that seen in human scleroderma than the model of chronic graft-versus-host disease. Therefore, this model can be seen as a first autoimmune model for the pathogenesis of the histological lesions of scleroderma in man. On the other hand, the absence of in vivo skin microvascular abnormalities is an important discrepancy between Cyclosporine-induced autoimmunity in the rat and scleroderma in man.

\section{REFERENCES TO CHAPTER IV}

Beschorner WE, PJ Tutschki, and GW Santos (1982) Sequential morphology of graft-wersus-host disease in the rat radiation chimera. Clin Immunol Immunopathol $22: 203-224$

Beschorner W, PJ Tutschka, and GW Santos (1982) Chronic graft versus host disease in the rat radiation chinitera. Tramsplantation 33:393-399

Beschorner WE, AD Hess, CA Shinn, and GW Santos (1988) Transfer of cyclosporine-associated syngeneic graft-versus-host disease by thymocytes. Resemblance to chronic graft-versus-host disease. Transplantation $45: 2099-215$

Bos GMJ, DW Slaaf, GD Majoor, G-J Tangelder, and RS Reneman (1987) A model for chronic study of vascullar morphology and reactivity of physically intact rat skin microcirculation. Int J Microcirc Clin \& $\operatorname{Exp} 6: 371-380$ 
Bos GMJ, GD Majjoor, DW Slaaf, RS Rememan, and PJC wan Breda Vriesman (1988) in wo denonsuration of microvascular pathology by intravital microscopy in experimental chromic graft-versus-host disease: Analogy with scleroderma. J Rheumatol 15:1339-1345

Bos GMJ, GD Majoor and PJC van Breda Vriesman (1988) Cyclosporin-A induces a selective, reversible suppression of T-helper lymphocyte regeneration after syngeneic bone marrow transplantation : association with syngeneic graft-wersus-host disease. Clin Exp Immunol 74:443-448

Claman HN (1985) Mast Cells, T cells and abnormal fibrosis. Immunol Today 6:192-196

Fleischmajer R, V Damiano, and A Nedwich (1971) Scleroderma and the subcutaneous tissue. Science $171: 1019-1021$

Friedman KJ, PE LeBoit, ER Farmer (1988) Acute follicular graft-vs-host reaction. A distinct clinicopathologic presentation. Arch Dermatol $124: 688-691$

Glazier A, PJ Tutschka, ER Farmer, GW Santos (1983) Graft versus hosi disease in cyclosporin-A treated rats after syngeneic and autologous bome marrow transplantation. J Exp Med $158: 1-8$

Glazier A, PJ Tutschka, and E Farmer (1983) Studies on the immunobiology of syngeneic and autologous graft-versus-host disease in cyclosporine-treated rats. Transplant Proc 15:3035-3041

Hess AD, AC Fischer, WE Beschorner, and GB Vogelsang (1989) Syngeneic graft-wersus-host disease. Inbalance of autoregulatory and autocytotoxic mechanisms. Transplant Proc In press

Hawkins RA, HN Claman, RAF Clark, and JC Steigerwald (1985) Increased dermal mast cell populations in progressive systemic sclerosis : A link in chronic fibrosis. Ann Int Med $102: 182-186$

Jaffee BD, and HN Claman (1983) Chronic graft-versus-host disease as a model for scleroderma. I. Description of models. Cell Immunol $77: 1-12$

LeRoy EC, C Black, R Fleischmajer, S Jablonska, T Krieg, TA Medsger, N Rowell, and F Wollheim (1988) Scleroderma (systemic sclerosis) : classification, subsets, and pathogenesis. J Rheumatol $15: 202-205$

Mekori YA, and HN Claman (1986) Is graft-versus-host disease a reliable model for scleroderma? La Ricerca Clin Lab $16: 509-514$

Oaks MK, and DV Cramer (1985) Chronic graft-versus-host disease in rats after syngeneic bone marrow transplantation. Transplantation $39: 504-510$

Pears on ME, JC Huff, RC Giiorno, S Panicheewa, HN Claman, and JC Steigerwald (1988) Immunologic dysfunction in scleroderma : evidence for increased mast cell releasability and HLA-DR positivity in the dermis. Arthr Rheum $31: 672-677$

Postlethwaite AE, and AH Kang (1984) Pathogenesis of progressive systemic sclerosis. J Clin Lab Med $103: 506-509$

Simis MA, E Johanson, and J Rapola (1977) Scleroderma-like graft-versus-host disease as late consequence of bone marrow grafting. Lancet II :831-832

Sorokin R, H Kimura, K Schroder, DH Wilson, and DB Wilson (1986) Cyclosporin-induced aut oimmu* nity. Conditions for expressing disease, requirement for intact thymus, and potency estimates of autoimmune lymphocytes in drug-treated rats. J Exp Med 164:1615-162.5

Stastny P, VA Stembridge, T Visicher, and M Ziff (1963) Homologous disease in the adult rat, a model for autoimmune disease. 1. General features and cutaneous lesions. J Exp Med 118:635 


\section{CHAPTER V}

\section{CD4-POSITIVE LYMPHOCYTES AND CYCLOSPORINE-INDUCED AUTOIMMUNE DISEASE}




\section{INTRODUCTION}

Cyclosporine-A (CyA)-induced syngeneic graft-versus-host ( $\mathrm{GVH}$ ) disease, also referred to as CyA-induced autoimmunity (CyA-AI), has been observed after a combination of lethal X-irradiation, syngeneic bone marrow transplantation (sBMT) and the administration of CyA (Glazier et al., 1983 ; chapter I). This observation has been used to develop a new autoimmune model for scleroderma (see chapter IV). In this chapter we describe cellular events involved in the development of this autoimmune reaction.

CyA-AI develops 2-4 weeks after withdrawal of CyA and clinically mimics acute graft-versus-host (GVH) disease after allogeneic BMT (Glazier et al., 1983). The development of CyA-AI has been explained by inadequate learning of self, a process that normally (re)occurs after BMT (Tutschka, 1986). As in acute GVH disease, the development of CyA-AI requires the presence of T ceills (Korngold and Sprent, 1987; Sorokin et al., 1986). Hess et al. have demonstrated the presence of cytotoxic T lymphocytes directed against public MHC class-II antigens after withdrawal of CyA (Hess et al., 1985). Passive transfer of autoimmunity, however, could only be achieved by unseparated $\mathrm{T}$ cell populations or $\mathrm{T}$ helper $(\mathrm{Th})$ cells, and not by transfer of $\mathrm{T}$ killer/suppressor $(\mathrm{Tk} / \mathrm{s})$ cells. (Sorokin et al. 1986). Therefore, there is no full understanding of the cellular mechanisms involved in the development of CyA-AI.

This study was performed to study the subsets of $T$ cells in peripheral blood after syngeneic BMT, during and after CyA administration and to establish their relation with CyA-AI in rats. During CyA administration suppression of repopulation of Th cells in peripheral blood was observed. This suppression of Th cells was maintained as long as CyA was administered, but reversed after CyA withdrawal. The reappearance of Th cells coincided with the development of clinical symptoms of autoimmune disease, suggesting that cells eliciting the autoimmune phenomenon reside in the Th population.

\section{MATERIALS AND METHODS}

\section{Animals}

Female inbred Lewis (LEW; RT1'), specific pathogen-free rats were derived from our own breeding stock (first experiment) or purchased from Charles River (Sulzfeld, West-Germany) (second experiment). Rats were used at 2 months of age.

\section{Bone marrow transplantation}

The technical procedure of syngeneic (LEW $\Rightarrow$ LEW) bone marrow transplantations (BMT) has been described in detail in chapter IV. In short, bone marrow donors were sacrificed on day 0 . Tibias and femurs were collected and the marrow cavity was per- 
fused with Dulbecco's balanced salt solution (DBSS) supplemented with $2 \%$ heatinactivated newborn calf serum (NBCS), penicillin $(100 \mathrm{U} / \mathrm{ml})$ and streptomycin (100 $\mu \mathrm{g} / \mathrm{ml}$ ). Cell aggregates were disrupted by passage through injection needles and marrow cells were counted. Recipient rats were lethally X-irradiated on day $-1(9,6 \mathrm{~Gy})$ using a Röntgen irradiator (Philips MG 320, Hamburg, W.-Germany). On day 0, recipient rats received $4-6.10^{\prime}$ viable syngeneic marrow cells in $1 \mathrm{ml}$ DBSS intravenously into a tail vein.

\section{Administration of CyA}

The administration of CyA has also been described in chapter IV. In short, CyA was dissolved in olive oil at a concentration of $7.5 \mathrm{mg} / \mathrm{ml}$. Injections of CyA were given subcutaneously at a dose of $7.5 \mathrm{mg} / \mathrm{kg}$.

\section{Determination of CyA blood levels}

Blood samples were obtained by retro-orbital puncture. CyA levels were determined from whole, heparinized blood ( $200-250 \mu \mathrm{l} / \mathrm{sample})$ by high performance liquid chromatography (HPLC) using an ultrasphere $\mathrm{C} 8$ column (Beckman, Mijdrecht, The Netherlands) as described before (Carruthers et al., 1983). In brief, heparinized blood was hemolyzed with a $2 \%$ Zaponin solution; thereafter CyA was extracted from the blood using a diethylether extraction method. The ether solution with the CyA was desiccated and the extract dissolved in $1 \%$ ammoniumsulphate. This solution is finally injected onto the HPLC column.

\section{Analysis of lewkocytes and lymphocyte subsets in peripheral blood.}

Blood samples of approximately $0.75 \mathrm{ml} / \mathrm{sample}$ were obtained by retro-orbital puncture. Leukocytes were counted in a hemocytometer in Türk's solution. The percentage of lymphocytes was determined from a peripheral blood smear, and the absolute number of lymphocytes was calculated by multiplying the number of leukocytes $\mathrm{ml}^{-1}$ by the percentage of lymphocytes $\times 10^{-2}$ (approximately $90 \%$ in normal rats). Leukocytes were recovered from the remainder of the bloodsample by lysis of the erythrocytes with isotonic ammoniumchloride $(0.15 \mathrm{M})$ and centrifugation of the suspension through a cushion of NBCS. Lymphocyte subsets were determined using mouse monoclonal antibodies (MABs) directed against the following rat lymphocyte (subset) markers : OX8 (Serotec, Blackthorn, UK), directed against a membrane marker of Tk/s lymphocytes and analogous to CD-8 in man and W3/25 (Serotec), directed to Th cells and analogous to CD-4. Although OX-8 also detects NK cells, and W3/25 also detects monocytes, these large granular lymphocytes and monocytes are not present within the lymphocyte population selected for analysis on the FACS. MARK (a kind gift of Dr. Bazin, Brussels, Belgium) is directed against the kappa chain of the immunoglobulin (Ig) molecules present on B lymphocytes; in the rat approximately $95 \%$ of the B lymphocytes have surface Ig bearing kappa light chains (Hood et al., 1967). Leukocytes were incubated with 
one of these respective MABs for 30-45 minutes on ice, and washed $3 x$ in DBSS to remove excess antibody. Fluoresceïn-isothiocyanate (FITC)-labeled goat anti-mouse IgG, void of cross-reactivity to rat antigens (Cappel, Cochranville, PA), was used as a second antibody. Incubation with this antibody and washing were repeated as described for MABs, and FITC-stained cells were counted on a FACS IV cell sorter (BectonDickinson, Sunnyvale, CA) equipped with a $4 \mathrm{~W}$ argon ion laser (modell 164-05, Spectra Physics, The Netherlands) operating at $488 \mathrm{~nm}$. Data on fluorescence intensity, $90^{\circ}$ scatter signal, and cell size of 5000 cells from each sample were recorded using a personal computer. The percentage of stained lymphocytes was determined off-line, using a computer programme which selected the lymphocytes from the total cell population by criteria of size and $90^{\circ}$ scatter signal. Lymphocytes incubated with the second antibody only were used for setting the lower fluorescence threshold value.

\section{Scoring of $C y A-A I$}

The presence of CyA-AI established from weight loss and clinical signs of hyperemia, dermatitis, and alopecia. Scoring was performed by one observer, not involved in this study, but familiar with the systems of the disease. These clinical signs mimic the pathology seen in acute GVH disease, and have been described in detail (Glazier et al., 1983).

\section{Controls}

Control groups in the experiments described in this chapter included bone marrow transplanted rats that received the solvent only, non-transplanted age-matched-controls (AMC) that received CyA, and AMC that received the solvent only.

\section{Statistics}

The Wilcoxon ranking test for unpaired samples was performed for statistical analysis.

\section{RESULTS}

\section{CyA selectively suppresses $\mathbf{T}$ helper cell regeneration after syngeneic BMT}

In order to study a possible role of different $T$ cell subsets in the model of CyA-AI, regeneration of the lymphoid cell population after syngeneic BMT and during the administration of CyA was studied in a first experiment (Table 1). A strong, selective suppressive effect on the repopulation of the Th lymphocyte subset was observed in Xirradiated, bone marrow transplanted, and CyA treated animals (group A) as determined by FACS analysis of the peripheral lymphoid cells on day 31 post-BMT (Table 1). 
Table 1. Peripheral blood leukocyte quantitation on day 31 post-BMT

\begin{tabular}{|c|c|c|c|c|c|c|c|c|c|c|}
\hline & \multirow[b]{3}{*}{ BMT } & \multirow[b]{3}{*}{$C y-A$} & \multirow[b]{3}{*}{$\mathbb{N}$} & \multicolumn{6}{|c|}{ Alvsolute cell numbers [mean $\times 10^{-6} \mathrm{ml}^{-1}$, range] } & \multirow{3}{*}{$\begin{array}{l}\mathrm{T}_{\mathrm{h}} \mathrm{T}_{\mathrm{k} /} \\
\text { ratio } \\
)^{2}\end{array}$} \\
\hline & & & & \multirow{2}{*}{$\begin{array}{l}\text { Leuko- } \\
\text { cytes }\end{array}$} & \multirow{2}{*}{$\begin{array}{l}\text { Lympho- } \\
\text { oytes }\end{array}$} & \multicolumn{3}{|c|}{ Lymphocyte subsets } & \multirow{2}{*}{$\mathrm{T}_{\mathrm{k} / \mathrm{s}}\left(\mathrm{OX}-\mathrm{8}^{+}\right.$} & \\
\hline & & & & & & $\mathrm{B}\left(\mathrm{Ig}^{4+}\right)$ & Null & $T_{h}\left(W 3 / 25^{+}\right)$ & & \\
\hline \multirow[t]{2}{*}{ A } & + & + & 6 & 5.2 & 3.7 & 19 & 0.9 & $0.4^{4 x}$ & 0.5 & $0.7^{*}$ \\
\hline & & & & $3.8 \cdot 10.2$ & 2.94 .7 & $1.2-2.6$ & $0.4 \cdot 1.5$ & $0.3-0.5$ & $0.4-0.7$ & $0.4-0.9$ \\
\hline \multirow[t]{2}{*}{ B } & + & - & 6 & 5.6 & 4.7 & 1.4 & 0.7 & $2.1^{*}$ & 0.6 & $3.3^{\text {th }}$ \\
\hline & & & & $4,6-7,1$ & $39-6.2$ & 1.1 .17 & 0.0 .9 & $1.8 \cdot 2.8$ & 0.54 .8 & $27-3.7$ \\
\hline \multirow[t]{2}{*}{$\mathrm{C}$} & - & + & 4 & 6.1 & 5.4 & 1.2 & 1.0 & 2.6 & 0.8 & 3.2 \\
\hline & & & & $5.3-7.4$ & 4.5 .6 .3 & $1.1 \cdot 1.3$ & $0.9-1.2$ & $2: 1.3 .3$ & $0.7-0.9$ & $26-3.7$ \\
\hline \multirow[t]{2}{*}{$\mathrm{D}$} & - & - & 4 & 8.6 & 7.8 & 1.4 & 0.6 & 4.5 & 1.5 & 3.0 \\
\hline & & & & $7.2-9.3$ & $6.7-8.6$ & $1.1-1.8$ & $-0.2-11.3$ & 3.94 .50 & $1.2-1.6$ & $2.6-3.2$ \\
\hline
\end{tabular}

*) A vs B: p. $<0.01$

TABLE 1: Quantitation of peripheral blood leukacyies and lymphocyte subsets on day 31 after syngeneic bone mamow transplantation ( $S B M T$ )

Group $A$ : $X$-irradiation, $s B M T$, and CyAL for 40 days

Group B: X-irradiation, $s B M T$, no CyA

Group C: Age matched controls, and CyA for 40 days

Group D: Age matched controls, no CyA

Although CyA reduced the mean number of lymphocytes $\mathrm{ml}^{-1}$ blood of rats treated with $\mathrm{X}$-irradiation, BMT and CyA (group A, Table 1) by $21 \%$ when compared to X-irradiated, bone marrow transplanted rats not treated with CyA (group B, Table 1), this does not explain the reduction by $81 \%$ observed for the Th cell subset (group A vs group B, Table 1). The mean number of Tk/s cells in group A was not different from that of rats in group B (Table 1). Consequently, the ratio of Th over Tk/s cells was reversed in recipients of BMT that were given CyA (Table 1). Repopulation of B-lymphocytes was not suppressed by CyA. A decrease in the total number of lymphoid cells was also observed in the non-grafted control group given CyA (group C) as compared to the non-grafted control group that received the solvent only (group D). However, there was no selective loss of any $\mathrm{T}$ cell subset due to the administration of CyA only, and therefore normal Th/Tk/s ratio's were calculated for these rats (Table 1). 


\section{Suppression of $\mathrm{T}$ helper cell regeneration is reversible}

The reversibility of the effect of CyA on the Th cell population was studied in six rats (group A, Table 1, Fig. 1) by determining the T lymphocyte subsets on day 53 and day 73,13 and 33 days after withdrawal of CyA on day 40 respectively. At day 40 the mean CyA level in blood was $1420 \mathrm{mg} / \mathrm{l}$ (range $700-2500 ; \mathrm{N}=10$ ). Analysis of $\mathrm{T}$ cell subsets revealed an increase in Th cells on day 53 [Mean : $2.2 \times 10^{6} / \mathrm{ml}$ (range 1.2-4.9)] and normal levels of Th cells on day 73 [Mean : $3.4 \times 10^{6 /} / \mathrm{ml}$ (range $2.0-4.6$ )]. Although there was a significant recovery of the ratio of Th/Tk/s cells on day 73 [Mean : 2.5 (range $1.4-3.7)$ ], this ratio was still just below the normal value range, since there was a slight concomitant increase in Tk/s cells after withdrawal of CyA [Mean : 1.5 (range 1.1 - 3.0)] (Fig. 1)

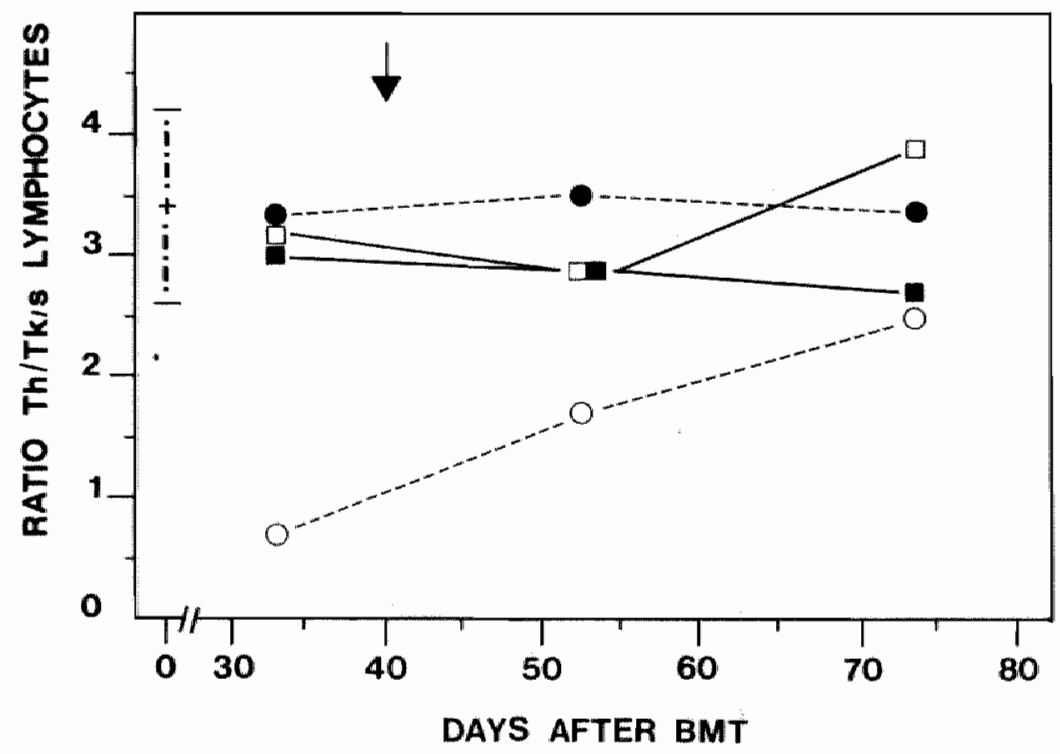

FIGURE 1: Ratio of T-helper/T-killer-suppressor lynphocyles in peripheral blood.

$O=$ Group $A: X$-irradiation, $s B M T, C y A$ for 40 days $(N=6)$

$0=$ Group $B: X$-irradiation, sBMT, no CyA $(N=6)$

$\square=$ Group $C$ : Age maicheul controls, CyA for 40 days $(N=4)$

I = Group D : Age matched controls, no CyA $(N=d)$

Arrow indicates day of withdrawal of CyA.

Bar indicales mean ratio $\pm 2 S D$ of 15 normal female Lewis rats. 
Table 2. Association between reappearance time of $W 3 / 25^{+}$cells in peripheral blood, and onset of disease in CyA-induced autoimmunity.

\begin{tabular}{|c|c|c|c|c|}
\hline & $\mathrm{N}$ & $\begin{array}{c}\text { Day posit } \\
\text { BMT }\end{array}$ & CyA-Al & $\begin{array}{r}W 3 / 25^{*} \text { cells } \\
\times 10^{6} / \mathrm{ml}\end{array}$ \\
\hline $\begin{array}{l}\text { Group A } \\
\text { (BMT and CYA } \\
\text { for } 40 \text { days) }\end{array}$ & 20 & $\begin{array}{r}61 \\
82 \\
102 \\
125\end{array}$ & $\begin{array}{l}3 / 19^{b} \\
6 / 14^{c} \\
6 / 14 \\
6 / 14\end{array}$ & $\begin{array}{l}0.8^{+0} \\
1.7+++ \\
2.0^{++} \\
2.8+\end{array}$ \\
\hline $\begin{array}{l}\text { Group B } \\
\text { (BMT and C } \% A \\
\text { for } 80 \text { days) }\end{array}$ & 5 & $\begin{array}{r}61 \\
82 \\
102 \\
125\end{array}$ & $\begin{array}{l}0 / 5 \\
0 / 5 \\
3 / 5 \\
4 / 5\end{array}$ & $\begin{array}{l}0.8^{4} \\
0.8^{+++} \\
1.3^{++} \\
2.7^{+}\end{array}$ \\
\hline $\begin{array}{l}\text { Group C } \\
(B M T, \text { no CyA })\end{array}$ & 5 & $\begin{array}{r}61 \\
82 \\
102 \\
125\end{array}$ & $\begin{array}{l}0 / 5 \\
0 / 5 \\
0 / 5 \\
0 / 5\end{array}$ & $\begin{array}{l}1.5 \\
2.1 \\
2.3 \\
2.2\end{array}$ \\
\hline $\begin{array}{l}\text { Lymphocyte s } \\
\text { day } 61 \text { in grou } \\
\text { One animal di } \\
\text { Five animals } d \\
\text { Group } A \text { wers }\end{array}$ & bet & $\begin{array}{l}\text { CyA bloo } \\
\text { ay } 125 \text { in } \\
\text { after withe } \\
\text { nday } 61 \\
:^{+} \text {:not si }\end{array}$ & $\begin{array}{l}\text { vels were } \\
\text { B when } \\
32,3 \text { of the } \\
\text { cant; }{ }^{++} \text {. }\end{array}$ & $\begin{array}{l}\text { rmined in } 5 \text { animals in each group, except for } \\
25^{+4} \text { cells were determined in } 4 \text { animals onlly. } \\
\text { hout signs of CyA-AI } \\
\text { with signs of CyA-AI } \\
0.055^{+++} \text {. p }=0.01\end{array}$ \\
\hline
\end{tabular}

TABLE 2: Association between reappearance time of $W 3 / 25^{+}$cells in peripheral blood, and onset of disease in Cyclosporine-A-induced autoinmunity.

\section{Reappearance of $\mathrm{T}$ helper cells in peripheral blood is related to cessation of CyA administration.}

The results obtained from the first experiment could not discriminate between two possible explanations : 1) CyA administration after BMT suppresses Th cell regeneration temporarily, but thereafter regeneration occurs independent of continuation or withdrawal of the drug ; and 2) CyA suppresses Th cell regeneration after BMT as long as the drug is applied and reversal occurs only after its withdrawal. Therefore, repopulation of Th cells was next studied in more detail under and after withdrawal of CyA, and in relation to the duration of CyA administration. In this second experiment rats were lethally $X$-irradiated, bone marrow transplanted and given $7.5 \mathrm{mg} / \mathrm{kg}$ CyA for 40 days (group A, Table 2 ) or for 80 days (group B, Table 2). 
The mean CyA blood level was $700, \mathrm{~g} / \mathrm{l}$ (range $440-2440 ; \mathrm{N}=10$ ) on day 40 in the rats from groups $A$ and $B$, and increased to $1282 \mu \mathrm{g} / \mathrm{l}$ (range $1050-1520 ; \mathrm{N}=5$ ) on day 80 in group B. In group A, on day 60,20 days after withdrawal of CyA, Cy A levels had declined to $110 \mu \mathrm{g} /$ (range $60-120 ; \mathrm{N}=5$ ).

As in the previous experiment, low numbers of Th cells and low $\mathrm{Th} / \mathrm{Tk} / \mathrm{s}$ ratio"s were observed after syngeneic BMT and during the administration of CyA as monitored on day 60 after BMT. CyA was with held after day 40 in group A and in this group a significant increase in the numbers of Th cells and in the Th/Tk/s ratio"s was observed between day 61 and 82 post BMT, from $0.8 \times 10^{6} / \mathrm{ml}$ (range $0.7-0.9$ ) on day 61 to $1.7 \times$ $10^{6}$ (range $1.4-2.3$ ) on day 82 . On the other hand, Th cells remained suppressed in rats in group B that were given CyA until day 80 . The mean ratio of Th/Tk/s cells in group $B$ was 0.8 on day 61 and remained at this level until day 82 (Mean :0.8 [range 0.4 - 0.9]: $(P=0,01)$. After withdrawal of $C y A$ from rats in group $B$, there was again recovery of Th cells in peripheral blood as determined by FACS analysis on day 102,125 and 152 after BMT. The percentages of Th lymphocytes, Tk/s lymphocytes and the ratio of $\mathrm{Th} / \mathrm{Tk} / \mathrm{s}$ are presented in Fig. 2.

\section{Development of autoimmune disease.}

The time-related association between withdrawal of CyA, reappearance of Th cells in peripheral blood, and the development of CyA-AI in the second experiment is presented in Table 2 . It can be concluded from this table that only animals that underwent lethal X-irradiation, BMT and that received CyA for 40 to 80 days developed the clinical signs of CyA-AI after withdrawal of CyA. Biopsies of the skin in these rats confirmed the clinical observations, by showing pathology comparable to that accompanying an acute graft-versus-host reaction (See chapter IV)(Glazier et al., 1983). None of the animals developed signs of disease during the administration of CyA, notably not the 5 rats that received CyA for 80 days. Of the total number of 34 animals that underwent a syngeneic BMT and that were given CyA, 7 died without clinical signs of CyA-AI. Of the remaining 27 animals 17 developed $C y A-A l$ within 6 weeks after withdrawal of $C y A$. In the first experiment signs of CyA-AI were observed in the $3^{\text {rd }}$ week after withdrawal of CyA. In the second experiment signs of CyA-AI were observed at the end of the $3^{\text {rd }}$ or at the beginning of the $4^{\text {th }}$ week after withdrawal of CyA. Age-matched and BMT controls remained healthy, the latter after recovery from irradiation.

\section{Kinetics of CyA in bllood.}

In both experiments described above, there is a certain time lag between the development of CyA-AI, repopulation of Th cells and withdrawal of CyA, notably in the second experiment (Fig. 2). Therefore, in a separate experiment the kinetics of CyA in peripheral blood was studied weekly after withd rawal of CyA administration. Rats were treated with lethal X-irradiation, sBMT and received $7.5 \mathrm{mg} / \mathrm{kg}$ CyA subcutaneously for 40 


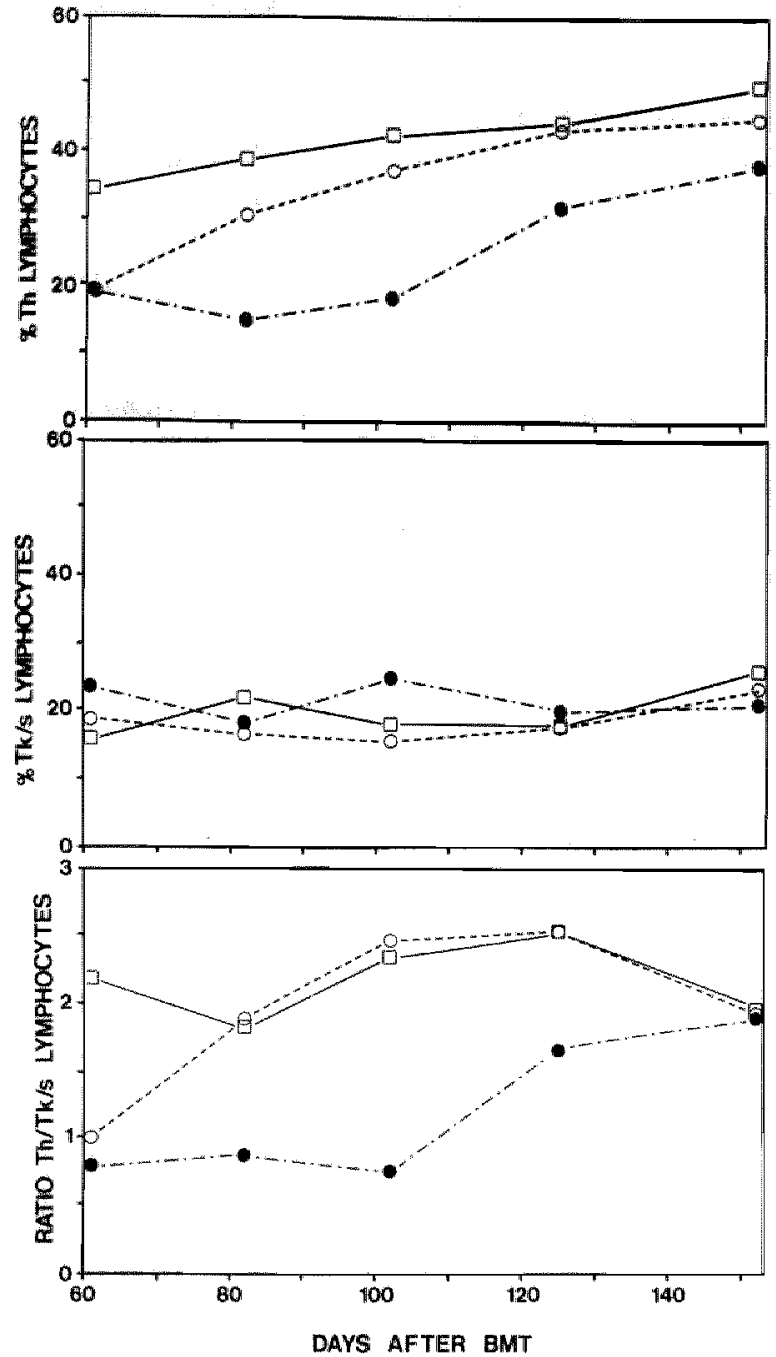

FIGURE 2: Repopulation of lymphocyte subsets in peripheral blood in relation to duration of CyA administration.

$O=$ Group $A: X$-imadiation, $s B M T$, and CyA for 40 days

$0=$ Group B : X-irradiation, $\triangle B M T$, and CyA for \&O days

$\square=$ Group $C: X$-imadiation, $s B M T$, no $C y A$

$N=5$ in all groups except for group $A$ of day 61 , when only 4 samples were determined, and day 125 and 152 in group $B$ when only 4 samples were determinted. $P=0.01$ for all three parameters comparing group $A$ and $B$ on day 82 . 
days. The mean CyA level was $964 \mu \mathrm{g} / 1$ (range $740-1280$ ) on day 40 , and $300 \mu \mathrm{g} / 1$ (range $280-330$ ) and $160 \mu \mathrm{g} / 1$ (range $130-220$ ) 7 and 14 days after withdrawal of Cy $A$ respectively; only 3 weeks after withdrawal of Cy A, blood levels were below those known to be therapeutic in man ( $94 \mu \mathrm{g} /$; range $40-120$ ).

\section{DISCUSSION}

This study was undertaken to analyze the peripheral lymphocyte subsets in a model of CyA-AI and to determine its relationship with the development of clinical autoimmune disease.

In the experiments described, the number of Th cells was reduced in the peripheral blood after sBMT, provided CyA was being administered. This observation reconfirmed the data of Hess et al., who also reported a low number of Th cells during CyA administration in bone marrow transplanted rats (Hess et al., 1985). How CyA suppresses normal recovery of Th cells is not clear. A reduced expression of medullary class II antigens in the thymus has been observed in this model (Cheney and Sprent, 1985). Experimental data derived from studies in mice and man indicated that these thymus class II antigens are necessary for the development of Th cells (Kruisbeek et al., 1985 ; Blue et al., 1985). After withdrawal of Cy A a marked recovery of Th cells was observed in both experiments as well as a concomitant correction of the Th/Tk/s ratio, since the mumber of Tk/s cells hardly changed during and after CyA administration. The suppression of Th lymphocyte regeneration observed is clearly dependent on the presence of CyA. As long as CyA is given ( 80 days in experiment II), normal repopulation of the "Th cells will not occur. These data indicate that the suppressive influence of CyA holds on as long as CyA is administered whereas a normal pattern of peripheral lymphocytes will again be present after withdrawal of CyA. This observation is comparable to the observation made in mice, where anti-I-A monoclonal antibodies (MAB) suppressed the development of Th cells as long as these MAB were administered and Th cells reappeared after withdrawal of the MAB (Kruisbeek et $a l$, 1985). In this respect, CyA possibly behaves as a temporary class II antigen blocker.

A subset of $\mathrm{T}$ cells in peripheral blood, carrying both Th and Tk/s markers $(>30 \%$ of lymphocytes) under CyA administration has also been documented in this model (Hess et al. 1985). We have not quantified cells that co-express Th and Tk/s markers. However, during CyA administration the number of cells expressing the Th marker only, was extremely low $(<15 \%)$. Therefore, it can be excluded that a high number of cells carrying both markers, comparable to that observed by Hess et al., were present in our rats during CyA administration.

There is a certain time lag between withdrawal of CyA and the development of CyAAI, both in our experiments and in those performed by others (Glazier $e$ t al., 1983). In addition, their is a time lag for the restoration of normal $T$ cell subsets after $C y A$ withdrawal. In a separate experiment we have demonstrated that a substantial level of CyA 
was still present in peripheral blood two weeks after withdrawal of CyA in this protocol. Only three weeks after withdrawal of CyA blood levels were below levels known to be therapeutic in man. This persistance of CyA might explain the slow reappearance of normal Th cell patterns.

In addition to the effect of Cy $\mathrm{A}$ on $\mathrm{Th}$ lymphocyte regeneration, a time-dependent relationship between the withdrawal of $\mathrm{CyA}$ and the development of CyA-AI was noticed. None of the animals developed CyA-AI during CyA administration, not even if administration of CyA was continued for a period of 80 days. In studies pertinent to this model, autoimmunity has been reported to develop after withdrawal of CyA. However, to our knowledge, in these studies CyA was administered for a maximum of 40 days. It is not clear whether the development of autoimmune disease related to withdrawal of CyA or occurred within a certain period after BMT (as a consequence of the presence of CyA early after BMT), notwithstanding continued administration of CyA. Our data demonstrate that CyA-AI indeed develops only after withdrawal of CyA.

It took a few weeks before clinical signs of CyA-AI developed after withdrawal of CyA. This time period was comparable to the period required before an increase of $T h$ cells was monitored in peripheral blood, strongly suggesting an association between these two observations. Hence, a role for Th cells in the induction of autoimmune disease is suggested. These data are compatible with the observation that Th cells allone suffice to induce autoimmune disease in secondary recipients (Sorokin et al., 1986). In addition, recently, the presence of Th cells (but not Tk/s cells) in the skin of animals with CyA-AI has been reported (Beschorner et al., 1988). However, this does not exclude that other $T$ cell subsets are involved in evoking the autoimmune pathology (Hess et al., 1985). For comparison, in acute graft-versus-host disease, after allogeneic BMT, in which Tk/s cells are purported to elicit the clinical pathology, initial activation of Th cells is obligatory (Pals et al., 1984).

It should be stressed that not all animals develop clinical CyA-Al in this model, although they show comparable Th lymphocyte repopulation profiles. Therefore, allthough a normal repopulation of Th cells is necessary before CyA-AI will develop, it cannot be the sole factor leading to this phenomenon.

Despite growing insight into mechanisms involved in the above described autoimmune reaction, the exact mechanisms eliciting this syndrome are not known. Normally, after lethal X-irradiation and BMT, a "recapitulation of ontogeny" occurs (Tutschka, 1986). In this process transplanted stem cells have to learn to define "self" in the new host environment, either matched or mismatched for the major histocompatibility complex. In what respect CyA disturbs this "recapitulation of ontogeny", leading to a failure to tolerate "self" has not yet been elucidated. 
Beschorner WE, AD Hess, CA Shinn, and GW Santos (1988) Transfer of cyclosporine-associated syngeneic graft-versus-host disease by thymocytes. Transplantation 45:209-215

Blue M-L, JF Daley, H Levine, and SF Schlossman (1985) Class II major histocompatibility complex molecules regulate the development of the $\mathrm{T}_{4}{ }^{+} \mathrm{T} 8$ inducer phenotype of cultured human thymocytes. Innmunology 82:8178-8184

Carruthers SG, DJ Freeman, JC Koegler, W Howsion, PA Keown, A Laupacis, and CR Stiller (1983) Simplified liquid-chromatographic analysis for cyclosporin- $\mathrm{A}$, and comparison with radioimmunoassay. Clin Chem 29:180-190

Cheney RT, and J Sprent (1985) Capacity of cyclosporine to induce auto-graft-versus-host disease and impair intrathymic $T$ cell differentiation. Transplant Proc 17:528-531

Glazier A, PJ Tutsichka, ER Farmer, and GW Santos (1983) Graft wersus host disease in cyclosporine-A treated rats after syngeneic and autologous bone marrow transpllantation. I Exp Med 158:1-8

Glazier A, PJ Tutschka, E Farmer (1983) Studies on the immunobiology of syngeneic and autologous graft-versus-host disease in cyclosporine-treated rats. Transplant Proc 15:3035-3041

Hess AD, L Horwitz, WE Beschorner, and GW Santos (1985) Development of graft-versws-host diseaselike syndrome in cyclosporine-treated rats after syngeneic bone marrow transplantation. $J$ Exp Med 161:71:8-730

Hess AD, GB Vogelsang, J Heyd, and WE Beschorner (1987) Cyclosporine-induced syngeneic graf (-versus-host disease : Assessment of T cell differentiation. Transplant Proc 21:2683-2686

Hood L, WR Gray, BG Sanders, and WJ Dreyer (1967) Cold Spring Harbor Symp Ouani Biol 32:133

Korngold $\mathbf{R}$, and J Sprent (1987) T cell subsets and graft-versus-host disease. Transplantation $44: 335-$ 339

Krulisbeek AM, JJ Mond, BJ Fowlkes, JA Carmen, S Bridges, and DL Longo (1985) Absence of the Lyt $2, \mathrm{~L} 3 \mathrm{~T}_{4}{ }^{+}$lineage of $\mathrm{T}$ cells in mice treated neonatally with anti-1-A correlates with absence of intrathymic I-A-bearing antigen-presenting cells. J Exp Med 161:1029-1036

Pals ST, T Radaskiewicz, and E Gleichman (1984) Allosuppressor and allohelper T cells in acute and chronic graft-vs-host disease. IV. Activation of donor allosuppressor cells is confined to acute GVHD. J Immunol 132:1669-1678

Sorokin R, H Kimura, K Schroder, DH Wilson, and DB Wilson (1986) Cyclosporin-induced autoimmunity. Conditions for expressing disease, requirement for intact thymus, and potency estimates of autoimmune lymphocytes in drug-treated rats. J Exp Med $164: 1615-1625$

Tutschka PJ (1986) Induction of tolerance with cyclosporine-A. In : Transplantation : approaches to grafi rejection. New York Alan R. Liss, Inc. pp. 209-226 


$$
\text { (1) }
$$

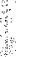




\section{SUMMARY AND CONCLUDING REMARKS}





\section{SUMMARY AND CONCLUDING REMARKS}

Scleroderma or systemic sclerosis is a disorder of connective tissue and the (micro-)circulation. The simultaneous occurrence of skin lesions and vascular abnormalities - sometimes as a first sign of disease - has led to many speculations on the etiology of this disease : is scleroderma a microvascular disorder, or are microvascular changes secondary to other primary events?

Chronic graft-versus-host skin pathology, in both man and rodents, shows striking similarities to scleroderma in man. Therefore, others have proposed experimental chronic graft-versus-host disease as a model to study the pathogenesis of scleroderma (see chapter 1 for literature review on scleroderma and graft-versus-host disease). However, thus far microvascular pathology had not been described in these models, whereas microvascular pathology is one of the hallmarks of scleroderma in man.

Therefore, the principle aim of this study was to establish the presence of microvascular skin pathology, if any, in an experimental model for scleroderma. The availability of an experimental model, showing both microvascular and histological lesions similar to scleroderma, might be worthwile to elucidate its pathogenesis.

To study the skin microcirculation of rats in vivo, we have developed a model comparable to that used in man to study microvascular abnormalities in the nailfold. By the use of intravital microscopy, a clear picture of red blood cell columns of capillaries, smaller arterioles and venules of the superficial skin can be obtained in a hairless area adjacent to a toe. These pictures can be recorded on videotape and velocity measurements of red blood cells in the microvessels can be made off-line (chapter II). Only one model to study the skin microcirculation of rats has been described, where intravital microscopy is performed on the ear (Hertel, 1984). Since this model needs physical manipulation of the skin, to remove hairs, for optimal visualization of the microvessels, it was not appropriate for our study. We intended to avoid any physical or chemical damage to the skin of the rats possibly interfering with the development of chronic graftversus-host disease. Besides, Hertel's model is not suitable to study reactive hyperemia, a parameter considered to be of interest to investigate the functionality of the microcirculation in models of experimental scleroderma.

The intravital microscopy model developed, turned out to be useful for our further studies. The pattern of the microvascular bed observed was similar in all animals investigated. Furthermore, the quality of the recordings was not hampered by aging of the animals, an important aspect because of the relatively long time period required for the development of experimental scleroderma in rats.

To assess the occurrence of microvascular skin pathology in experimental chronicgraftversus-host disease, bone marrow transplantations were performed in rats across fuli major histocompatibility barriers. By performing this bone marrow transplantation, chronic graft-versus-host disease was elicited which yielded histologically determined 
skin pathology similar to that seen in scleroderma in man. In vivo these rats also showed milcrovascular capillary dilatations with a pattern similar to that in patients with scleroderma (chapter III). The latter observation supports the histological arguments to accept chronic graft-versus-host disease as a model for scleroderma.

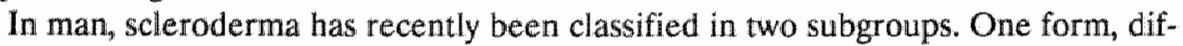
fuse cutaneous systemic sclerosis, is characterized by both skin and organ lesions indicative of scleroderma. Besides enlarged skin capillaries, these patients often show avascular areas in the microvascular bed of the skin nailfold. In the second group of patients, classified as limited cutaneous scleroderma, the disease is limited to the skin. In these patients capillary dilatations, but no avascular areas can be observed. Since the rats studied only showed skin pathology, and since avascular areas were not observed in these animals, we propose that this model for scleroderma represents limited cutaneous scleroderma and not diffuse cutaneous systemic sclerosis.

In addition to capillary abnormalities occluded arteries may also be observed in patients with scleroderma. In our model, the possible presence of arterial occlusions was investigated by eliciting reactive hyperemia reactions in the paws. As described in chapter III, no abnormal patterns of this reaction were observed in rats with chronic graft-versus-host disease. In addition, no lesions of the arteries were detected in skin biopsies. If arterial lesions are indeed absent in this model, this constitutes an important discrepancy between this model of experimental scleroderma and scleroderma in man. However, additional studies of the microcirculation are required to exclude the presence of arterial lesions in this model. Besides, the investigation of a larger number of animals might reveal arterial manifestations of disease.

After the presence of dilated capillaries had been established in this model, it was of interest to see whether microvascular lesions or histological lesions are primary in this model. Therefore, several attempts were made to study the development of clinical, histological and microvascular parameters prospectively. However, these attempts failed since we were not able to obtain enough animals with chronic graft-versus-bost disease in later experiments. Although we have no definitive explanation for this failure, the absence of pathogens in the animals used may have been responsible for this phenomenon. The first experiments, which yielded the highest incidence of both acute and chronic graft-versus-host disease, were performed in animals possibly infected with a Sendai virus. It is known that viral infections can enhance the development of graft-versus-host disease. Since later experiments were performed in animals that were "specific pathogen-free" (no antibodies against pathogenic rodent bacteria and viruses detectable), this might explain the low incidence of graft-versus-host disease in these experiments.

To make the model of graft-versus-host disease more suitable for the study of the pathogenetic mechanisms in experimental scleroderma, a higher incidence of rats with chronic graft-versus-host disease per experiment is needed. To achieve this, two possibilities can be considered. Firstly, the same model can be reproduced using other rat strains. It is known that some rat strains are more susceptible to develop certain diseases, including chronic graft-versus-host disease, than others. Secondly, the number 
of animals with acute graft-versus-host disease may be increased by adding donor Tlymphocytes to the grafted bone marrow transplant. Although this protocol might raise the risk of early death due to severe acute graft-versus-host disease, an optimal number of cells might possibly increase the incidence of chronic graft-versus-host disease.

The second aim of this study was to develop a new model for experimental scleroderma. Two arguments prompted us to seek for another model. Firstly, the fact that chronic graft-versus-host disease cannot definitively be seen as an autoimmune model, whereas scleroderma in man is likely to be so (see chapter I), and secondly; the low number of rats developing experimental scleroderma in the classical graft-versus-host model.

Hence, we have adopted the model of Glazier et al., in which autoimmune disease is evoked by manipulation of hemopoietical reconstitution after syngeneic bone marrow transplantation. Temporal administration of Cyclosporine-A after syngeneic bone marrow transplantation has been shown to induce an autoimmune reaction after withdrawal of the drug. This autoimmune reaction yields disease clinically and histologically indistinguishable from that elicited by the classical graft-versus-host reaction. In chapter IV, the pathology of this model is described. In the chronic phase of this autoimmune disease, remarkable similarities to chronic graft-versus-host disease were noticed, including scleroderma-like pathology. An inflammatory reaction with a mononuclear cell infiltrate and increased collagen formation in the lower dermis and subdermal regions in this model, were comparable to the histological manifestations of (early) scleroderma in patients.

Whether a folliculitis, prominently present in this experimental model, is also a main event in scleroderma in man is less clear. Inflammation around hair follicles has been described, but early inflammatory reactions in scleroderma are not restricted to hair follicles. This difference suggests that inflammatory (auto-)immune reactions against (unknown) antigens, which might be different in rat and man, might lead to similar pathology in the chronic phase of the disease. To what extent the target antigens attacked in the autoimmune experimental model are similar to those in human scleroderma cannot be concluded from the present study. Nevertheless, this model is the first to show that autoimmune phenomena may lead to scleroderma-like histological alteram tions.

Vascular abnormalities were not observed in the autoimmune model for scleroderma. In chapter IV it has been mentioned that the number of animals with scleroderma-like histopathological lesions may have been too small to observe vascular pathology. Besides, there may be a principal difference between classical chronic graftversus-host disease and the Cyclosporine-induced autoimmune model. In the latter, changes in the chronic phase are mainly present in the lower dermis and subdermal region. At that level of the skin, vascular alterations cannot be observed by intravital microscopy. 
To study the cellular mechanisms involved in the development of disease in the Cyclosporine-induced autoimmune model, we have analyzed the lymphocyte subsets after bone marrow transplantation. In this study it was demonstrated that reappearance of T-lymphocytes of the CD4 (W3/25) phenotype was suppressed as long as Cyclosporine-A was given, whereas the repopulation of this subset of cells was associated with the development of autoimmune disease, suggesting a role for these cells in initiating the disease (chapter V).

Cells of the CD4 phenotype are usually class II restricted T-helper cells. However, more recent studies have shown that cells with this phenotype may also effect killer activity. Therefore, if the CD4 positive lymphocytes do indeed initiate the autoimmune disease, this does not reveal the immunopathogenetic mechanisms involved in its progress. Hence, functional investigations on this CD4-lymphocyte subset are necessary to understand the mechanism(s) by which the disease is elicited, and, perhaps most importantly, to determine the antigen(s) against which their reactivity is directed.

Are chronic graft-versus-host disease and Cyclosporine-induced chronic autoimmunity in rats adequate models for scleroderma in man?

The observation of capillary dilatations in the skin of rats with experimental scleroderma due to chronic graft-versus-host disease is an important argument to add to the already existing evidence that chronic graft-versus-host disease can be used as a model for scleroderma. Because of the manifestations of the disease (limited to the skin and no avascular areas in the skin microvascular bed) the model rather represents limited cutaneous scleroderma than diffuse cutaneous systemic scleroderma. However, the possible absence of arterial pathology is an important discrepancy between experimental and clinical scleroderma. It should be said that if arterial pathology cannot be demonstrated in further studies, the model does not fully represent systemic scleroderma in man.

In case of Cyclosporine-induced experimental scleroderma, the question regarding its relevance as a model for scleroderma in man is even more difficult to answer, since we observed no microvascular abnormalities thus far. Only screening of larger groups of animals with experimental scleroderma can prove or disprove the presence of microvascular manifestations in this model. Without vascular manifestations the model is unlikely to be fully representative for scleroderma in man.

It remains to be established whether the two models described reflect the immune mechanisms leading to scleroderma in man. Most importantly, it is intriguing to see that two fundamentally different models give rise to similar clinical and histological manifestations of the disease. This observation raises the question as to what the actual difference between these models might be. The acute phase in the classical graft-versus-host reaction is probably due to a reaction directed against histocompatibility antigens not shared between donor and recipient. In the Cyclosporine-A model, autoimmune phenomena are more likely to play a role. 
It is unlikely that the primary events of scleroderma are in any respect related to the above described models, since in scleroderma acute graft-versus-host-like pathology or epidermal lesions have never been described, neither clinically nor histologically. How could these models than be related to scleroderma? In early scleroderma inflammatory reactions have been observed which suggest an (auto-)immune reaction against unknown antigens. The parallel between the experimental models and scleroderma in man could be that the acute phase of graft-versus-host/autoimmune disease induces the expression of formerly unexpressed neo- or auto-antigens. If tolerance against these antigens fails to be established, this may give rise to a continuous (auto-)immune reaction both in experimental chronic graft-versus-host disease and Cyclosporine-A induced autoimmune disease. This continous (auto-)immune reaction might be comparable to the pathophysiological process in scleroderma in man, although the event(s) inducing expression of normally absent antigens remains unidentified.

The identification of the antigens responsible for the continuing (auto-)immune reaction in the experimental models described in this thesis, might trace the (auto-)antigens responsible for the (auto-)immune reactions leading to scleroderma in man. 

NEDERLANDSTALIGE SAMENVATTING 



\section{NEDERLANDSTALIGE SAMENVATTING}

Sclerodermie (Grieks: verharding van de huid) is een bindweefselziekte, waarbij vootnamelijk de huid is aangedaan. Maar ook de slokdarm, longen, het hart en de nieren kunnen bij het ziekteproces betrokken zijn. Bij deze ziekte is er sprake van een toename van bindweefsel-afzetting in de hierboven genoemde organen, met als gevolg dat deze organen hun functie geheel of gedeeltelijk kunnen verliezen. Naast de toegenomen bindweefselafzetting, kunnen er bij patienten met sclerodermie ook afwijkingen aan de bloedvaten optreden. Ook hierdoor kunnen organen belemmerd worden in hun functie. In het geval van een verminderde bloedvoorziening naar de huid, kan er sprake zijn van het zogenaamde Raynaud fenomeen (achtereenvolgens een witte, blauwe en rode verkleuring van met name de vingers), ten teken dat de doorbloeding (tijdelijk) belemmerd is. In voortgeschreden gevallen kan de belemmerde bloedvoorziening echter ook leiden tot afsterven van de huid.

De ontstaanswijze van sclerodermie is onduidelijk. Mogelijk is sclerodermie een autoimmuunziekte, d.w.z. de witte bloedcellen die bij normaal functioneren een rol spelen bij de bestrijding van indringers van buitenaf, richten zich nu tegen onbekende structuren (antigenen) van het eigen lichaam. Omdat bij sclerodermie zowel sprake is van afwijkingen aan de bloedvaten, alsook van een toegenomen afzetting van bindweefsel, is een lang bestaande vraag welke afwijkingen oorzaak en welke gevolg zijn. In de literatuur hierover kan men zowel aanwijzingen vinden dat afwijkingen aan de bloedwaten leiden tot beschadiging aan de organen, met als gevolg een verhoogde afzetting van bindweefsel, maar ook dat primaire beschadiging van de organen leidt tot afwijkingen van de bloedvaten.

Gezien het chronische karakter van scierodermie, is het moeilijk om bij patienten verder inzicht te verkrijgen in de oorzaak van het ziekteproces. Daarom hebben diverse onderzoekers getracht om diermodellen geschikt te maken voor het bestuderen van dit ziektebeeld. Eén van deze modellen is voortgekomen uit de observatie dat chronische afstotingsreacties na een beenmergtransplantatie, waarbij donor en ontvanger genetisch niet identiek zijn (de chronische graft-versus-host reactie), pathologische veranderingen laat zien die sterke gelijkenissen vertonen met de afwijkingen bij sclerodermie. Echter, bij dit model zijn geen afwijkingen aan de bloedvaten beschreven. Gezien het feit dat afwijkende bloedvaten een belangrijke rol spelen bij sclerodermie moet de relevantie van dit model betwijfeld worden. Bovendien, om de interactie van bindweefselziekte en vaatpathologie te kunnen bestuderen is dle aanwezigheid van vaatpathologie een voorwaarde. Het eerste doel van ons onderzoek was er derhalve op gericht om te bestuderen of er in het model van chronische graft-versus-host ziekte aanwijzingen voor vaatpathologie gevonden konden worden.

Om deze vraagstelling te kunnen beantwoorden was allereerst de ontwikkeling van een systeem nodig waarbij de kleine bloedvaten in de huid van een rat (het proefdier waarmee in deze studie is gewerkt) kunnen worden geobserveerd. Bij patienten is dit mogelijk door middel van intravitaal-microscopie, een techniek waarbij met een mi- 
croscoop haarvaten (capillairen) van de huid o.a. in de magelriem zichtbaar kunnen worden gemaakt. Deze capillairen vertonen bij patienten met sclerodermie afwijkingen die met intrawital-microscopie eenvoudig waarneembaar zijn. De techniek van intravitaal-microscopie is ook toegepast bij onze proefdieren. Een voordeel van deze techniek is dat bestudering van de huid-bloedvaten mogelijk is, zonder de huid daarbij te moeten beschadigen. Bovendien kunnen met deze techniek bij eenzelfde proefdier in de loop van de tijd dezelfde vaten bestudeerd worden (zie hoofdstuk 2).

Na de ampassing van de techniek van intravitaal-microscopie voor ratten, is deze techniek toegepast op ratten waarbij sclerodermie was uitgelokt door middel van een graft-versus-host reactie ten gevolge van een beenmergtransplantatie. Bij die ratten die histologische ( = weefselstructuur) aanwijzingen hadden voor sclerodermie van de huid, bleken dezelfde vaatafwijkingen (verwijding van de capillairen) voor te komen als wargenomen bij patienten met sclerodermie. De observatie van het tegelijkertijd optreden van bindweefselafwijkingen en het optreden van vaatpathologie in de huid wordt gezien als een nieuw argument om dit proefdiermodel te accepteren als model voor sclerodermie. Bovendien maakt deze combinatie van afwijkingen het mogelijk de hierboven beschreven vraagstelling over de interactie tussen vaatpathologie en bindweefselafwijkingen in dit model te bestuderen.

Behalve aan het model van de chronische graft-versus-host reactie, is in deze studie ook aandacht besteed aan een het ontwikkelen van een nieuw model voor sclerodermie. Dit model maakt gebruik van de waarneming dat een beenmergtransplantatie, waarbij het beenmerg van donor en ontwanger genetisch aan elkaar gelijk zijn (syngeen), gecombineerd met het tijdelijk toedienen wan het als immunosuppressivum bekende cyclosporine-A leidt tot een autoimmunreactie. Met andere woorden, de combinatie van bestraling en cyclosporine-A veroorzaakt een reactie waarbij de witte bloedcellen zich tegen structuren wan het eigen lichaam richten. In dit model, waarbij nog weinig duidelijkheid bestaat over de reden waarom deze autoimmuunreactie ontstaat, treden afwijkingen op die sterk lijken op de afwijkingen die ontstaan bij een graft-versus-host reactie zoals die hierboven beschreven is. In hoofdstuk 4 is een studie weergegeven, waarbij het beloop van deze autoimmunnreactie bestudeerd is. Hieruit blijkt dat ook in dit tweede model, bij een langer bestaan van de autoimmunreactie, de afwijkingen in de lhuid duidelijke gelijkenissen vertonen met de afwijkingen zoals die gezien worden bij patienten met sclerodermie. Dit model kan dan ook gezien worden als een nieuw experimenteel model voor sclerodermie. Echter, het zoeken naar vaatpathologie met behulp van intravitaal-microscopie heeft in dit model nog geen waarneming van afwijkende capillairen opgeleverd. Bestudering van grotere aantalllen ratten met deze vorm van sclerodermie is derhalve nodig om het wel of niet bestaan van vaatafwijkingen in dit model aan te tonen. Het moge duidelijk zijn dat slechts het optreden van deze vaatafwijkingen de gewenste bestudering van de interactie tussen vaatpathologie en verhoogde bindweefselafzetting mogelijk maakt. 
Omdat de inductie van de autoimmun nreactie na de combinatie van een syngene beenmergtransplantatie en het toedienen van cyclosporine-A verloopt via nog niet opgehelderde mechanismen, hebben wij binnen dit model het patroon van lymfocyten ( $\mathrm{T}$ ) cellen, een subgroep van de witte bloedcellen) bestudeerd. Uit deze studie is gebleken dat Thelper lymfocyten na de beenmergtransplantatie en gedurende de toediening van cyclosporine-A verminderd aanwezig zijn in het bloed. Na het stoppen van de cyclosporime-A toediening treedt een herstel op van deze Thelper lymfocyten. Het weer verschijnen van deze lymfocyten in het bloed gaat samen met het ontstaan van de autoimmunreactie, hetgeen suggereert dat deze cellen een rol spelen bij de inductie van de autoimmunreactie (zie hoofdstuk 5).

Samenvattend heeft de studie beschreven in dit proefschrift betrekking op twee modellen ter bestudering van het ziektebeeld sclerodermie. In het eerste model, waarbij sclerodermie opgewekt wordt door middel van een afstotingsreactie na een beenmergtransplantatie, is zowel bindweefselpathologie alsook vaatpathologie gevonden gelijkend op die bij patienten met sclerodermie. Deze observatie maakt de bestudering van de interactie tussen vaatpathologie en bindweefselpathologie in dit model mogelijk. In het tweede model, waarbij een autoimmuunreactie wordt uitgelokt na een beenmergtransplantatie met genetisch identiek beenmerg, zijn weliswaar ook aanwijzingen gevonden voor het bestaan van sclerodermie, maar konden (nog) geen vaatafwijkingen worden aangetoond. De bestudering van de aanwezigheid van lymfocyten in dit tweede model makt het opstellen van een meer gedetailleerde hypothese met betrekking to de onderliggende mechanismen bij deze autoimmuunreacte mogelijk.

Verdere uitwerking van deze modellen kan het inzicht in de mechanismen welke een rol spelen bij het ontstaan van de ziekte sclerodermie vergroten. 


\section{LIST OF ABBREVIATIONS}

BMT : Bone marrow transplantation

CD : Cellular differentation antigene

CyA : Cyclosporine-A

CyA-All: Cyclosporine-A induced autoimmunity

F1 : F1 Hybrid (strain)

GVH : Graft-versus-host

HA : Histocompatibility antigens

IgG : Immunoglobuline- $G$

MABs : Monoclonal antibodies

MHA : Major histocompatibility antigens

MHC : Major histocompatibility complex

MiHA : Minor histocompatibility antigens

P : Parental (strain)

SLE : Systemic lupus erythomatodes

Th : T-helper (lymphocytes)

Tk/s : T-killer/suppressor (lymphocytes) 


\section{PUBLICATIONS}

In the course of the studies, presented in part in this thesis, the following publications were elaborated:

\section{Papers}

Bos GMJ, DW Slaaf, GD Majoor, G-J Tangelder, and RS Reneman (1987) A model for chronic sudy of vascular morphology and reactivity of physically intact rat skin microcitculation. Int I Microcirc Clin \& Exp 6:371-380

Bos GMJ, GD Majoor, DW Slaaf, RS Reneman, and PJC van Breda Vriesman (1988) In vivo demonstra* tion of microvascular pathology by int ravital microscopy in experimental chronic graft-versus-host disease Analogy with scleroderma. I Rheumatol $15: 1339-1345$

Bos GMJ, GD Majoor, and PJC van Breda Vriesman (1988) Cyclosporin-A induces a selective, reversible suppression of T-helper lymphocyte regeneration after syngeneic bone marrow transplantation : association with syngeneic graft-versus-host disease. Clin Exp lmmunol 74:443-448

Bos GMJ, GD Majoor, RGJ Willighagen and PJC van Breda Vriesman Chronic cyclosporine-induced autoimmune disease in the rat: A new experimental model for scleroderma. J Invest Dermatol Accepted for publication

\section{Proceedings / Abstracts}

Bos GMJ, DW Slaaf, GJ Tangelder, GD Majoor, and PJC van Breda Vriesman (1986) A model for chronic study of the intact ratskin microcirculation. Int J Microcirc Clin \& Exp 5:236 (abstract)

Bos GMJ, GD Majoor, DW Slaaf, and PJC van Bareda Vriesman (1987) Observation of dilated clinical skin capillaries in experimental chronic graft-versus-host disease by intravital microscopy. Gesellischaft fur Mikrozirkulation. 11. Jahrestagung Heidelberg

Bos GMJ, GD Majoor, DW Slaaf, and PJC van Breda Vriesman (1987) Assessnent of microvascular pathology in an experimental model for scleroderma by intravital microscopy. Microcirculation, an update, Volume 2. M Tsuchiya et al. (eds.) Excerpta Medica, Amsterdam pp. 745-746

Bos GMJ, GD Majoor, M-J WH wan de Gas, and PJC van Breda Vriesman (1988) Autoimmune roactivity after sygeneic bone marrow transplantation and cyclosporine treatment is asisociated with repopu Iation of the T-helper subset. The Faseb Journal 2:A910

Wijsek AMW, GMJ Bos, DW Slaaf, G-J Tangelder, and G10 Majoor (1988) ln who assessment of vagcth lar permeability during delayed type-hypersensitivity reaction in the rat. Int J Microcitc Clin 1 Exp $7: \$ 75$ (abstract)

Bos GMJ, GD Majoor, CA Bruggeman, G Grauls, M-JWH van de Gaar, and PJC van Breda Vriesman (1989) Rat cytomegalowirus can be translerred by bone marrow cells but does not affect the course of aculti graft-versius-host disease. Transplant Proc In press

Bos GMJ, CD Majowr, M-JWH van de Gaar and PJC van Breda Vriesman (1989) T-helper lymphocyles and syngeneic graft-versus-host disease. Tramplant Proc In press

Bos GMJ, GD Majoor, DW Slaat, M-J WH van de Gaar, JS Weljmer-van Velzen, and PJC van Breda Vriesman (1989) Similarity of scleroderna-like skun lesions in allogeneic and syngeneic bone marrow transplantation models. Transplant Proc In press. 


\section{Wij zijn klaar!}

Ook al geeft het schrijven van een dankwoord op deze plaats een ietwat majestueus gevoel, het woordje "wij" in de aanhef is niet bedoeld als pluralis majestatis. Het wordt door vrijwel iedere promovendus opgemerkt: promoveren is teamwerk. Sterker nog, als promovendus maak je veelal slechts tijdelijk deel uit van een onderzoeksgroep die doorgaat ook na het verschijnen van een boekje. Een proefschrift is dan ook niet slechts voor de promovendus van belang, maar weerspiegelt ook de resultaten van een totaal onderzoeksteam. Aan de promovendus daarbij de taak aan de afzonderlijke artikelen een inleiding, literatuuroverzicht en algemene discussie toe te woegen. Het geheel wordt daarna van een (kostbaar) nietje voorzien en het zo ontstane "geesteskind" is vervolgens het resultaat van de promovendus, en de promovendus het "resultaat" van het tearn.

Als tijdelijke gast in een door de heroriëntatie veroorzaakt groot team, wil ik graag van de gelegenheid gebruik maken allen voor hun bijdrage aan het in dit boekje gepresenteerde werk te bedanken. Allereerst diegene die min of meer op de achtergrond aanwezig waren. Om te beginnen alle personen van de vakgroep immunologie die tijdens werkbesprekingen het werk van het nodige kommentaar voorzagen. Hierbij moet met name Jan Verschuuren genoemd worden met wie ik daarnaast ook in de privé uurtjes over het onderzoek en het leven van de promovendus heel wat geboomd heb en die bovendien talrijke ratten scoorde in hun klinisch beloop. De medewerkers van de dienst centrale proefdiervoorzieningen, die een wakend oog hielden op de ratten. Gert Grauls en Cathrien Bruggeman, van de afdeling medische microbiologie, met wie wij een helaas niet zo succesvol pad bewandelden. Michèle Reynders en Bert Schutte van de afdeling inwendige geneeskunde die heel wat monster op de FACS bepaalden alvorens ons het vertrouwen te geven om zelf de apparatuur te bedienen. Jack van der Heijden en Gert Beuman, die het mogelijk maakten om bij de klinische farmacie (Academisch Ziekenhuis Maastricht) de cyclosporine-spiegels te laten bepalen. En met hen Jennie, Harry en Huub die het merendeel van de bepalingen daadwerkelijk uitvoerden.

Extra dank gaat bovenal uit naar die mensen die nauw bij het onderzoek betrokken waren. Allereerst de diverse medewerkers van het microcirculatie-laboratorium waar wij vanuit de immunologie te gast waren. Dr. Slaaf, beste Dick, jij introduceerde me in het werk van de microcirculatie en gaf mij als nieuweling ruimschoots de ruimte om te oefenen. Je manier van discussiëren was even wennen, maar nadat we de goede toon gevonden hadden waren de discussies voor mij zeer vruchtbaar. Rinus Alewijnse, beste Rinus, jouw kennis van de apparatuur was met name in de begintijd onontbeerlijk voor het aan de praat krijgen van ons model. Een gouden tip heeft het werk daarbij een noodzakelijke impuls gegeven. Sabrina Weijmer-van Velsen, beste Sabrina, zelfs in bed zag 
je nog bloedvaatjes op het plafond. Bedankt voor het uren turen naar helaas te weinig afwijkingen. Dr. Tangelder, beste Geert-Jan, door je vertrek naar Amerika was je met name bij de opstart van het onderzoek betrokken. Je enthousiaste bijdrage heb ik toen zeer gewaardeerd. Prof. Reneman, beste Rob, onze gesprekken waren niet talrijk, maar altijd even verhelderend. Jouw analyses van de stand van zaken waren telkens weer even scherp. Met name jouw aanwezigheid "op de achtergrond" was misschien wel een belangrijker deel van het "betonnen pad" dan de onderzoeksthematiek.

Van de afdeling immunologie wil ik als eerste Prof. van Breda Vriesman bedanken. Beste Peter, bedankt voor je uitnodiging om enkele jaren aan de experimentele immunologie te snuffelen. Ik hoop dat de toekomst zal uitwijzen dat dit voor een dokter een nuttige tijdsbesteding is geweest. Jouw kennis van de literatuur was van groot belang voor de analyse van de gang van zaken en leverde heel veel goede ideeën op. Door slechts die ideeën te selecteren die je minimaal drie maal herhaalde konden we ze tot een werkzaam aantal terug brengen.

Marie-José van de Gaar, lieve José, het zijn van paranimf brengt nog onvoldoende tot uiting welke bijdrage jij aan het onderzoek hebt geleverd. Maar niet de hoeveelheid werk die je verzet hebt zal ik het langste herinneren, maar vooral de enthousiaste manier waarop je de dingen aanpakte hebben op mij een bijzondere indruk gemaakt. Je was slecht korte tijd afwezig om van Simon te bevallen, maar deze maanden waren voor mij dan ook gelijk dubbele! Jacob Post, beste Jacob, slechts kort op onze afdeling om José te vervangen, hebt je in die tijd talloze coupes gesneden. Jouw tongetjes zullen we niet vergeten.

Als laatste will ik graag diegene noemen die voor mij goud waard was: Dr. Majoor. Beste Gerard, ik hoef je waarschijnlijk hier niet meer te zeggen dat dit nawoord niet (nu al) geschreven zou zijn zonder jouw inspanningen. Naast de werkinspanningen was echter ook de gezelligheid van groot belang om een promovendus op de been te houden. Het zal waarschijnlijk wel bij Tokyo en Sydney blijven wat ons gezamenlijk congresbezoek betreft, maar dat waren dan ook bijzondere hoogtepunten voor een vriendschap die hopelijk niet zal uitdoven na het verschijnen van dit boekje. 
Gerardus Marinus Josef Bos was born on the fifth of May 1960 in Wageningen, The Netherlands. He attended high school at the Rijksscholengemeenschap "Het Wagenings Lyceum", Gymnasium $B$, in Wageningen. He went to Medical school at the University of Limburg, Maastricht, The Netherlands (1978-1984). From 1982 until 1983 he was a research assistant at the department of internal medicine, under the supervision of Dr. G. van Deijck (Head: Prof H. Hulsmans). From 1985 until 1988 he was a research fellow at the department of immunology of the University of Limburg, Maastricht, where the work of this thesis was performed. (Head: Prof P. van Breda Vriesman). At present he is a resident in internal medicine at the University Hospital Maastricht (Head: Prof J. Flendrig). 


\section{KLIMMEN EN DALEN.}

Een rechthoekige binnenplaats wordt begrensd door een gebouw dat een trap zonder einde als dakbedekking heeft. De bewoners van dit huizencomplex zijn misschien wel monniken, leden van een onbekende secte. Mogelijk is het hun rituele plicht om dagelijks enkele uren deze trap te beklimmen. Als ze moe zijn mogen ze blijkbaar omkeren en afdalen inplaats van klimmen. Maar beide richtingen, hoewel zinvol, zijn even rusteloos. Twee weerspannige individuen weigeren vooralsnog om aan deze oefening mee te doen. Zij denken er het hunne van, maar misschien zullen zij vroeg of laat hun dwalling inzien.

M.C. Escher, 1959. 


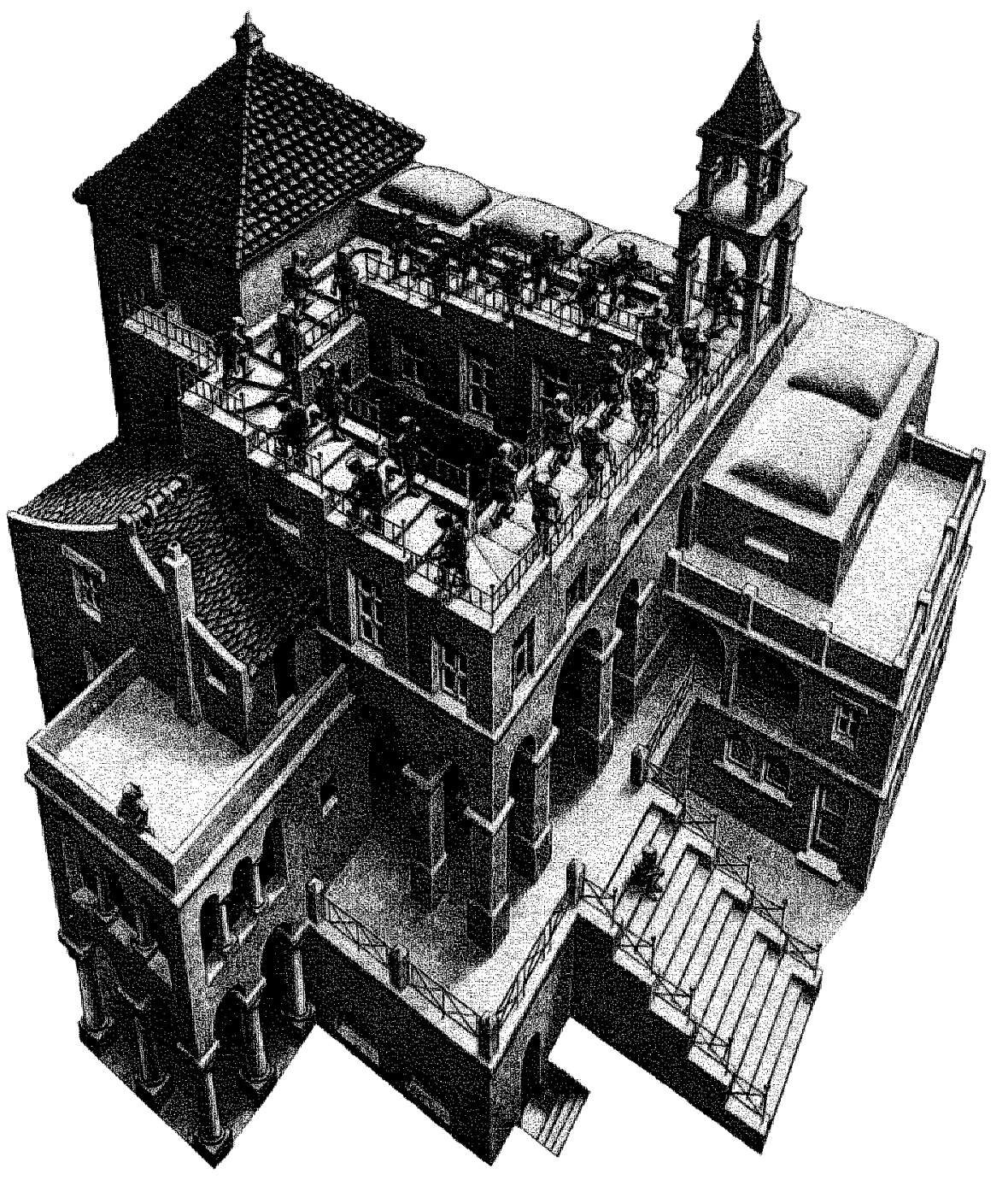

